\title{
State-of-the-Art Research on Chemiresistive Gas Sensors in Korea: Emphasis on the Achievements of the Research Labs of Professors Hyoun Woo Kim and Sang Sub Kim
}

\author{
Sachin Navale ${ }^{1,2,3,+}$, Ali Mirzaei ${ }^{4,+}+$ , Sanjit Manohar Majhi ${ }^{1,2}$, Hyoun Woo Kim ${ }^{1,2, *}$ and Sang Sub Kim ${ }^{3, *}$ \\ 1 Division of Materials Science and Engineering, Hanyang University, Seoul 04763, Korea; \\ stnavale2@yahoo.com (S.N.); sanjeetmjh@gmail.com (S.M.M.) \\ 2 The Research Institute of Industrial Science, Hanyang University, Seoul 04763, Korea \\ 3 Department of Materials Science and Engineering, Inha University, Incheon 22212, Korea \\ 4 Department of Materials Science and Engineering, Shiraz University of Technology, Shiraz 715557-13876, Iran; \\ mirzaei@sutech.ac.ir \\ * Correspondence: Hyounwoo@hanyang.ac.kr (H.W.K.); sangsub@inha.ac.kr (S.S.K.) \\ + These authors contributed equally to this work.
}

check for

updates

Citation: Navale, S.; Mirzaei, A.; Majhi, S.M.; Kim, H.W.; Kim, S.S. State-of-the-Art Research on Chemiresistive Gas Sensors in Korea: Emphasis on the Achievements of the Research Labs of Professors Hyoun Woo Kim and Sang Sub Kim. Sensors 2022, 22, 61. https://doi.org/ $10.3390 / \mathrm{s} 22010061$

Academic Editor: Manuel Aleixandre

Received: 12 November 2021

Accepted: 17 December 2021

Published: 23 December 2021

Publisher's Note: MDPI stays neutral with regard to jurisdictional claims in published maps and institutional affiliations.

Copyright: (C) 2021 by the authors. Licensee MDPI, Basel, Switzerland. This article is an open access article distributed under the terms and conditions of the Creative Commons Attribution (CC BY) license (https:// creativecommons.org/licenses/by/ $4.0 /)$.

\begin{abstract}
This review presents the results of cutting-edge research on chemiresistive gas sensors in Korea with a focus on the research activities of the laboratories of Professors Sang Sub Kim and Hyoun Woo Kim. The advances in the synthesis techniques and various strategies to enhance the gas-sensing performances of metal-oxide-, sulfide-, and polymer-based nanomaterials are described. In particular, the gas-sensing characteristics of different types of sensors reported in recent years, including coreshell, self-heated, irradiated, flexible, Si-based, glass, and metal-organic framework sensors, have been reviewed. The most crucial achievements include the optimization of shell thickness in coreshell gas sensors, decrease in applied voltage in self-heated gas sensors to less than $5 \mathrm{~V}$, optimization of irradiation dose to achieve the highest response to gases, and the design of selective and highly flexible gas sensors-based $\mathrm{WS}_{2}$ nanosheets. The underlying sensing mechanisms are discussed in detail. In summary, this review provides an overview of the chemiresistive gas-sensing research activities led by the corresponding authors of this manuscript.
\end{abstract}

Keywords: gas sensor; core-shell sensors; self-heated sensors; flexible sensors; irradiation sensors; sensing mechanism

\section{Introduction: Overview of the Oxide-Based Gas Sensors}

Atmospheric pollution typically comprises particulate matter, ozone $\left(\mathrm{O}_{3}\right)$, sulfur dioxide $\left(\mathrm{SO}_{2}\right)$, nitrogen dioxide $\left(\mathrm{NO}_{2}\right)$, and carbon monoxide $(\mathrm{CO})$ [1]. Furthermore, benzene $\left(\mathrm{C}_{6} \mathrm{H}_{6}\right)$, toluene $\left(\mathrm{C}_{7} \mathrm{H}_{8}\right)$, and xylene $\left(\mathrm{C}_{8} \mathrm{H}_{10}\right)(\mathrm{BTX})$ gases are also generally present in pollutant air. It is considered that $92 \%$ of the world's population lives in areas with poor air quality, which can cause premature death [2]. Pollution is the most important cause of premature death and illness worldwide, and it accounts for $16 \%$ of global death [3]. As a result, air pollution is currently an active area of research. Although the human olfactory system is considered to be the least significant of the human senses, it is critical to human lives because it alerts us to the potential risks pollutant air. In addition, it is the only active sense during sleep. When a gas has an extremely low concentration or no odor, the human olfactory system cannot sense it. As a result, sensitive devices are required to detect toxic and hazardous gases in the environment [4,5]. Gas chromatography-mass spectrometry [6], flame ionization detectors [7], and Fourier-transform infrared spectrometry [8] have been traditionally used for the recognition of toxic/hazardous gases. However, most of these systems are large in size, costly, and require trained operators. As the instruments are not portable because of their large sizes, their applications in different areas are limited [9]. Additionally, these instruments cannot be incorporated into small smart electronic devices 
such as smartphones. Thus, sensitive and reliable sensing devices with small sizes are needed to be incorporated in portable devices.

Table 1 presents the historical milestones of semiconductor-based chemiresistive gas sensors [10-17]. The idea of utilizing metal oxides as gas-detecting materials dates back to 1954 when Heiland applied zinc oxide $(\mathrm{ZnO})$ as a sensing material [10], extending the original idea of Brattain and Barteen describing the change in the composition of the surrounding atmosphere on the electrical conductivity of Ge-based electronic devices [11]. Motivated by the extensive gas explosions in Japan, Seiyama (1962) invented a simple resistive-based gas sensor using $\mathrm{ZnO}$ thin films for sensing propane, which afforded a response approximately 100 times higher than the thermal conductivity detector utilized at the time [12]. In 1968, Taguchi commercialized a simple gas sensor using semiconducting tin oxide $\left(\mathrm{SnO}_{2}\right)$ to detect low concentrations of combustible/reducing gases [13].

Table 1. Milestones in history of resistive-based gas sensors.

\begin{tabular}{ccc}
\hline Year & Milestone & Ref. \\
\hline 1953 & $\begin{array}{c}\text { Brattain and Bardeen reported the effects of gases on the electrical conductivity of } \\
\text { Ge-based devices }\end{array}$ & {$[10]$} \\
\hline 1954 & $\begin{array}{c}\text { Heiland reported a change in the electrical properties of } \mathrm{ZnO} \text { in the presence of } \\
\text { various gases }\end{array}$ & {$[11]$} \\
\hline 1962 & Seiyama et al. reported the first resistive-based gas sensor using ZnO & {$[12]$} \\
\hline 1962 & Taguchi patented the first $\mathrm{SnO}_{2}$ gas sensor & {$[13]$} \\
\hline 1963 & Taguchi investigated effect of noble metals on the gas-sensing properties of $\mathrm{SnO}_{2}$ & {$[14]$} \\
\hline 1968 & Taguchi commercialized the first resistive-based gas sensors using $\mathrm{SnO}_{2}$ & {$[15]$} \\
\hline 2003 & Salehi reported the first self-heated gas sensor based on SnO $\mathrm{O}_{2}$ & {$[16]$} \\
\hline 2007 & Schedin et al. for the first time reported the gas-sensing properties of graphene & {$[17]$} \\
\hline
\end{tabular}

To date, a variety of gas sensors have been utilized to detect toxic and hazardous gases. Among these, metal-oxide semiconductor (MOS) gas sensors, whose operation is based on the change in the resistance upon exposure to target gases, have attracted significant attention owing to their low cost, low toxicity, simple fabrication route, robustness, high stability, fast response/recovery times, and sensitivity to detect a wide range of target gases [18-63]. Notably, in addition to MOS, materials based on conducting polymers and graphene have been employed for the realization of resistive-gas sensors [18]. However, their performances, particularly in the pristine form, is significantly inferior to those of the MOS-based sensors. The main characteristics of a resistive-gas sensor are its response, selectivity, response time, stability, and sensing temperature. In other words, a good gas sensor should (i) afford a high response to the target gas, (ii) show no or low response to interfering gases, (iii) show high stability over a long time, and (iv) be used at low or room temperatures to minimize energy consumption [18]. Thus, various synthesis approaches or strategies have been used to overcome the limitations of this type of gas sensors: namely, poor selectivity and high operating temperature. A comparison of the most commonly used pristine metal oxides, with different surface morphologies, as a sensing layer in chemiresistive-type of gas sensors is presented in Table 2 [19-63]. 
Table 2. A comparison of the most commonly used metal oxides, with different surface morphologies, as chemiresistive gas sensors.

\begin{tabular}{|c|c|c|c|c|c|c|c|c|}
\hline Dimensions & Sensing Material & Target Gas & $\begin{array}{c}\text { Gas Conc. } \\
\text { (ppm) }\end{array}$ & $\begin{array}{c}\mathrm{T} \\
\left({ }^{\circ} \mathrm{C}\right)\end{array}$ & $\begin{array}{c}\text { Response } \\
\left(R_{a} / R_{g}\right) \text { or }\left(R_{g} / R_{a}\right) \text { or } \\
{\left[\left(R_{a}-R_{g}\right) / R_{a}\right]^{*} 100 \%}\end{array}$ & $\operatorname{Res}(\mathrm{s}) / \operatorname{Rec}(\mathrm{s})$ & $\begin{array}{c}\text { LDL } \\
(\mathrm{ppm})\end{array}$ & Ref \\
\hline \multirow{10}{*}{$0 \mathrm{D}$} & $\mathrm{Fe}_{2} \mathrm{O}_{3} \mathrm{NPs}$ & $\mathrm{CH}_{3} \mathrm{COCH}_{3}$ & 100 & 300 & 11.6 & $4 / 10$ & 0.5 & [19] \\
\hline & $\mathrm{In}_{2} \mathrm{O}_{3} \mathrm{NPs}$ & $\mathrm{HCHO}$ & 10 & 280 & 20 & $4 / 8$ & NA & [20] \\
\hline & ZnO NPs & $\mathrm{Cl}_{2}$ & 200 & 200 & $1278 \%$ & $6 / 64$ & 5 & [21] \\
\hline & $\mathrm{SnO}_{2} \mathrm{NPs}$ & $\mathrm{C}_{2} \mathrm{H}_{5} \mathrm{OH}$ & 250 & 100 & 30 & $16 / 25$ & NA & [22] \\
\hline & $\mathrm{NiO} N P s$ & $\mathrm{HCHO}$ & 1 & 230 & 80 & $\approx 54 / \approx 14$ & NA & [23] \\
\hline & $\mathrm{WO}_{3} \mathrm{NPs}$ & $\mathrm{NO}_{2}$ & 100 & 200 & $34 \%$ & $24 / 300$ & 5 & [24] \\
\hline & $\mathrm{Co}_{3} \mathrm{O}_{4} \mathrm{NPs}$ & $\mathrm{CH}_{3} \mathrm{COCH}_{3}$ & 100 & 200 & 8.61 & $43 / 92$ & 0.1 & [25] \\
\hline & $\mathrm{CeO}_{2} \mathrm{NPs}$ & $\mathrm{H}_{2} \mathrm{~S}$ & 40 & RT & 5.5 & $64 / 62$ & NA & [26] \\
\hline & $\mathrm{TiO}_{2} \mathrm{NPs}$ & $\mathrm{CH}_{3} \mathrm{COCH}_{3}$ & 1000 & 270 & 15.24 & $10 / 9$ & 0.5 & [27] \\
\hline & CuO NPs & $\mathrm{H}_{2} \mathrm{~S}$ & 5 & 40 & 4.9 & $297 / 54$ & 0.2 & [28] \\
\hline \multirow{12}{*}{$1 \mathrm{D}$} & $\mathrm{SnO}_{2} \mathrm{NWs}$ & $\mathrm{CO}$ & 20 & RT & 4 & NA & NA & [29] \\
\hline & $\mathrm{In}_{2} \mathrm{O}_{3} \mathrm{MRs}$ & $\mathrm{C}_{2} \mathrm{H}_{5} \mathrm{OH}$ & 100 & 300 & 18.33 & $15 / 20$ & 1 & [31] \\
\hline & $\mathrm{Co}_{3} \mathrm{O}_{4} \mathrm{MRs}$ & $\mathrm{C}_{2} \mathrm{H}_{5} \mathrm{OH}$ & 100 & 220 & 9.8 & $\approx 1 / \approx 11$ & NA & [32] \\
\hline & $\mathrm{WO}_{3} \mathrm{NFs}$ & $\mathrm{CH}_{3} \mathrm{COCH}_{3}$ & 50 & 270 & 55.6 & $13 / 9$ & 0.1 & [33] \\
\hline & $\mathrm{ZnO}$ NWs & $\mathrm{C}_{2} \mathrm{H}_{5} \mathrm{OH}$ & 500 & 340 & 10.68 & $6 / 26$ & NA & [34] \\
\hline & $\mathrm{Fe}_{2} \mathrm{O}_{3} \mathrm{NRs}$ & $\mathrm{CH}_{3} \mathrm{COCH}_{3}$ & 100 & 280 & 23.5 & $\approx 1 / \approx 3$ & NA & [35] \\
\hline & $\mathrm{NiO} N W s$ & $\mathrm{NH}_{3}$ & 50 & RT & 0.19 & $36 / \mathrm{NA}$ & NA & [36] \\
\hline & $\mathrm{WO}_{3} \mathrm{NWs}$ & NO & 500 & 300 & 37 & $63 / 88$ & 50 & [37] \\
\hline & $\mathrm{TiO}_{2} \mathrm{NTs}$ & $\mathrm{C}_{7} \mathrm{H}_{8}$ & 50 & 500 & 3 & $110 / 800$ & NA & [38] \\
\hline & $\mathrm{WO}_{3} \mathrm{NWs}$ & $\mathrm{C}_{2} \mathrm{H}_{2}$ & 200 & 300 & 58 & $6 / 7$ & NA & [39] \\
\hline & $\mathrm{NiO}$ nanochains & $\mathrm{HCHO}$ & 50 & 210 & NA & $1 / 10$ & 1 & [40] \\
\hline & $\mathrm{CuONWs}$ & n-propanol & 100 & 190 & 6.2 & $\approx 2 / \approx 7$ & 1 & [41] \\
\hline
\end{tabular}


Table 2. Cont.

\begin{tabular}{|c|c|c|c|c|c|c|c|c|}
\hline Dimensions & Sensing Material & Target Gas & $\begin{array}{l}\text { Gas Conc. } \\
\text { (ppm) }\end{array}$ & $\begin{array}{c}\mathrm{T} \\
\left({ }^{\circ} \mathrm{C}\right)\end{array}$ & $\begin{array}{c}\text { Response } \\
\left(R_{a} / R_{g}\right) \text { or }\left(R_{g} / R_{a}\right) \text { or } \\
{\left[\left(R_{a}-R_{g}\right) / R_{a}\right]^{*} 100 \%}\end{array}$ & $\operatorname{Res}(\mathbf{s}) / \operatorname{Rec}(s)$ & $\begin{array}{c}\text { LDL } \\
\text { (ppm) }\end{array}$ & Ref. \\
\hline \multirow{11}{*}{$2 \mathrm{D}$} & $\mathrm{CuONTs}$ & $\mathrm{CO}$ & 100 & 175 & 1.55 & $24 / 29$ & 0.6 & [42] \\
\hline & $\mathrm{V}_{2} \mathrm{O}_{5} \mathrm{NWs}$ & $\mathrm{C}_{2} \mathrm{H}_{5} \mathrm{OH}$ & 1000 & 330 & 9.03 & NA & NA & [43] \\
\hline & ZnO NSs & $\mathrm{C}_{2} \mathrm{H}_{2}$ & 100 & 400 & 101.1 & $11 / 5$ & 1 & [44] \\
\hline & CuO NSs & $\mathrm{H}_{2} \mathrm{~S}$ & $10 \mathrm{ppb}$ & RT & 1.25 & $234 / 76$ & 10 & [45] \\
\hline & $\mathrm{Co}_{3} \mathrm{O}_{4} \mathrm{NSs}$ & $\mathrm{CH}_{3} \mathrm{COCH}_{3}$ & 1000 & 111 & 36.5 & NA & 20 & [46] \\
\hline & $\mathrm{NiO} N S s$ & $\mathrm{C}_{2} \mathrm{H}_{5} \mathrm{OH}$ & 50 & 240 & 11.15 & $4 / 7$ & 1 & [47] \\
\hline & $\alpha-\mathrm{Fe}_{2} \mathrm{O}_{3} \mathrm{NSs}$ & TEA & 100 & 300 & 520 & NA & 1 & [48] \\
\hline & $\mathrm{V}_{2} \mathrm{O}_{5} \mathrm{NSs}$ & $\mathrm{CH}_{3} \mathrm{COCH}_{3}$ & 100 & 300 & $\sim 3.2$ & $25 / 13$ & 5 & [49] \\
\hline & $\mathrm{TiO}_{2} \mathrm{NSs}$ & $\mathrm{CH}_{3} \mathrm{OH}$ & 1 & 100 & $17.46 \%$ & NA & 1 & [50] \\
\hline & $\mathrm{WO}_{3} \mathrm{NSs}$ & $\mathrm{NO}_{2}$ & 10 & 100 & 460 & $54 / 63$ & 1 & [51] \\
\hline & $\mathrm{SnO}_{2} \mathrm{NSs}$ & $\mathrm{CH}_{3} \mathrm{COCH}_{3}$ & 1 & 280 & 10.4 & NA & 0.2 & [52] \\
\hline \multirow{10}{*}{$3 \mathrm{D}$} & $\mathrm{Co}_{3} \mathrm{O}_{4}$ nanocubes & $\mathrm{CH}_{3} \mathrm{COCH}_{3}$ & 500 & 240 & 4.9 & $2 / 5$ & 10 & [54] \\
\hline & $\mathrm{Fe}_{2} \mathrm{O}_{3} \mathrm{MFs}$ & $\mathrm{CH}_{3} \mathrm{COCH}_{3}$ & 100 & 220 & 52 & $8 / 19$ & NA & [55] \\
\hline & $\mathrm{ZnO}$ NFs & $\mathrm{C}_{2} \mathrm{H}_{2}$ & $200 \mu \mathrm{L} / \mathrm{L}$ & 375 & 48.2 & $8 / 11$ & NA & [56] \\
\hline & $\mathrm{SnO}_{2}$ nanocages & $\mathrm{C}_{7} \mathrm{H}_{8}$ & 20 & 250 & 33.4 & $\approx 3 / \approx 6$ & NA & [57] \\
\hline & $\mathrm{In}_{2} \mathrm{O}_{3} \mathrm{MSs}$ & $\mathrm{C}_{7} \mathrm{H}_{8}$ & 50 & 350 & $85 \%$ & $12 / 25$ & 0.5 & [58] \\
\hline & $\mathrm{NiO}$ nanotetrahedra & $\mathrm{HCHO}$ & 50 & 250 & 11.6 & NA & NA & [59] \\
\hline & $\mathrm{CuOMSs}$ & $\mathrm{HCHO}$ & 100 & 300 & 3.2 & $26 / 28$ & NA & {$[60]$} \\
\hline & $\mathrm{WO}_{3}$ urchin-like structures & $\mathrm{C}_{2} \mathrm{H}_{5} \mathrm{OH}$ & 100 & 350 & 68.56 & $28 / 12$ & NA & [61] \\
\hline & $\mathrm{V}_{2} \mathrm{O}_{5}$ hollow spheres & $\mathrm{H}_{2}$ & 200 & RT & 2.8 & $50 / 10$ & 10 & [62] \\
\hline & $\mathrm{TiO}_{2}$ Bowl-like structure & $\mathrm{C}_{8} \mathrm{H}_{10}$ & 100 & 302 & 1.8 & $12 / 2$ & NA & [63] \\
\hline
\end{tabular}

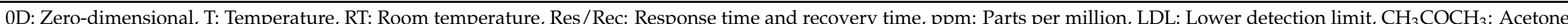
$\mathrm{NH}_{3}$ : Ammonia, $\mathrm{HCHO}$ : Formaldehyde, $\mathrm{Cl}_{2}$ : Chlorine, $\mathrm{CH}_{3} \mathrm{OH}$; Methanol; $\mathrm{C}_{2} \mathrm{H}_{2}$ : Acetylene, $\mathrm{H}_{2} \mathrm{~S}$ : Hydrogen sulfide, $\mathrm{H}_{2}$ : Hydrogen, NA: Not available, NPs: Nanoparticles, NWs: Nanowires, NRs: Nanorods, MRs: Microrods, NFs: Nanofibers, NTs: Nanotubes, NSs: Nanosheets, MFs: Microflowers, NFs: Nanoflowers, MSs: Microspheres. 
The general gas-sensing mechanism of resistive-based gas sensors is mainly based on the resistance variations of the sensing materials in the presence of target gases [19-63]. A scheme of the general detection mechanism of resistive-based n-type and $p$-type MOSs sensors, in the presence of oxidizing/reducing gases, is presented in Scheme 1. As shown in Scheme 1, in air, an electron depletion layer (EDL) and a hole accumulation layer (HAL) forms on the surfaces of $n$-type and $p$-type MOSs, respectively, due to the abstraction of electrons by adsorbed oxygen species on the surface of the gas sensor. Considering an $n$-type gas sensor, when it is exposed to reducing gases, due to the reaction between the gas and adsorbed oxygen species, the electrons will be released and come back to the sensor surface, leading to a decrease in the width of the EDL and increase in the sensor resistance. Upon exposure to oxidizing gas, the width of the EDL increases, leading to an increase in the sensor resistance. For $p$-type gas sensors, the width of the HAL decreases and increases upon exposure to reducing and oxidizing gases, respectively, leading to the appearance of a sensing signal. More details about the gas-sensing mechanism of resistive-based gas sensors will be discussed in the next sections.

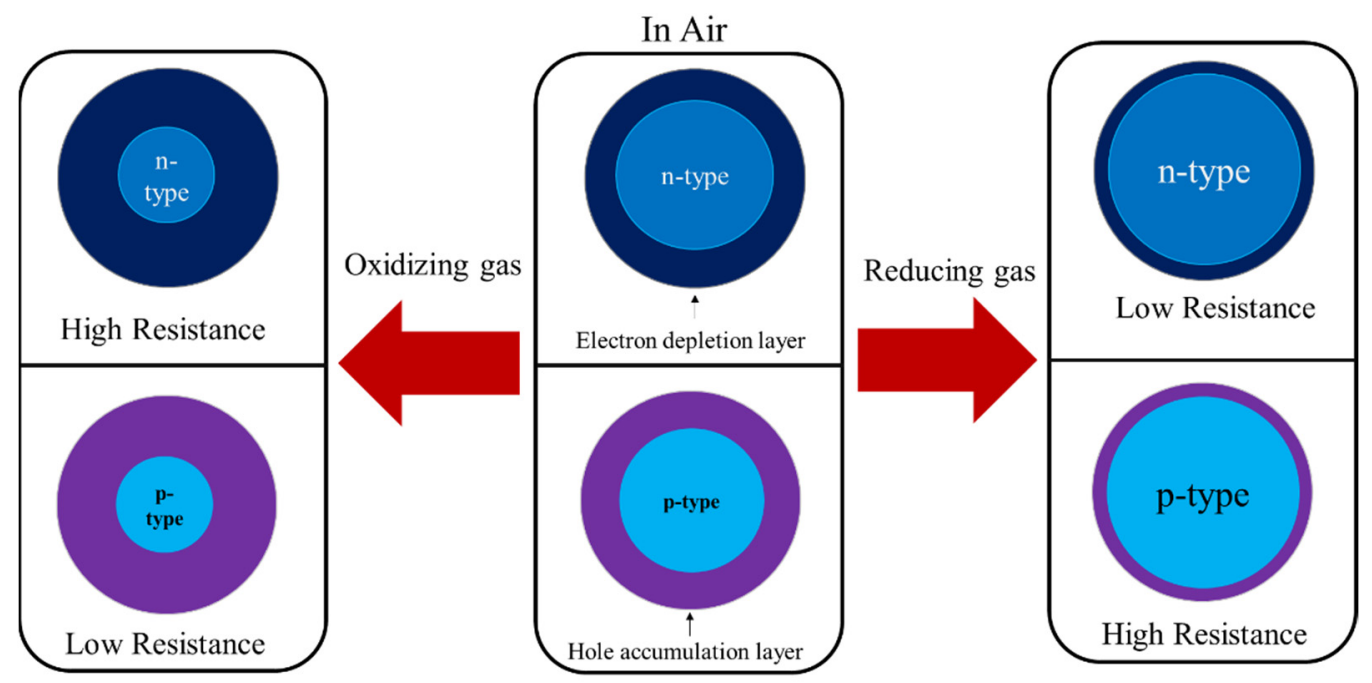

Scheme 1. General gas-sensing mechanism of $n$ - and $p$-type MOS-based chemiresistors in oxidizing and reducing gas atmosphere.

In brief, this review focuses on the different gas-sensing approaches used to enhance the sensing performance, which can provide the researchers with specific and targeted strategies for developing high-performance gas sensors. In this review, the state-of-the-art research on semiconductor-based chemiresistive-type gas sensors in Korea is described, with a focus on the research conducted by the laboratories of Professors Hyoun Woo Kim (Hanyang University) and Sang Sub Kim (Inha University). The success of our groups in the field of gas sensors stems from following items. (i) First, there is the synthesis of new materials with the desired morphology for sensing studies. For example, extensive efforts has been devoted to the synthesis of composite nanowires and nanofibers in coreshell (C-S) structure with different compositions. (ii) Second, there are advanced, almost automatic and precise measuring systems, where very small changes in the sensing signal can be detected and recorded by the system. (iii) Third, there is the optimization of sensing materials to obtain the highest sensing response. For example, the optimization of shell thickness or irradiation dose. (iv) Fourth, we focus on the finding the possible sensing mechanism by concrete evidence and using different characterization techniques. (v) Fifth, our success is the product of a highly motivated research group always monitoring the gas sensor-related literature, participating in gas sensor-related conferences, and collaborating with research groups all around the world. The studies performed in recent years on the core-shell, self-heated, irradiated, flexible, and Si/glass-based sensors are discussed. 
Accordingly, this review paper presents a lot of information about different gas sensors and their sensing mechanism.

\section{Gas Sensors Based on Morphology Engineering: Core-Shell (C-S) Sensing Materials}

Smart C-S nanocomposites, in which a core is covered with a nanoscale shell, have been subjected to sensing studies [19]. Different types of hybrid gas detection materials based on the C-S structure, such as MOS-MOS C-S, noble metal-MOS C-S, and noble metal-void oxide shell (yolk-shell), have been reported in the literature [64]. Among the MOS-MOS C-S type materials, one-dimensional (1D) C-S nanocomposites such as C-S nanowires (NWs) are well known for gas detection because these have large surfaces with a rapid diffusion pathway for gas molecules and provide a large number of heterojunctions, which are all important characteristics for realizing a good gas sensor [65]. Although there is a large difference in the structures of the nanofiber (NF) and NW sensors, a similar detection mechanism is likely involved in both cases. The results suggest that the radial modulation of the conduction channel is a common detection mechanism inside the C$S$ structures together with C-S NFs/NWs. In a C-S structure, when the shell thickness is equivalent to or less than the Debye length $\left(\lambda_{D}\right)$ of the shell layer, the whole of the shell is completely depleted from electrons due to (i) oxygen adsorption from air and (ii) flow of electrons at the C-S interface. Atomic layer deposition (ALD) is a suitable deposition method that allows the growth of smooth and high-quality films with excellent conformal on the underlying surface by controlling the thickness on the atomic scale at low temperatures [66,67]. Therefore, ALD is one of the best methods for depositing a layer of shell onto the core material. In addition, electrospinning is one of the simplest and most versatile techniques used for constructing a range of structures with different configurations, such as hollow, normal, porous, aligned, and C-S 1D nanostructures. This technique is very flexible for fabricating continuous and long NFs. It is expected that this will gradually advance from laboratory-scale to industrial-scale processes. From a marketing standpoint, electrospinning is the only preferred method for the large-scale fabrication of NFs compared to other existing techniques because of its ease of handling, low cost, minimum solution consumption, controllable NF diameter, and reproducible NF processing, in addition to technical advances compared to other techniques [68]. The following section is about the main results of the key research on the C-S nanostructurebased gas sensors published by the research groups led by Hyoun Woo Kim, Sang Sub Kim, and Yeon-Tae Yu (Jeonbuk National University, Jeonju, Korea). In most of this research, there is a detailed study about the mechanism of gas sensing in C-S-based gas sensors.

Park et al. [69] prepared $\mathrm{TiO}_{2}-\mathrm{ZnO}$ C-S NFs for oxygen sensing, wherein the shell thickness of $\mathrm{ZnO}$ grew almost linearly with the number of ALD cycles. Thus, the thickness of the shell layer could be readily controlled by adjusting the number of ALD cycles. The optimal sensor showed a response of $\approx 19$ to $5000 \mathrm{ppm}$ oxygen gas at $300{ }^{\circ} \mathrm{C}$. Thus, the oxygen-sensing data suggested that the C-S NFs afforded a better response than the bulkor film-type gas sensors because of the numerous surface adsorption sites for gaseous molecules owing to their higher surface-to-volume ratios. Choi et al. [70] fabricated $\mathrm{SnO}_{2-}$ $\mathrm{ZnO}$ C-S NFs via a two-step approach, where $\mathrm{SnO}_{2}$ NFs were initially synthesized using an electrospinning technique, and ALD was subsequently used to deposit $\mathrm{ZnO}$ shell layers. The fabricated sensor exhibited a good response $\mathrm{O}_{2}$ gas at $300{ }^{\circ} \mathrm{C}$. The response to $1000 \mathrm{ppm}$ oxygen was $\approx 2$, and it showed a detection limit of $70 \mathrm{ppm}$. The sensing enhancement relative to the pristine sensor could be attributed to a combination of homoand heterointerfaces developed at the junctions within the C-S NF sensor. The increased response of the gas sensor was related to the resistance changes caused by the surface depletion layer of the C-S NF and potential barriers at the interfaces. Kim et al. [71] investigated the sensing properties of $\mathrm{ZnO}-\mathrm{SnO}_{2} \mathrm{C}-\mathrm{S} \mathrm{NWs}$, where a $\mathrm{SnO}_{2}$ shell layer was deposited by ALD. Gas detection studies demonstrated that a sensor with an optimal shell thickness of $40 \mathrm{~nm}$ at $300{ }^{\circ} \mathrm{C}$ revealed good responses of $18.24,14.94$, and 16.46 to 1 ppm for $\mathrm{CO}, \mathrm{C}_{7} \mathrm{H}_{8}$, and $\mathrm{C}_{6} \mathrm{H}_{6}$ gases, respectively. The degree of modulation of the electron-depleted 
shell was mostly dependent on the shell thickness (Figure 1a). When the shell thickness was almost equal to $\lambda_{\mathrm{D}}$, the electrons returned to the shell layer when they were exposed to the reducing gas, leading to the development of a partially electron-depleted shell from an original completely electron-depleted shell, resulting in a high response. In an air atmosphere, the shell was not completely depleted when the shell thickness was greater than $\lambda_{\mathrm{D}}$. Upon exposure to the reducing gas, the electron-depleted layer was reduced, and there was a slight change in the resistance, which resulted in a low gas response. Thus, in the case of C-S NWs, the shell thickness must be of the order of $\lambda_{\mathrm{D}}$ to achieve a high sensing response. In the case of a $\mathrm{SnO}_{2}$ shell with a thickness $\leq \lambda_{\mathrm{D}}$, the modulation of resistance should be nearly equivalent. However, the primary resistance values showed that the resistance increased with an increase in the shell thickness until the maximum value was obtained for a shell thickness of $40 \mathrm{~nm}$.

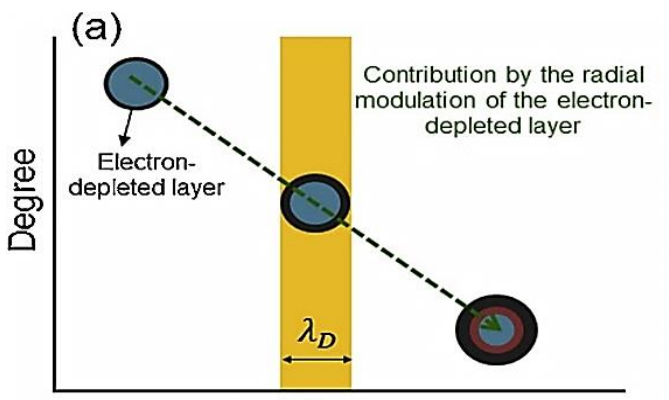

Shell thickness

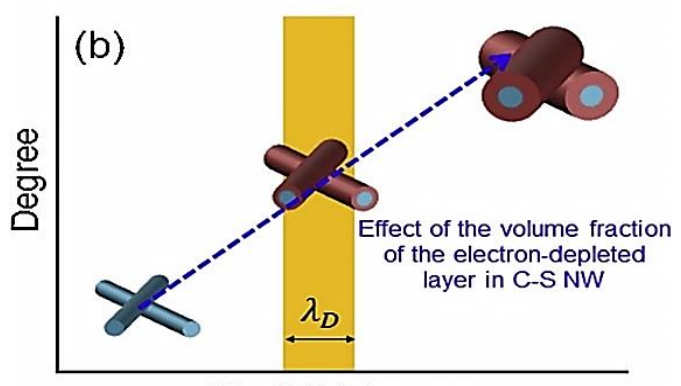

Shell thickness

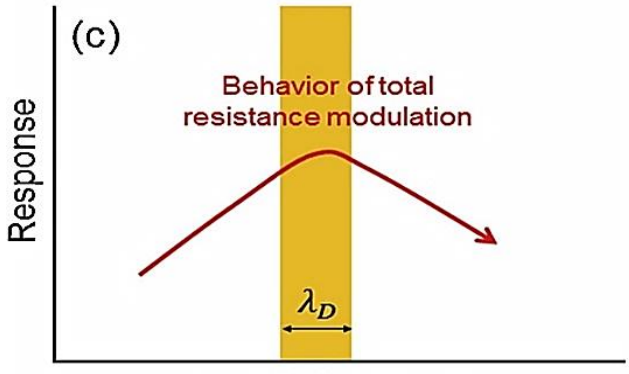

Shell thickness

Figure 1. Effect of various mechanisms on the $\mathrm{ZnO}-S n O_{2} \mathrm{C}-\mathrm{S} \mathrm{NW}$ sensor response: (a) radial modulation effect, (b) volume fraction effect, and (c) response variation as a function of shell thickness. Reproduced from [71] with the permission of Elsevier.

Accordingly, along with radial modulation, other factors must be considered to determine the initial resistance and detection performance. For the C-S NWs, the portion of the total volume of the C-S NWs was proportional to the shell thickness (Figure 1b). Therefore, the overall combined reducing gas response could be envisioned as a bell-shaped curve, which was correlated to the shell thickness (Figure 1c). In reality, the net effect of the contributions from the two detection mechanisms mentioned above eventually determined the gas response of the C-S NW sensor, where the highest response was observed for the shell with a thickness of $40 \mathrm{~nm}$. Together with the aforementioned mechanisms, the 
smearing effect related to the electric field must also be considered. For shell layers with thicknesses $\leq \lambda_{\mathrm{D}}$, the electrical currents were not confined to the shell area and passed through the core and shell. In such a case, the shell was completely electron-depleted in ambient air and subjected to significant resistance modulation after exposure to the reducing gas. However, a significant proportion of the electron current also flowed through the NW core, resulting in a slight resistance change of the C-S NWs. However, for shell thicknesses $\geq \lambda_{\mathrm{D}}$, the electrical currents most likely passed through the shell, and the resistance modulation was mainly governed by the radial modulation of the resistance. Choi et al. [72] synthesized C-S NWs via a two-step process, where core $\mathrm{SnO}_{2} \mathrm{NW}_{\text {s }}$ were primarily fabricated by a vapor-liquid-solid (VLS) growth process, and the ZnO shell layers were subsequently deposited using ALD. The $\mathrm{SnO}_{2}-\mathrm{ZnO} \mathrm{C}-\mathrm{S} \mathrm{NW}$ sensor with a shell thickness of $40 \mathrm{~nm}$ showed an excellent response to different reducing gases such as benzene $\left(R_{a} / R_{g}=88\right.$ to $\left.10 \mathrm{ppm} \mathrm{C}_{6} \mathrm{H}_{6}\right), \mathrm{CO}\left(R_{a} / R_{g}=80\right.$ to $\left.10 \mathrm{ppm} \mathrm{CO}\right)$, and toluene $\left(R_{a} / R_{g}=75\right.$ to $\left.10 \mathrm{ppm} \mathrm{C}_{7} \mathrm{H}_{8}\right)$ at $300{ }^{\circ} \mathrm{C}$. However, the $\mathrm{NO}_{2}$-sensing responses of the sensors were decreased because of the formation of the shell layers.

The shells with thicknesses less than the Debye length are speculated to partially coat the core NWs, leading to a low gas response. Since the thickness of the shell is equal to or less than the Debye length of the shell layer, the modulation of resistance resulting from the release of electrons captured in the shell layer during the interaction of reducing gases must be nearly equal for all the C-S structures. However, for $\mathrm{ZnO}$ sensors with shell layers of thicknesses less than the Debye length, the modulation of resistance increases with increasing shell thickness up to the Debye length. This is in contrast to the interpretation based on the radial modulation mechanism of the electron-depleted shell layer. Accordingly, additional factors should be considered to account for the sensing outcomes. The degree of resistance modulation initiated by the radial modulation of the electron-depleted shell layer varies according to the shell thickness (Figure $2 \mathrm{a}$ ). Figure $2 \mathrm{~b}$ shows the sensing mechanism based on the electric field smearing effect. A thinner shell layer allows the development of the Debye length on the core material, and electrical transport is induced within the shell layer and around the C-S core interface because the passage is not restricted to the shell layer. This partially enhances the modulation of resistance when the C-S NWs are subjected to reducing gases because partial electrical transport is observed within the shell layer, which is an electrically depleted region. Even if the shell layer, which is completely depleted of electrons, undergoes a large modulation of the resistance, a considerable portion of electron transport is observed in the inner NW core, leading to a marginal modulation of resistance of the entire C-S NWs. In addition, for a shell layer thickness equal to or greater than the Debye length, the electrical transport is generally limited to the shell layer and not smeared to the core region. In such a case, the smearing effect becomes negligible, and the resistance modulation of the C-S NWs through reducing gases is governed by the radial modulation of the electron-depleted layer. The two above-mentioned effects cumulatively contribute to the gas response, as shown in Figure 2c.

Katoch et al. [73] reported the synthesis of $\mathrm{SnO}_{2}-\mathrm{ZnO}$ C-S NFs via a combination of electrospinning and ALD techniques for $\mathrm{CO}$ and $\mathrm{NO}_{2}$ gas-sensing applications. The optimal gas sensor showed a response of 6.5 to 1 ppm $\mathrm{CO}$ gas at $300{ }^{\circ} \mathrm{C}$, while the response to 1 ppm $\mathrm{NO}_{2}$ gas was 1.5. In the $\mathrm{SnO}_{2}-\mathrm{ZnO}$ C-S NFs, a heterojunction was formed between the core and shell, and the potential barrier of the heterojunction played an important role in enhancing the sensing capabilities of the C-S NFs. The height of the heterojunction potential barrier was modulated by reaction with the target gases. In the $\mathrm{SnO}_{2}-\mathrm{ZnO} \mathrm{C}-\mathrm{S}$ NFs, the shell layer was entirely electron-depleted when the thickness of the shell was equal to that of the shell material. The resistance of the pristine $\mathrm{SnO}_{2} \mathrm{NF}$ sensor was significantly improved when a $\mathrm{ZnO}$ shell layer was created. In particular, the $20 \mathrm{~nm}$-thick C-S NF sensor showed the maximum resistance, which indicated a completely depleted state of electrons in the ZnO shell. For the C-S NFs with shells of thicknesses greater than the Debye length, the resistance decreased again because of the partially depleted state of electrons. This change in resistance with varying shell thickness supported the electron transport 
mechanism in C-S, which was mainly controlled by the characteristics and thickness of the shell layer (Figure 3). The C-S NF sensors showed a low sensitivity to $\mathrm{NO}_{2}$ because of the unavailability of electrons in the shell layer. In the case of the C-S NFs with shell thicknesses greater than the $\lambda_{\mathrm{D}}$ of $\mathrm{ZnO}$, the layer partially depleted by the electrons afforded a smaller number of electrons for the adsorbed $\mathrm{NO}_{2}$ gas molecules, which led to a larger resistance change than in the case of thick sensors [28].

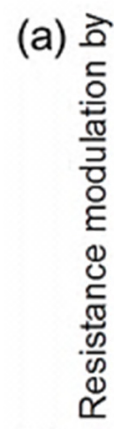

(b)
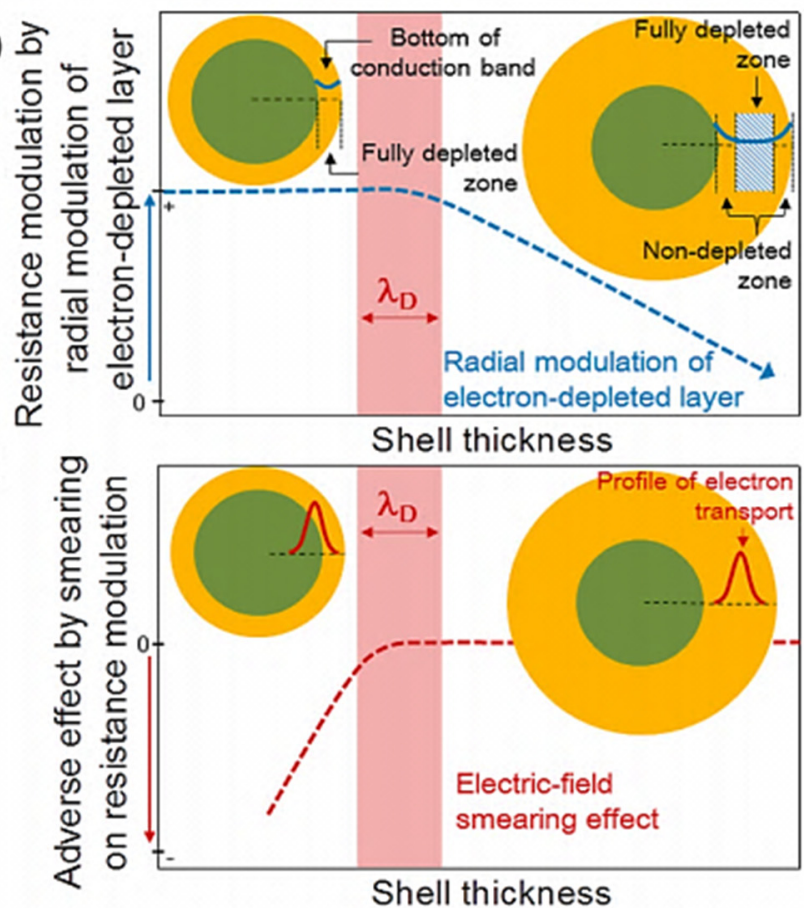

(c)

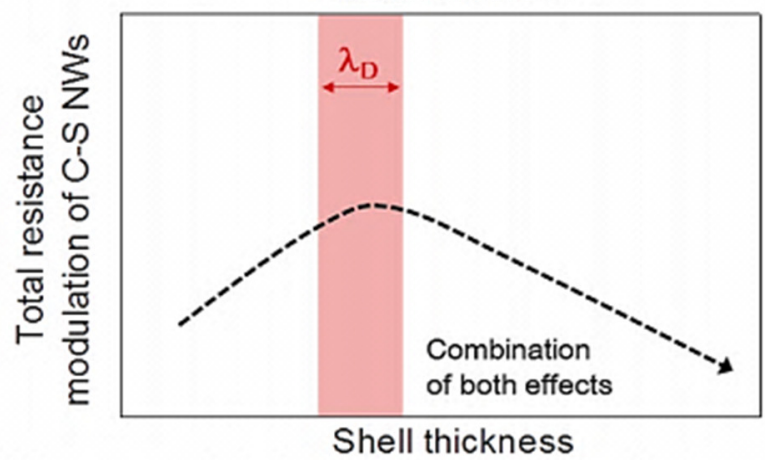

Figure 2. Conceptual explanation demonstrating the sensing mechanism of C-S NWs: (a) radial modulation, (b) adverse effect through smearing on resistance modulation, and (c) overall resistance modulation. Reproduced from [72] with the permission of the American Chemical Society.

Similarly, Kim et al. [74] investigated the gas-sensing characteristics of the $p-n$ copper oxide $(\mathrm{CuO})-\mathrm{ZnO} \mathrm{C}-\mathrm{S}$ NWs toward the reducing gases, such as $\mathrm{CO}$ and $\mathrm{C}_{6} \mathrm{H}_{6}$ gases, where a sensor with a shell thickness equal to the $\lambda_{\mathrm{D}}$ of $\mathrm{ZnO}$ exhibited excellent sensing performance. The optimal gas sensor showed responses of 6 and 5.8 to $1 \mathrm{ppm} \mathrm{CO}$ and $\mathrm{C}_{6} \mathrm{H}_{6}$ gases, respectively at $300{ }^{\circ} \mathrm{C}$ with a detection limit of $1 \mathrm{ppm}$. For the shell layers with thicknesses equal to the $\lambda_{\mathrm{D}}$ of $\mathrm{ZnO}$, the electrons from the $\mathrm{ZnO}$ shell were completely depleted owing to the combined effect of the $p$ - $n$ junction and oxygen adsorption on the shell. The sensing mechanism for the shell layer with a thickness less than $\lambda_{\mathrm{D}}$ is shown in Figure 4a. Notably, the shell thickness affording the highest sensing performance is almost equal to $\lambda_{\mathrm{D}}$, indicating a correlation between the sensing mechanism and $\lambda_{\mathrm{D}}$ value. When the sensors with a completely depleted shell layer were exposed to the reducing gases, the desorption surface oxygen released electrons into the conduction band of the 
shell to regain its original configuration, which significantly increased the conductivity of the C-S NWs. When the shell thickness was considerably smaller than $\lambda_{\mathrm{D}}$, the variation in resistance initiated mainly from the shell part was insignificant because of a small portion of the shell layer in the entire volume of the C-S NWs, even though the shell layer was fully electron-depleted and afforded a large variation in resistance. Thus, shells thinner than the critical value exhibited low a gas-sensing capability when compared to those with optimized thicker shells. In contrast, for the sensors with shell layers thicker than $\lambda_{\mathrm{D}}, \mathrm{a}$ slight change in resistance was observed (Figure $4 \mathrm{~b}$ ). Consequently, a shell with a thickness comparable to $\lambda_{\mathrm{D}}$ is crucial to achieve excellent performance for reducing gases.

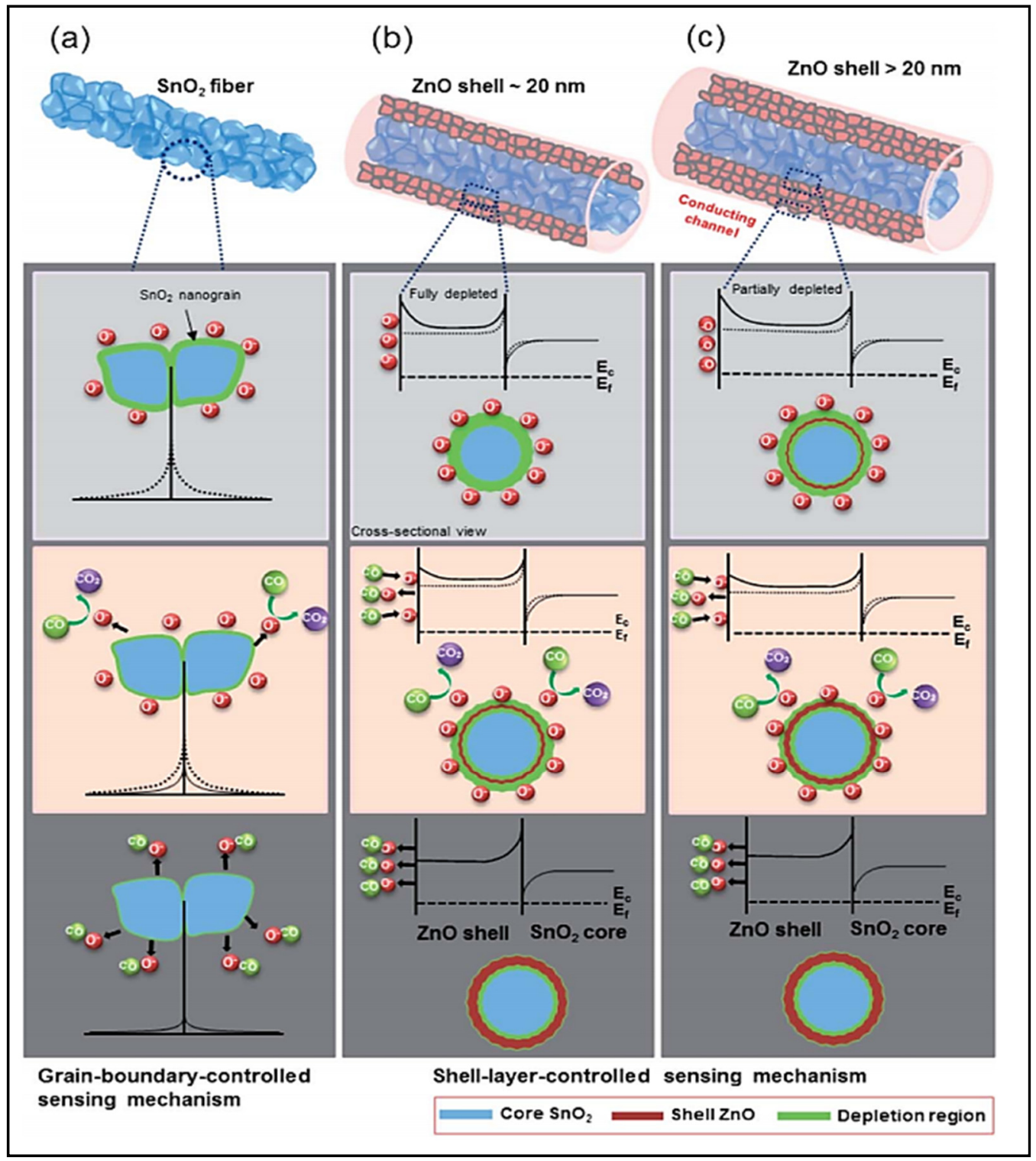

Figure 3. Schematic representation of the radial modulation of the $\mathrm{ZnO}$ shell layer: (a) pristine $\mathrm{SnO}_{2}$ NFs and $\mathrm{SnO}_{2}-\mathrm{ZnO}$ C-S with a shell thickness of (b) $\lambda_{\mathrm{D}}$ and (c) $>\lambda_{\mathrm{D}}$ [73]. Reproduced from [73] with the permission of Royal Society of Chemistry.

In another study, Kim et al. [75] synthesized $\mathrm{SnO}_{2} / \mathrm{Cu}_{2} \mathrm{O}$ C-S NFs by electrospinning followed by ALD of a $\mathrm{Cu}_{2} \mathrm{O}$ layer. The pristine $\mathrm{SnO}_{2}$ sensor showed the highest response toward $\mathrm{NO}_{2}$ gas $\left(R_{g} / R_{a}=5.3\right.$ to $10 \mathrm{ppm} \mathrm{NO}$ gas at $\left.300{ }^{\circ} \mathrm{C}\right)$, and the $\mathrm{C}-\mathrm{S}$ NF sensor with a shell thickness of $30 \mathrm{~nm}$ showed the maximum response to $\mathrm{CO}$ gas. The optimal gas sensor showed a response of 5.3 to $10 \mathrm{ppm} \mathrm{CO}$ gas at $300^{\circ} \mathrm{C}$. The sensing characteristics were 
not only affected by the initial concentration of holes in the shell but also by hindering the development of the hole-accumulation layers (HAL) (Figure 5a). The released electrons eradicated the holes and increased the shell layer resistance. In a shell of $15 \mathrm{~nm}$ thickness, the total layer was hole-accumulated, and hence, the subsequent transfer of holes from $\mathrm{NO}_{2}$ gas was not effective. Furthermore, the injection of $\mathrm{CO}$ gas eliminated the holes from the entire hole-accumulated layer and increased the resistance. For a shell thickness of $30 \mathrm{~nm}$, a part of the shell was hole-accumulated by the adsorbed oxygen ions. The entire thickness was hole-accumulated by the adsorption of $\mathrm{NO}_{2}$ gas, which resulted in an enhanced sensor response. In addition, the accumulation of holes was decreased by the adsorption of $\mathrm{CO}$ gas, which increased the hole resistance, thereby affording a high sensor response. For an optimal shell thickness of $30 \mathrm{~nm}$, it was assumed that the shell layer would be nearly hole-depleted upon $\mathrm{CO}$ incorporation, where the change in the hole resistance caused by the incorporation of $\mathrm{CO}$ gas would be maximized. Consequently, the sensor response increased for $\mathrm{NO}_{2}$ and $\mathrm{CO}$ gases with an increase in shell thickness beyond $15 \mathrm{~nm}$. In contrast, the expansion of the rich-HAL layer was restricted by the presence of an $n-p$ heterojunction, which acted as a blocking layer for expansion. Therefore, a further increase in the thickness of the shell resulted in low responses to $\mathrm{NO}_{2}$ and $\mathrm{CO}$ gases. For a shell thickness of $45 \mathrm{~nm}$, the sensor response to $\mathrm{CO}$ gas was significantly decreased compared to that for a shell thickness of $30 \mathrm{~nm}$. Additionally, the response to $\mathrm{NO}_{2}$ gas decreased slightly with a decrease in the shell thickness from 45 to $30 \mathrm{~nm}$. For a shell thickness of $45 \mathrm{~nm}$, the HAL layer was decreased to less than half the thickness of the shell layer. Therefore, a decrease in HAL through $\mathrm{CO}$ injection was insufficient, while an increase in HAL by injecting $\mathrm{NO}_{2}$ was sufficient. In addition, the sensing was not only affected by contribution from the degree of resistance modulation but also by the contribution of the overall volume fraction in the C-S NFs (Figure $5 b-d$ ). The resistance modulation caused by the radial modulation of the rich-HAL varied inversely with the shell thickness (Figure 5b). Along with this process, the degree of resistance modulation was higher in the thinner shells; however, the opposite was observed for thicker shells. 


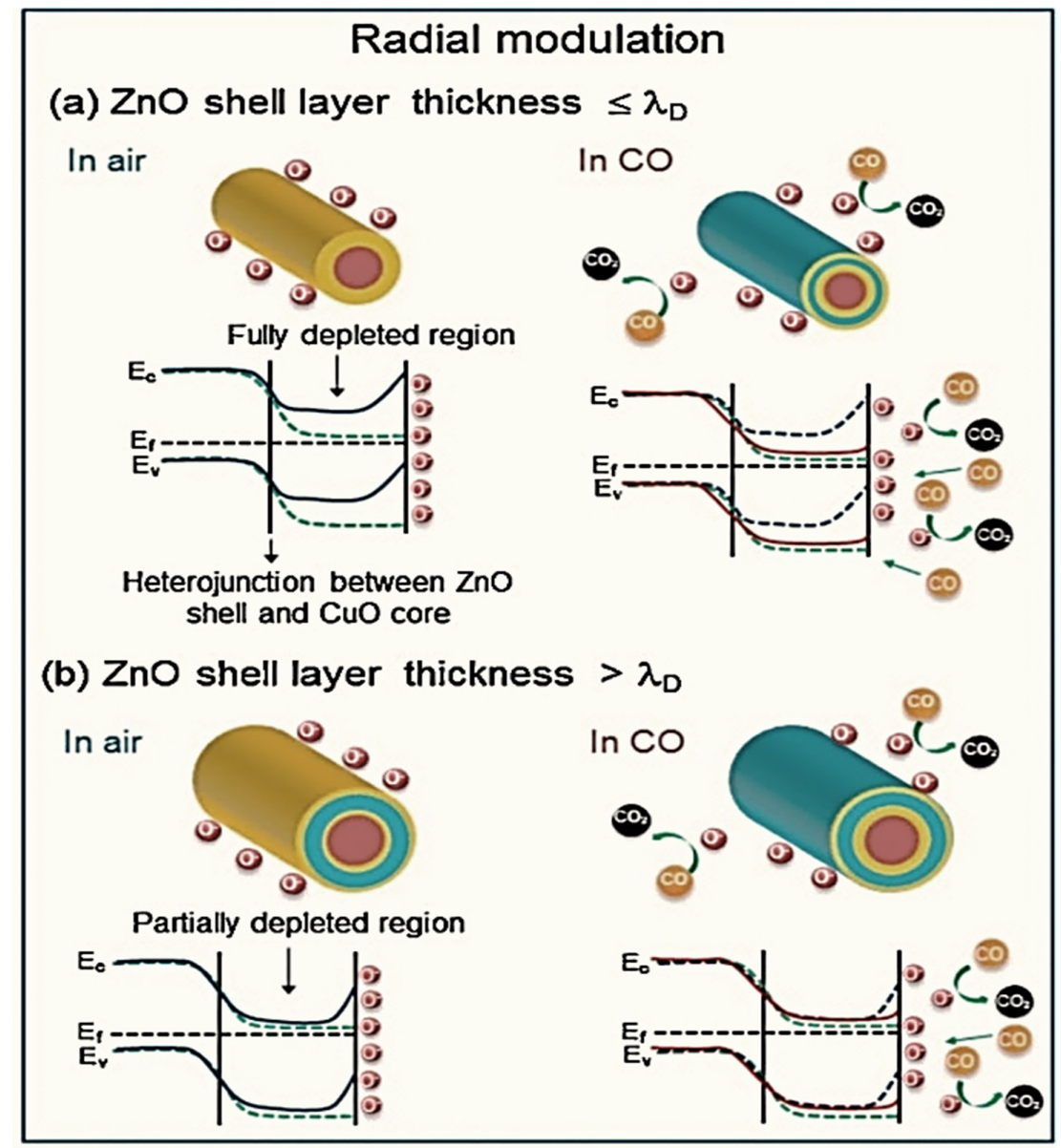

Figure 4. Schematic of the reducing gas-sensing mechanism of the $\mathrm{CuO}-\mathrm{ZnO} \mathrm{C}-\mathrm{S} \mathrm{NW}$ sensor for $\mathrm{ZnO}$ shell layers with thicknesses (a) less than $\lambda_{\mathrm{D}}$ and (b) greater than $\lambda_{\mathrm{D}}$. Reproduced from [74] with the permission of Elsevier. 


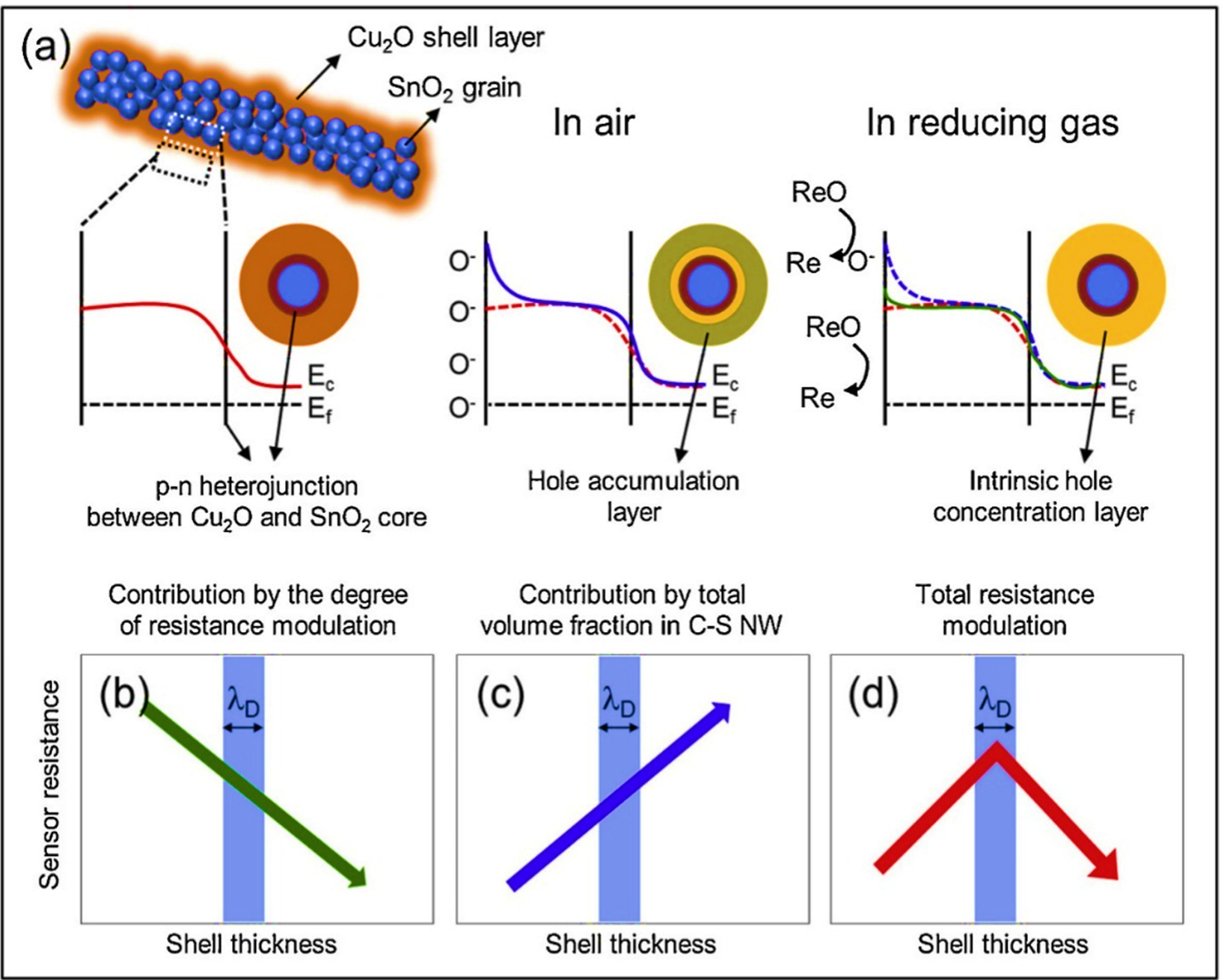

Figure 5. Schematic representation of the gas-sensing mechanisms of the $\mathrm{SnO}_{2}-\mathrm{Cu}_{2} \mathrm{O}$ C-S NF sensors. (a) Hole concentration profile and (b-d) variation in sensor resistance due to different contributions. Reproduced from [75] with the permission of Elsevier.

Regardless of other factors, it was expected that the thinnest shell would afford the highest gas response. However, sensing studies showed the dependency of the bell-shaped response on the shell thickness. An additional contribution was that of the fraction of the $\mathrm{Cu}_{2} \mathrm{O}$ shell to the overall volume of the C-S NFs, which was proportional to the thickness of the shell (Figure 5c). Therefore, the modulation of the total resistance showed a maximum at an exact thickness of the shell (Figure 5d). For a pristine $\mathrm{SnO}_{2}$ sensor, the $\mathrm{NO}_{2}$ response was greater than that of CO, whereas the developed C-S NF sensor showed a very poor response to $\mathrm{NO}_{2}$ in comparison to the pristine $\mathrm{SnO}_{2}$ sensors, indicating that the $\mathrm{SnO}_{2}-\mathrm{Cu}_{2} \mathrm{O}$ C-S NFs sensors were not effective in detecting $\mathrm{NO}_{2}$. The capability of $\mathrm{NO}_{2}$ gas for electron transfer from the $\mathrm{Cu}_{2} \mathrm{O}$ surface was significantly inferior to that of the $\mathrm{SnO}_{2}$ surface.

Kim et al. [76] studied the effect of Pt functionalization with an the optimal shell thicknesses on the $\mathrm{C}_{7} \mathrm{H}_{8}$-sensing characteristics of $\mathrm{SnO}_{2}-\mathrm{ZnO}$ C-S NWs. The sensor showed a high response of 279 to 0.1 ppm $\mathrm{C}_{7} \mathrm{H}_{8}$ gas at $300{ }^{\circ} \mathrm{C}$. Functionalization using Pt NPs resulted in two contributions to the sensing characteristics of the $\mathrm{SnO}_{2}-\mathrm{ZnO}$ C-S NWs. The first contribution was related to the electronic sensitization (ES) that was initiated by the electron flow from the $\mathrm{ZnO}$ shell layer to the Pt NPs, which led to a further suppression of the conduction channels configured inside the layer of the $\mathrm{ZnO}$ shell (Figure 6a). 
Toluene-sensing mechanism in Pt NPs-functionalized $\mathrm{SnO}_{2}-\mathrm{ZnO}$ C-S NWs

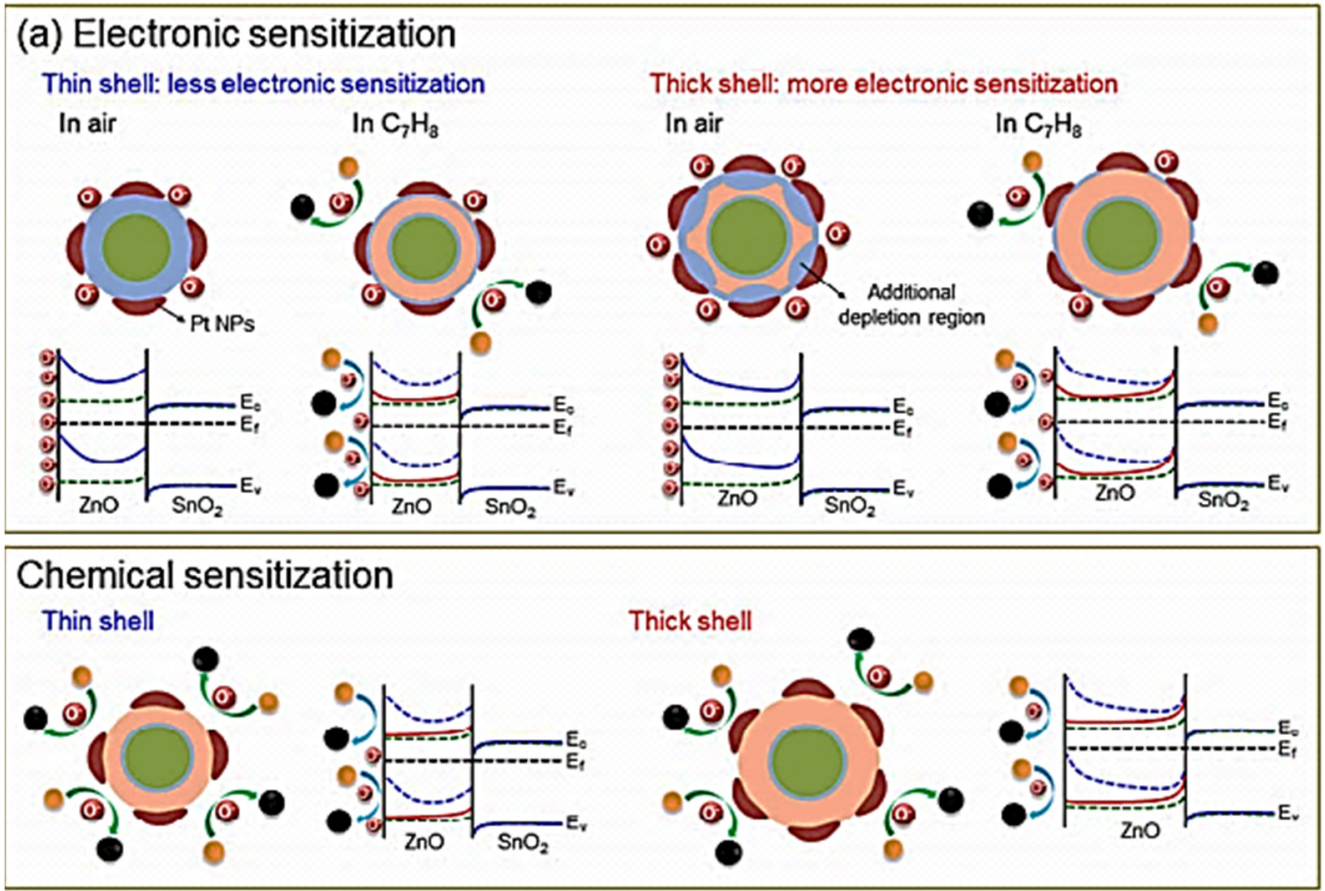

(b) Resistance modulation of Pt NPs-functionalized C-S NWs
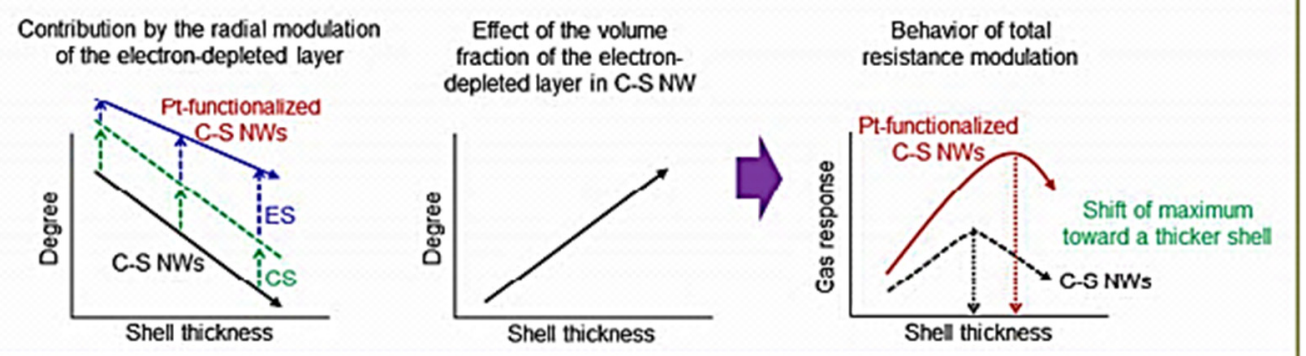

Figure 6. Schematic representation of the $\mathrm{C}_{7} \mathrm{H}_{8}$-sensing mechanism of the Pt-decorated $\mathrm{SnO}_{2}-\mathrm{ZnO}$ C-S NWs; (a) ES and CS effects of the Pt NPs and (b) shift of the response toward a thicker shell in the presence of Pt. Reproduced from [76] with the permission of the American Chemical Society.

When the $\mathrm{C}_{7} \mathrm{H}_{8}$ molecules reacted with chemisorbed oxygen species, the width of the depletion layer changed, resulting in the resistance modulation of the gas sensor. The second contribution was the catalytic effect of the Pt NPs through chemical sensitization (CS), which allowed further interactions between the $\mathrm{C}_{7} \mathrm{H}_{8}$ molecules and chemisorbed oxygen species. The ES and CS effects are shown in Figure 6a. The ES contribution depended only on Pt NPs, and accordingly, the CS contribution was mainly accountable for selective sensing because of various phases of catalytic interactions between the metal NPs and a specific gas. As shown in Figure 6b, owing to the ES and CS contributions of the $\mathrm{Pt} \mathrm{NPs}$, the gas response of the sensor based on Pt-functionalized $\mathrm{SnO}_{2}-\mathrm{ZnO}$ C-S NWs was further enhanced, and the response maxima shifted toward a thicker shell. As shown in Figure 6, the gas response of the Pt-functionalized $\mathrm{SnO}_{2}-\mathrm{ZnO}$ C-S NWs increases linearly with an increase in the shell thickness, unlike the $\mathrm{SnO}_{2}-\mathrm{ZnO}$ C-S NWs without Pt NPs. The $\mathrm{Pt}$ NPs could dissociate the $\mathrm{C}_{7} \mathrm{H}_{8}$ gas molecules more efficiently than the other gases. The adsorption of $\mathrm{C}_{7} \mathrm{H}_{8}$ gas molecules onto the $\mathrm{Pt}$ surface was largely affected by the electronic effects, which decreased the barrier for $\mathrm{C}_{7} \mathrm{H}_{8}$ adsorption by making it easier to donate the electrons from the $\pi \mathrm{CH}_{3}$ level to the Fermi level and readily allowing back-donation from the Fermi level to the $\pi \mathrm{CH}_{3}{ }^{*}$ level. 
Zirconium oxide $\left(\mathrm{ZrO}_{2}\right)$ is typically utilized for electrochemical gas sensing at high temperatures [77], and the number of reports on its resistive-based gas sensing is limited. Bang et al. [78] synthesized- $\mathrm{SnO}_{2}-\mathrm{ZrO}_{2} \mathrm{C}-\mathrm{S}$ NWs with different shell thicknesses $(10.5-34.1 \mathrm{~nm})$ and studied their $\mathrm{NO}_{2}$ gas-sensing properties (Figure $7 \mathrm{a}$ ).

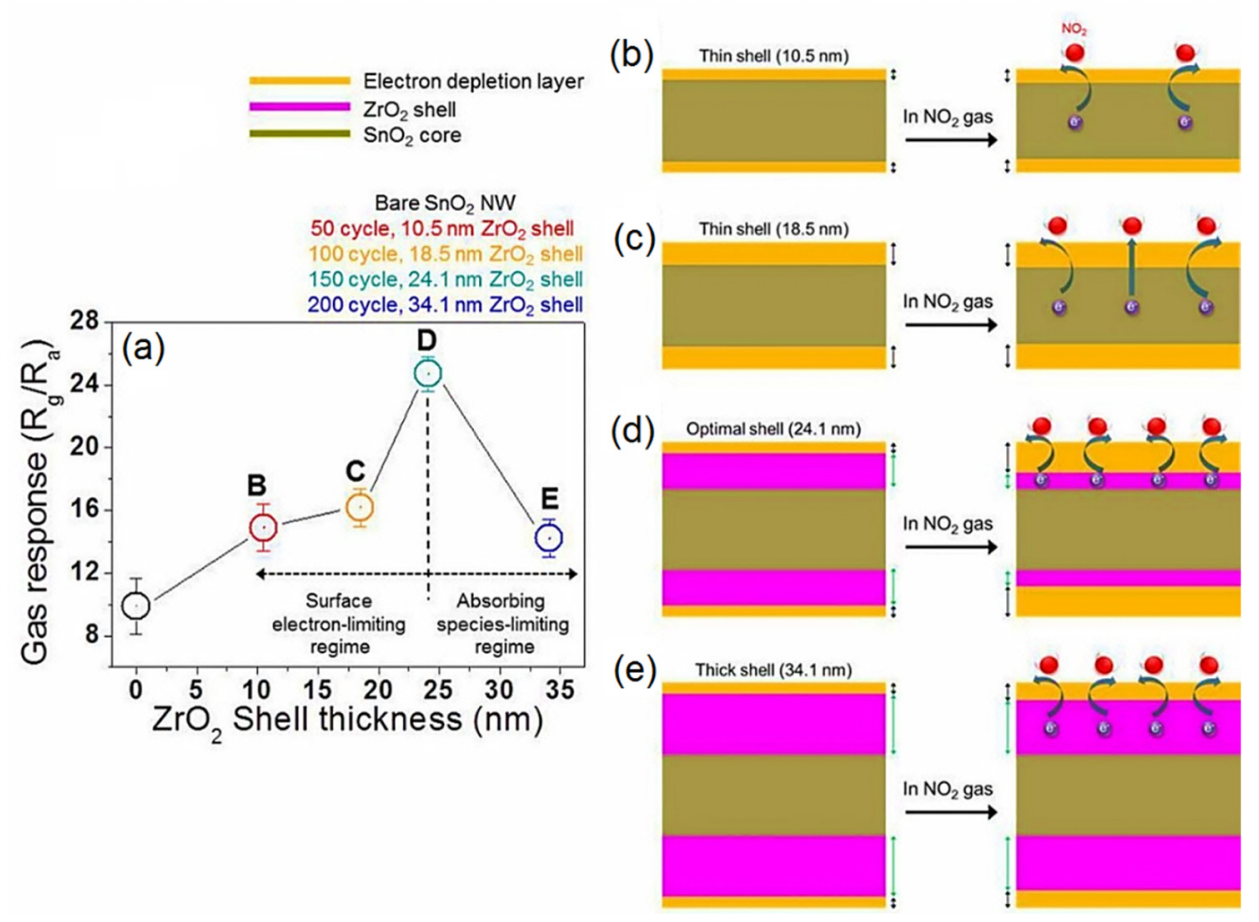

Figure 7. (a) $\mathrm{NO}_{2}$ responses of $\mathrm{SnO}_{2}-\mathrm{ZrO}_{2}$ C-S NW sensors as a function of $\mathrm{ZrO}_{2}$ shell thickness. (b-e) Illustration of $\mathrm{NO}_{2}$ sensing by the gas sensors with $\mathrm{ZrO}_{2}$ shell thicknesses of (b) 10.5, (c) 18.5, (d) 24.1, and (e) $34.1 \mathrm{~nm}$. Reproduced from [78] with the permission of Elsevier.

The optimal sensor showed a response of 24.7 to $10 \mathrm{ppm} \mathrm{NO}$ gas at $150^{\circ} \mathrm{C}$. The schematics showing $\mathrm{NO}_{2}$ gas sensing with various shell thicknesses are shown in Figure $7 \mathrm{~b}-\mathrm{e}$. With an increase in the shell thickness of $\mathrm{ZrO}_{2}$, the number of electrons in $\mathrm{ZrO}_{2}$ increased in the range of $0-24.1 \mathrm{~nm}$. As the $\mathrm{r}$ esponse of $\mathrm{ZrO}_{2}$ increased with respect to the electron conduction volume, the developed sensor system in the range of 0-24.1 nm was in command, where the surface electron concentration of $\mathrm{ZrO}_{2}$ was lower than that of the adsorbing gas species. In this surface-electron-limiting regime, most of the available surface electrons interact with the adsorbed gaseous species. Accordingly, an increase in the volume of electron conduction led to an increase in the sensor response. For a shell thickness less than the optimum value, almost the entire thickness was depleted. Upon $\mathrm{NO}_{2}$ exposure, insufficient electrons were extracted from the $\mathrm{ZrO}_{2}$ layer. Accordingly, the number of surface electrons was inadequate in the sensor with thin shells, and consequently, the response of the sensor was restricted. Consequently, the detection capability improved with an increase in the shell thickness from 0 to $24.1 \mathrm{~nm}$. At an optimum shell thickness of $24.1 \mathrm{~nm}$, the shell layer of $\mathrm{ZrO}_{2}$ was significantly depleted by electrons. Upon exposure to $\mathrm{NO}_{2}$ gas, the remaining electrons from $\mathrm{ZrO}_{2}$ were completely depleted by the adsorption of $\mathrm{NO}_{2}$ species. The initial concentration of electrons was extremely high for the thin shells; therefore, a large number of electrons were consumed during the reactions with $\mathrm{NO}_{2}$ gas. The sensor response decreased with an increase in the shell thickness from 24.1 to $34.1 \mathrm{~nm}$ because of the presence of adequate surface electrons above $24.1 \mathrm{~nm}$ owing to the thick shell of $\mathrm{ZrO}_{2}$. This modified the system to afford a regimen in which the concentration of surface electrons in $\mathrm{ZrO}_{2}$ was greater than that of the adsorbed gaseous species. In such an adsorbing-species-limiting regimen with a high initial conduction volume, a decrease in the $\mathrm{ZrO}_{2}$ surface electrons upon the injection of the target gas resulted in a low sensor response, 
which was achieved through a thick shell layer. Further increase in the shell thickness resulted in a lower sensor response. Relative to the optimized shell thickness, a large portion of the shell layer was not depleted by the electrons. Even though $\mathrm{NO}_{2}$ adsorption led to the adsorption of some electrons, the relative change in the electron concentration within $\mathrm{ZrO}_{2}$ was not very significant, resulting in a relatively lower sensor response.

Kim et al. [79] synthesized $\mathrm{SnO}_{2}-\mathrm{Cu}_{2} \mathrm{O}$ C-S NWs and applied these to the detection of trace amounts of gases. The resistance curves for the C-S NW sensors with different shell thicknesses were obtained upon exposure to $10 \mathrm{ppm} \mathrm{C}_{7} \mathrm{H}_{8}, \mathrm{C}_{6} \mathrm{H}_{6}$, and $\mathrm{NO}_{2}$. The sensor based on C-S NWs with a shell thickness of $30 \mathrm{~nm}$ exhibited the best response to reducing

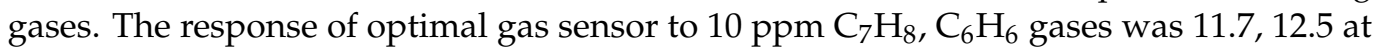
$300{ }^{\circ} \mathrm{C}$. In addition, the response and recovery times were almost $4 \mathrm{~s}$ for both gases. The presence of the $\mathrm{Cu}_{2} \mathrm{O}$ shell decreased the $\mathrm{NO}_{2}$-sensing response of the $\mathrm{C}$-S NW sensors. The sensing mechanism of the $\mathrm{SnO}_{2}-\mathrm{Cu}_{2} \mathrm{O}$ C-S NW sensor is shown in Figure 8. In ambient air, the concentration of holes can be divided into three regions (considering the vacuum case (Figure 8a) because of oxygen adsorption onto the $\mathrm{Cu}_{2} \mathrm{O}$ shell and development of the $\mathrm{C}-\mathrm{S}$ heterojunctions (shown in Figure $8 \mathrm{~b}$ ). The HAL $\left(p^{+}\right)$is created by the extraction of electrons from the valence band of $\mathrm{Cu}_{2} \mathrm{O}$ by chemisorbed oxygen species. At a specific temperature, the intrinsic hole concentration layer $\left(p_{0}\right)$ remains at the equilibrium hole concentration in $\mathrm{Cu}_{2} \mathrm{O}$, and the hole-deficient layer $\left(p^{-}\right)$results from an electrostatic response to the hole layer by the electrons in the $n-p$ heterojunction. The red line in Figure $8 \mathrm{~b}$ shows the profile of the hole concentration in ambient air, and the dotted black line shows the case in vacuum. An increase in the concentration of holes is observed in air. When the sensor is exposed to the reducing gas, the resistance of the $p-\mathrm{Cu}_{2} \mathrm{O}$ shell layer increases. As shown in Figure $8 c$, the profile of hole concentration (blue line) in air shifts toward the red line, which supports a decrease in the concentration of holes in the " $p$ " shell layer. Therefore, the detection capability of pure $\mathrm{Cu}_{2} \mathrm{O}$ NWs was inferior to that of the C-S NWs because of the weaker hole-accumulation layer. The degree to which the resistance of the $p^{+}$layer is modulated varies inversely with the shell thickness. As a result, a thicker shell experiences less resistance modulation because it is in a state of partial hole accumulation. Considering the fraction of shell layers in the overall volume of the $n-p$ C-S NWs (which is comparable to shell thickness), the response affords a bell-shaped curve as a function of shell thickness (Figure 8d). As shown in Figure 8e-g, the extension of the $p^{+}$layer is constrained owing to the existence of the $p^{-} \mid n^{-}$interface, which acts as a blocking layer for the expansion of the $p^{+}$layer, resulting in a slight resistance modulation to oxidizing $\mathrm{NO}_{2}$ and low response to $\mathrm{NO}_{2}$.

In another study, Lee et al. [80] reported the gas-sensing characteristics of $p-n \mathrm{CuO}-\mathrm{TiO}_{2}$ C-S NWs, where a sensor with a $40 \mathrm{~nm}$ shell thickness exhibited an enhanced gas response $\left(R_{a} / R_{g}=7.14\right.$ to $1 \mathrm{ppm} \mathrm{CO}$ at $\left.300{ }^{\circ} \mathrm{C}\right)$. The $\mathrm{TiO}_{2}$ shell layer was depleted by electrons through oxygen adsorption together with the transfer of electrons to $\mathrm{CuO}$ (Figure $9 \mathrm{a}$ ). The degree of electron depletion increased when the shell thickness was below the $\lambda_{\mathrm{D}}$ of $\mathrm{CuO}$. Specifically, a depleted state of electrons was formed in the thin-shell layer. In contrast, only partial electron depletion was observed for thick shells (Figure $9 b$ ). Therefore, the degree of resistance modulation initiated by radial modulation within the shell layer varied inversely with the shell thickness. The thinner shells underwent further resistance modulation, whereas the thicker shells showed less resistance modulation with the partial depletion of electrons in the shell. When the $\mathrm{TiO}_{2}$ shell thickness was greater than $40 \mathrm{~nm}$, the shell prevented the gas molecules from interrelating with the core $\mathrm{CuO}$ as it was sufficiently thick to act as a barrier layer. In this state, the sensor based on C-S NWs exhibited $n$-type sensing characteristics because the $\mathrm{TiO}_{2}$ shell layer was the only sensing material subjected to gas molecules. 


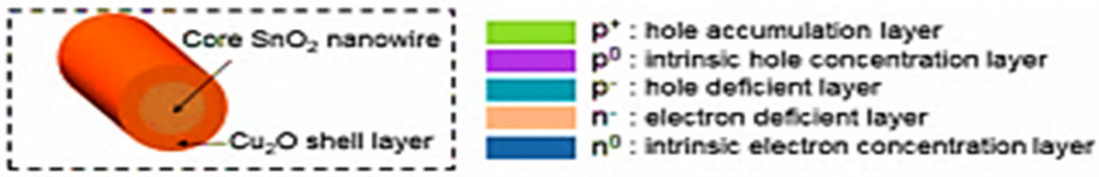

In reducing gas

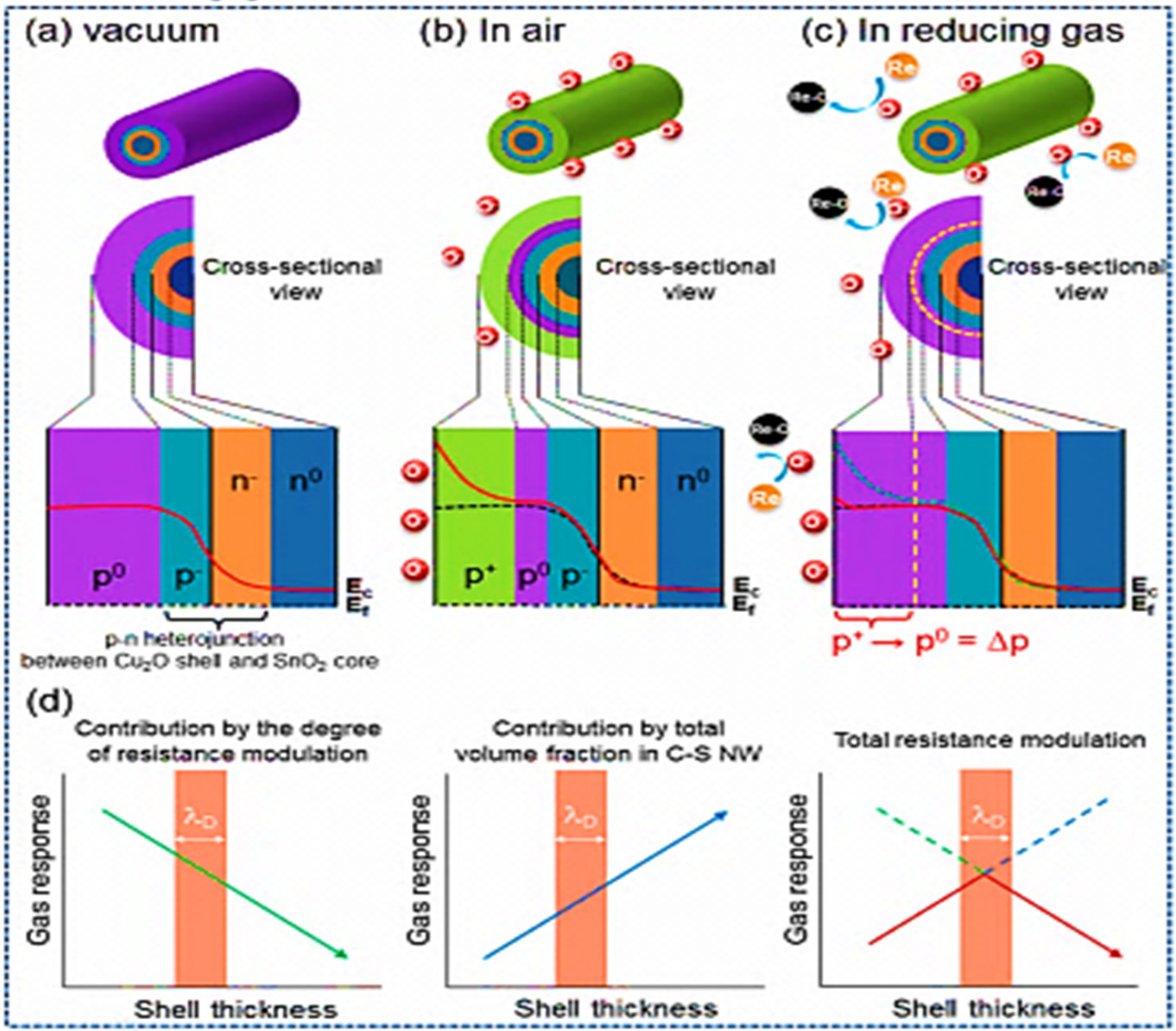

In oxidizing gas

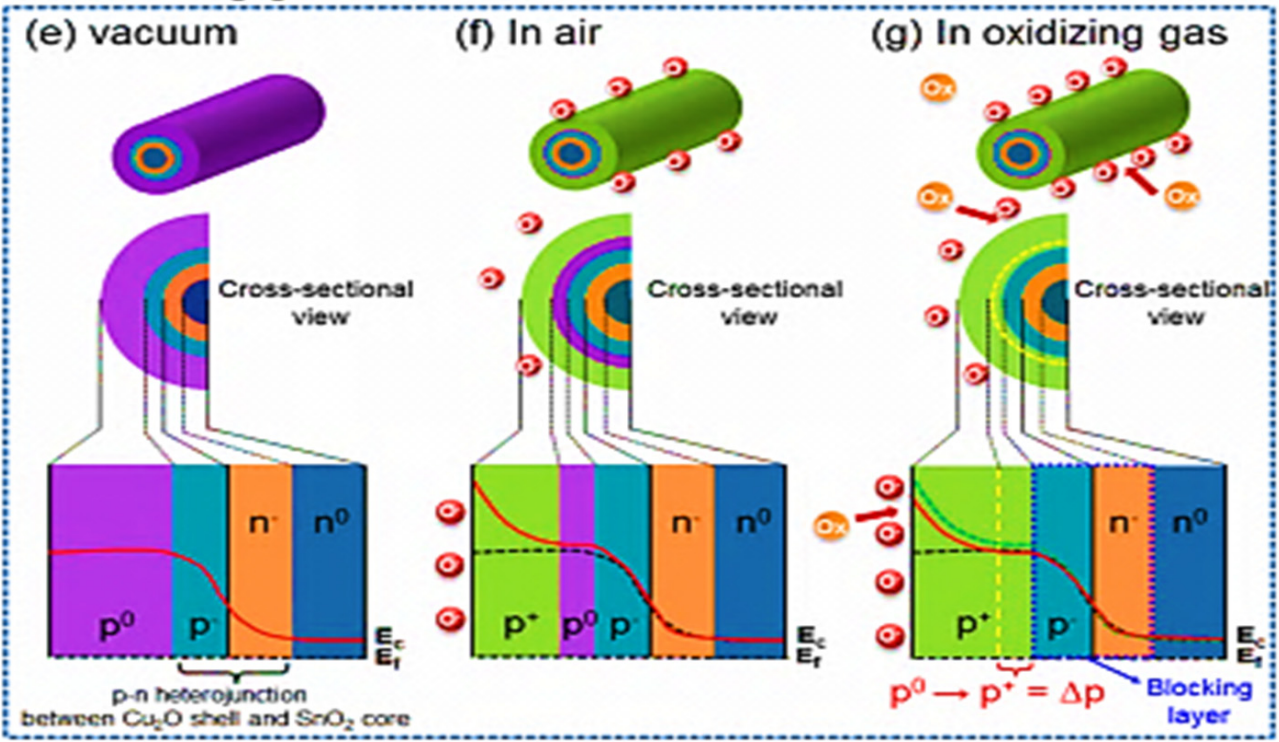

Figure 8. Conceptual explanation of the sensing mechanism in the $\mathrm{SnO}_{2}-\mathrm{Cu}_{2} \mathrm{O}$ C-S NWs; (a) in vacuum, (b) in air, and (c) in the presence of reducing gases, and (d) overall modulation of the resistance. The sensing mechanism for oxidizing gases in (e) vacuum, (f) air, and (g) oxidizing gases. Reproduced from [79] with the permission of the American Chemical Society. 


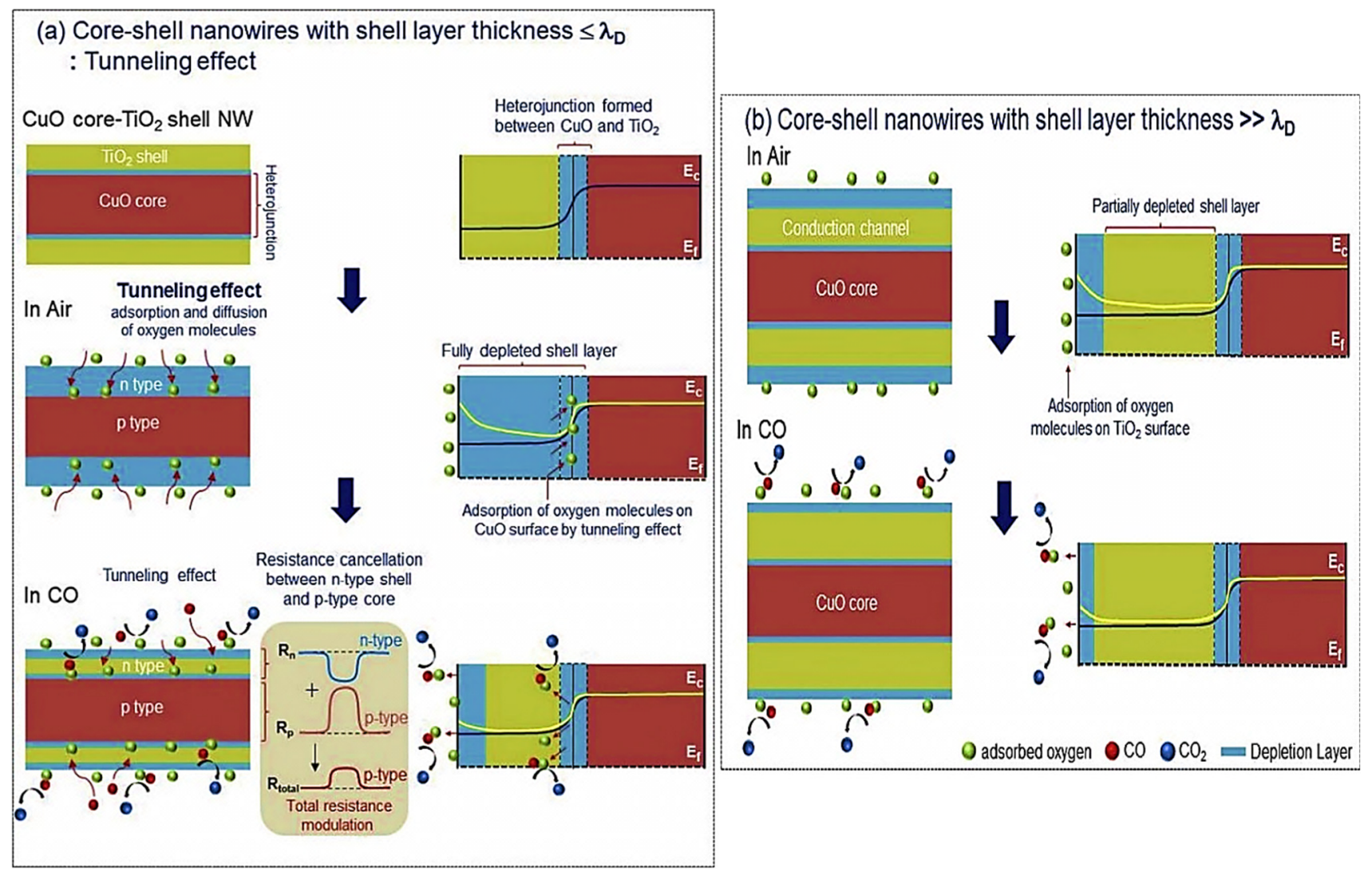

Figure 9. Schematic of the detection mechanism of $\mathrm{CuO}-\mathrm{TiO}_{2} \mathrm{C}-\mathrm{S}$ NWs with the shell layer thickness of $(\mathbf{a})<\lambda_{\mathrm{D}}$ and $(\mathbf{b})>\lambda_{\mathrm{D}}$ [80]. Reproduced from [34] with the permission of Elsevier.

Katoch et al. [81] synthesized $p$-CuO/n-ZnO C-S NFs for $\mathrm{CO}$ gas-sensing applications. In the $\mathrm{p}-\mathrm{n} \mathrm{CuO} / \mathrm{ZnO} \mathrm{C}-\mathrm{S} \mathrm{NFs}$, the shell layer was completely depleted by the electrons when the shell thickness was equivalent to the Debye length of the shell material. This confirmed that the C-S NF sensors showed a better response when the shell thickness was lower than that of the Debye length of the shell material. The highest sensor response to CO was observed with a $16 \mathrm{~nm}$-thick shell (Response $=7$ to $0.1 \mathrm{CO}$ at $300^{\circ} \mathrm{C}$ ), suggesting that the $p$ - $n$ C-S NFs with $16 \mathrm{~nm}$-thick shells were completely depleted. When a fully depleted $p-n$ C-S NF shell layer was exposed to CO, the oxygen species that were eliminated from the surface released electrons into the conduction band of the shell layer and the original configuration of the band was recovered, thereby increasing the conductivity. In addition, the $p-n$ C-S NFs with a shell layer thickness greater than the Debye length only had partially depleted shell layers. Upon exposure to $\mathrm{CO}$ gas, the $\mathrm{CO}$ molecules were adsorbed onto the partially electron-depleted shell layer. A slight change in resistance was observed because of the presence of a conduction channel below the partially electron-depleted shell layer. This indicated that the shell thickness modulated the electron-depleted layer in the shell. Therefore, preparing a shell with a thickness less than or equivalent to the Debye length is important to achieve excellent gas-sensing properties of the $p-n$ C-S NF sensors. Notably, the $p-n$ C-S NF sensors did not have a better capability to detect oxidizing gases than normal NFs. Generally, oxidizing gases extract many electrons from the shell surface. Considering that $n$-type shells contain free electrons throughout their partial volume irrespective of the type of core nanofiber, these are simply depleted. Therefore, the free electrons are depleted just before or immediately after introducing the oxidizing gas, leading to a change in the resistance and a low response. Thus, the lower response to oxidizing gas is mainly due to the inadequate accessibility of free electrons in the completely depleted shell layer for inbound oxidizing gas molecules. Similarly, Park et al. [82] introduced a model to improve the gas-sensing capacity of $\mathrm{SnO}_{2}-\mathrm{ZnO}$ C-S NFs. The $\mathrm{ZnO}$ shell was completely 
depleted by the electrons via the combined effect of (i) band bending at the heterojunction between the $\mathrm{ZnO}$ shell layer and the core $\mathrm{SnO}_{2}$ fiber and (ii) the band bending at the $\mathrm{ZnO}$ shell layer surface through the adsorption of oxygen molecules. Upon CO exposure, the released electrons gradually recovered to the original configuration of the band. Through this process, the resistance change along the NFs was more noticeable than the normal NFs without a fully depleted layer owing to the absence of the completely depleted shell layer.

In another study, Kim et al. [83] achieved outstanding selective sensing of $\mathrm{C}_{6} \mathrm{H}_{6}$ gas using Pd NP-functionalized $\mathrm{SnO}_{2}-\mathrm{ZnO}$ C-S NWs. The authors reported an excellent response of 71-100 $\mathrm{ppb} \mathrm{C}_{6} \mathrm{H}_{6}$. The C-S NWs showed enhanced sensing properties toward reducing gases for the optimized shell thickness with respect to the pristine core NWs. A potential barrier was formed at the heterointerfaces (Figure 10a) because of the different work functions of different materials via charge transfer. The sensor response was attributed to the changes in the potential barriers in air and $\mathrm{C}_{6} \mathrm{H}_{6}$ gas atmosphere. An additional contribution to the detection signal was the modification of the conduction channel by $\mathrm{Pd}$ NPs (Figure 10b). Furthermore, specific attention should be paid to CS through the catalytic effect of the Pd NPs (Figure 10c), which facilitate $\mathrm{C}_{6} \mathrm{H}_{6}$ interactions with the chemisorbed oxygen species and enhance the resistance modulation of the $\mathrm{SnO}_{2}-\mathrm{ZnO}$ C-S NWs. The Pd NPs are likely to more efficiently dissociate $\mathrm{C}_{6} \mathrm{H}_{6}$ gas molecules than other reducing gases. The catalytic properties of $\mathrm{Pd}$ allow the adsorption of $\mathrm{C}_{6} \mathrm{H}_{6}$ molecules to Pd NPs.
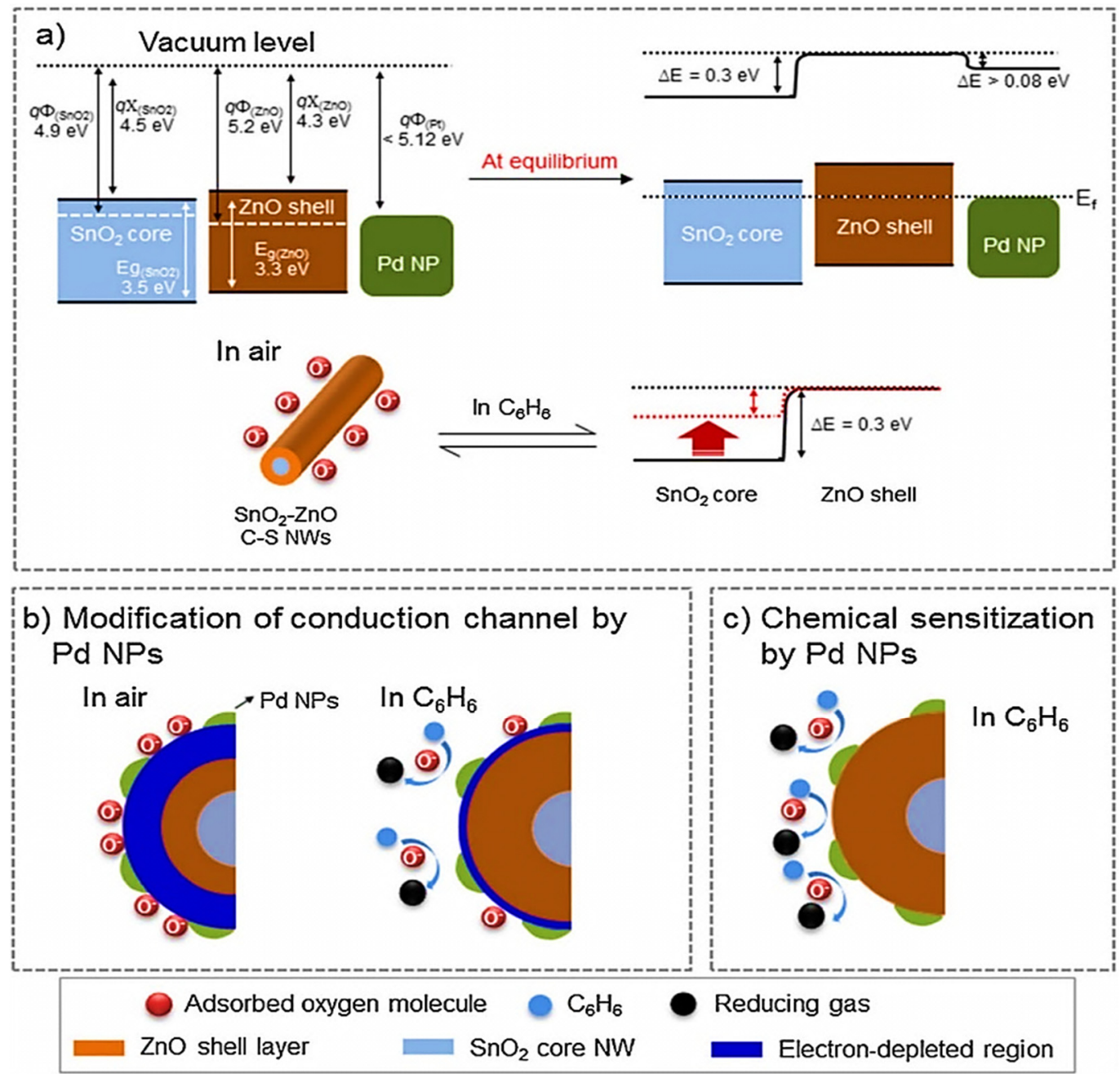

Figure 10. (a) Schematics of the energy levels of $\mathrm{ZnO}, \mathrm{SnO}_{2}$, and $\mathrm{Pd}$, (b) conduction channel modification in the shell layer, and (c) the CS effect achieved through Pd NPs. Reproduced from [83] with the permission of Elsevier. 
In addition, Choi et al. [84] utilized Au-decorated $\mathrm{Si} \mathrm{NW-ZnO} \mathrm{C-S} \mathrm{for} \mathrm{H}_{2} \mathrm{~S}$ gas-sensing applications. The optimal gas sensor showed a response of 11 to $50 \mathrm{ppm} \mathrm{H}_{2} \mathrm{~S}$ at $300{ }^{\circ} \mathrm{C}$. The response and recovery times were 48 and $63 \mathrm{~s}$, respectively. A possible sensing mechanism for the Au-decorated Si NWs-ZnO C-S is shown in Figure 11. Various factors were considered for the elucidation of the sensing mechanism, including (i) $\mathrm{ZnO} / \mathrm{Au}$ heterojunctions, (ii) catalytic properties of $\mathrm{Au}$, and (iii) the heterojunction between $\mathrm{ZnO} / \mathrm{Si}$. As a result of the catalytic activity of $\mathrm{Au}$, gas molecules dissociated, and the spillover effect was transferred onto the $\mathrm{ZnO}$ shell surface. Furthermore, the increase in the sensor response by increased electron flow in $\mathrm{ZnO}-\mathrm{Si}-\mathrm{ZnO}$ occurred when the $\mathrm{ZnO}$ work function was higher than that of $p$-Si. In addition, the $\mathrm{ZnO} / \mathrm{Au}$ heterojunction barriers increased the sensor performance. The sensor displayed better selectivity toward $\mathrm{H}_{2} \mathrm{~S}$ gas because of its high reactivity, and therefore, it could simply react with the chemisorbed oxygen ions on the $\mathrm{ZnO}$ surface. In addition, the bond energy between $\mathrm{H}$ and $\mathrm{SH}$ in $\mathrm{H}_{2} \mathrm{~S}$ is $381 \mathrm{KJ} / \mathrm{mol}$, which is lower than those of other interfering gases. As a result, the $\mathrm{H}-\mathrm{SH}$ bond may readily collapse at $300{ }^{\circ} \mathrm{C}$ during chemical adsorption. Although the bond energy of O-NO is less than that of $\mathrm{H}-\mathrm{SH}$, the interaction strength between the sensor and target gas is another significant parameter that allows the determination of the gas response. The adsorption of $\mathrm{H}_{2} \mathrm{~S}$ gas molecules onto Au NPs may potentially result in the formation of Au-S or Au-SHtype species on the Au NP surface. Consequently, a sulfide shell covered the surfaces of the Au NPs, which decreased the surface work function of the Au NPs. According to this change, the amount of electron exchange between the Au NPs and $\mathrm{ZnO}$ could be changed, which could improve the sensor response to $\mathrm{H}_{2} \mathrm{~S}$ gas.

Another type of C-S structure relies on noble metals and metal oxides. Pioneering research on noble metal-metal-oxide C-S based gas sensors was first developed by Prof. Yeon-Tae Yu et al. at Jeonbuk National University, Korea. This research group successfully developed a series of noble metal and metal-oxide-based C-S gas-sensing materials, such as $\mathrm{Au}-\mathrm{SnO}_{2}$ [85-87], $\mathrm{Au}-\mathrm{Cu}_{2} \mathrm{O}$ [88,89], $\mathrm{Au}-\mathrm{ZnO}$ [90], $\mathrm{Au}-\mathrm{NiO}$ [91], $\mathrm{PdO}-\mathrm{ZnO}$ [92], $\mathrm{Au}-$ $\mathrm{In}_{2} \mathrm{O}_{3}$ [93], and $\mathrm{AuPd}_{\text {alloy }}-\mathrm{ZnO}$ [94]. Among various C-S sensors, the first type of C-S gas sensor based on $\mathrm{Au} @ \mathrm{SnO}_{2} \mathrm{C}-\mathrm{S}$ nanoparticles (NPs) was reported by Yu et al. in 2011 [85]. The authors synthesized $\mathrm{Au}-\mathrm{SnO}_{2} \mathrm{C}-\mathrm{S} \mathrm{NPs}$ via a microwave-assisted hydrothermal reaction and investigated their $\mathrm{CO}$ gas-sensing properties. The response $\left(R_{a} / R_{g}\right)$ of the $\mathrm{Au}-\mathrm{SnO}_{2} \mathrm{C}-\mathrm{S}$ $\mathrm{NPs}$ was $\approx 1$ for $1000 \mathrm{ppm} \mathrm{CO}$ at $100^{\circ} \mathrm{C}$. It was speculated that the catalytic activity of $\mathrm{Au}$ NPs was responsible for the superior response of the $\mathrm{Au} / \mathrm{SnO}_{2} \mathrm{C}-\mathrm{S}$ NPs at temperatures below $200{ }^{\circ} \mathrm{C}$ compared to pure $\mathrm{SnO}_{2} \mathrm{NPs}$ [95]. To further enhance the sensing properties of C-S NPs, Majhi et al. [89], synthesized three kinds of $\mathrm{Cu}_{2} \mathrm{O}$ NPs in 2014, namely cubic $\mathrm{Cu}_{2} \mathrm{O}$ NPs, spherical Au NRs- $\mathrm{Cu}_{2} \mathrm{O}$ C-S, and brick-shaped Au NRs-Cu $\mathrm{C}_{2} \mathrm{O}$ C-S NPs for $\mathrm{CO}$ gas-sensing applications. Figure 12a shows the $\mathrm{CO}$ gas-sensing performances of the three types of $\mathrm{Cu}_{2} \mathrm{O}$ NPs at $250^{\circ} \mathrm{C}$ and concentrations of 10-1000 ppm. The brick-shaped $\mathrm{Au}-\mathrm{Cu}_{2} \mathrm{O}$ C-S NP sensor exhibited a typical $p$-type semiconductor behavior with the highest response of $5.67\left(R_{g} / R_{a}\right)$, which was followed by 4.38 for the spherical-shaped $\mathrm{Au}-\mathrm{Cu}_{2} \mathrm{O}$ $\mathrm{C}-\mathrm{S}$ and 3.35 for pristine cubic $\mathrm{Cu}_{2} \mathrm{O}$ NPs. As shown in Figure 12a, significant variations in baseline resistance are observed, which are attributed to the unique structure of the $\mathrm{Au}$ $\mathrm{Cu}_{2} \mathrm{O}$ C-S NPs, ES of the Au NRs, and arrangement of particles between the two electrodes. Figure $12 \mathrm{~b}$ shows a schematic of the flow of electrons in the three types of sensing layers with their corresponding microscopic images. Spherical Au NRs-Cu $\mathrm{Cu}_{2} \mathrm{O}$ C-S NPs were well connected to each other because of their spherical geometry, which facilitates the charge flow and results in a low baseline resistance. 


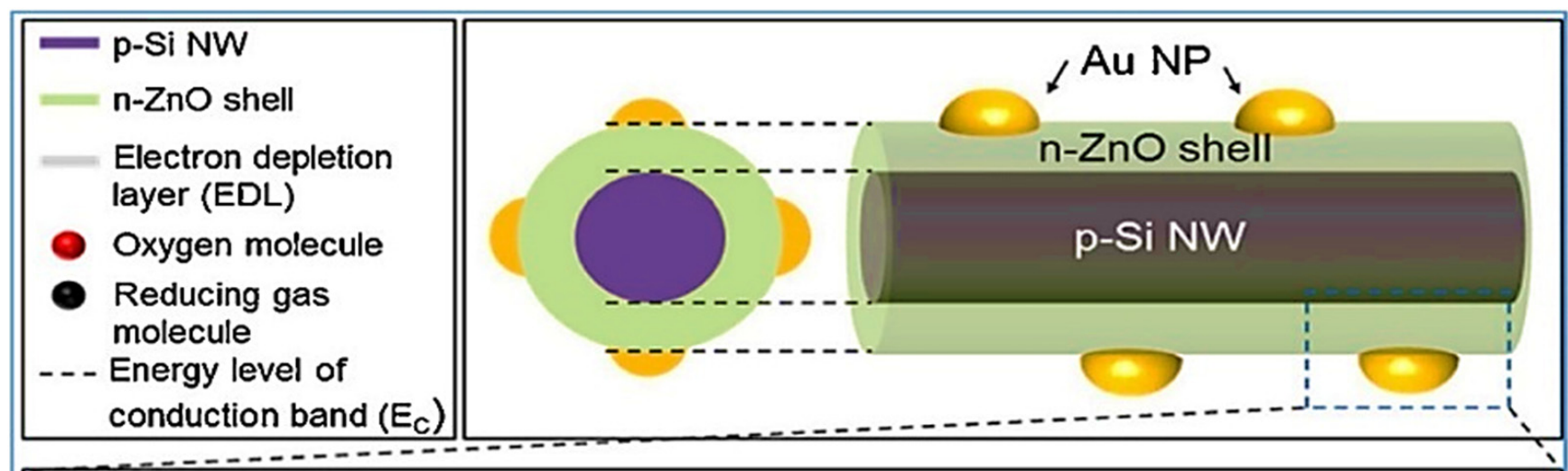

A Modulation of EDL in pristine $\mathrm{ZnO}$ shell layer

In air

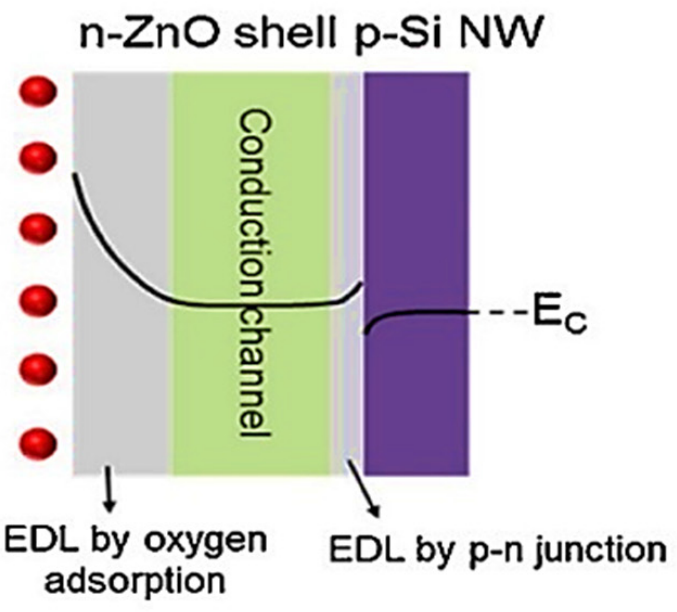

In reducing gas

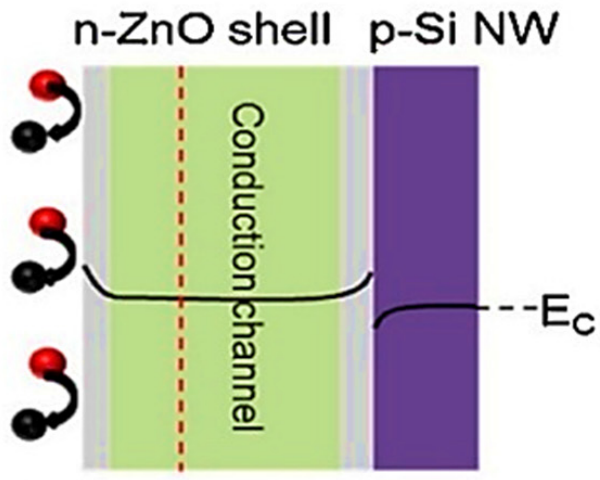

Modulation of conduction channel is amplified by the presence of EDL by p-n junction

B Amplified modulation of conduction channel by Au NP

In air

$\longrightarrow \quad$ In reducing gas

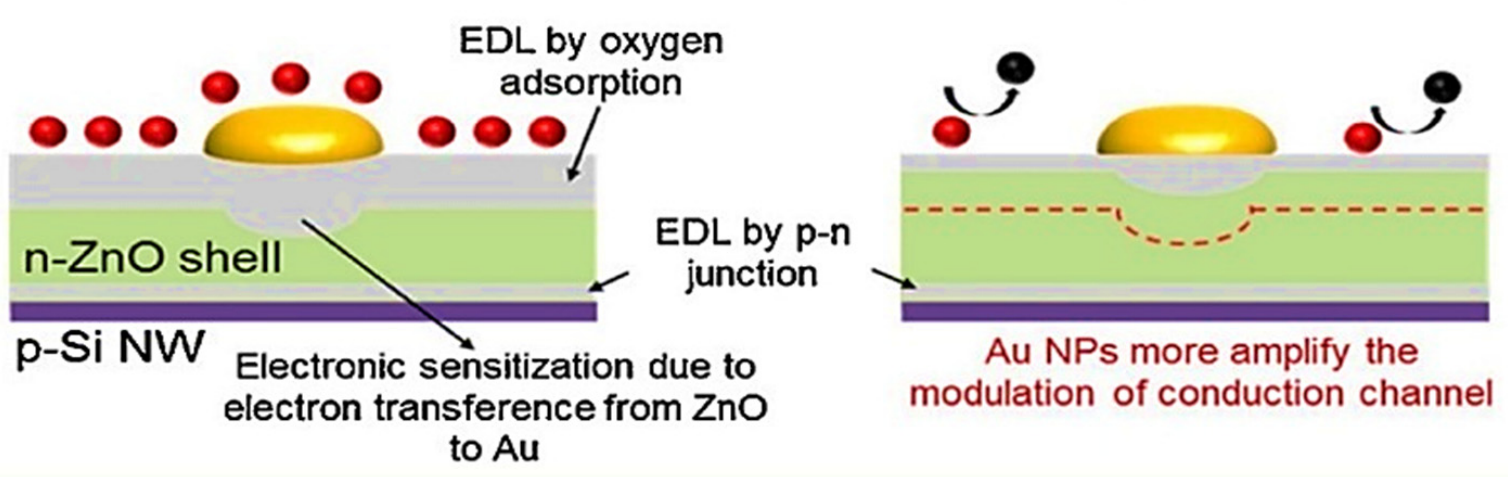

Figure 11. Schematic of the sensing mechanism in the Au-decorated Si NWs/ZnO C-S sensor; (A) depletion layers in pure Si NWs/ZnO C-S layer, and (B) expansion of electron depletion layer in the presence of Au. Reproduced from [84] with the permission of Elsevier. 

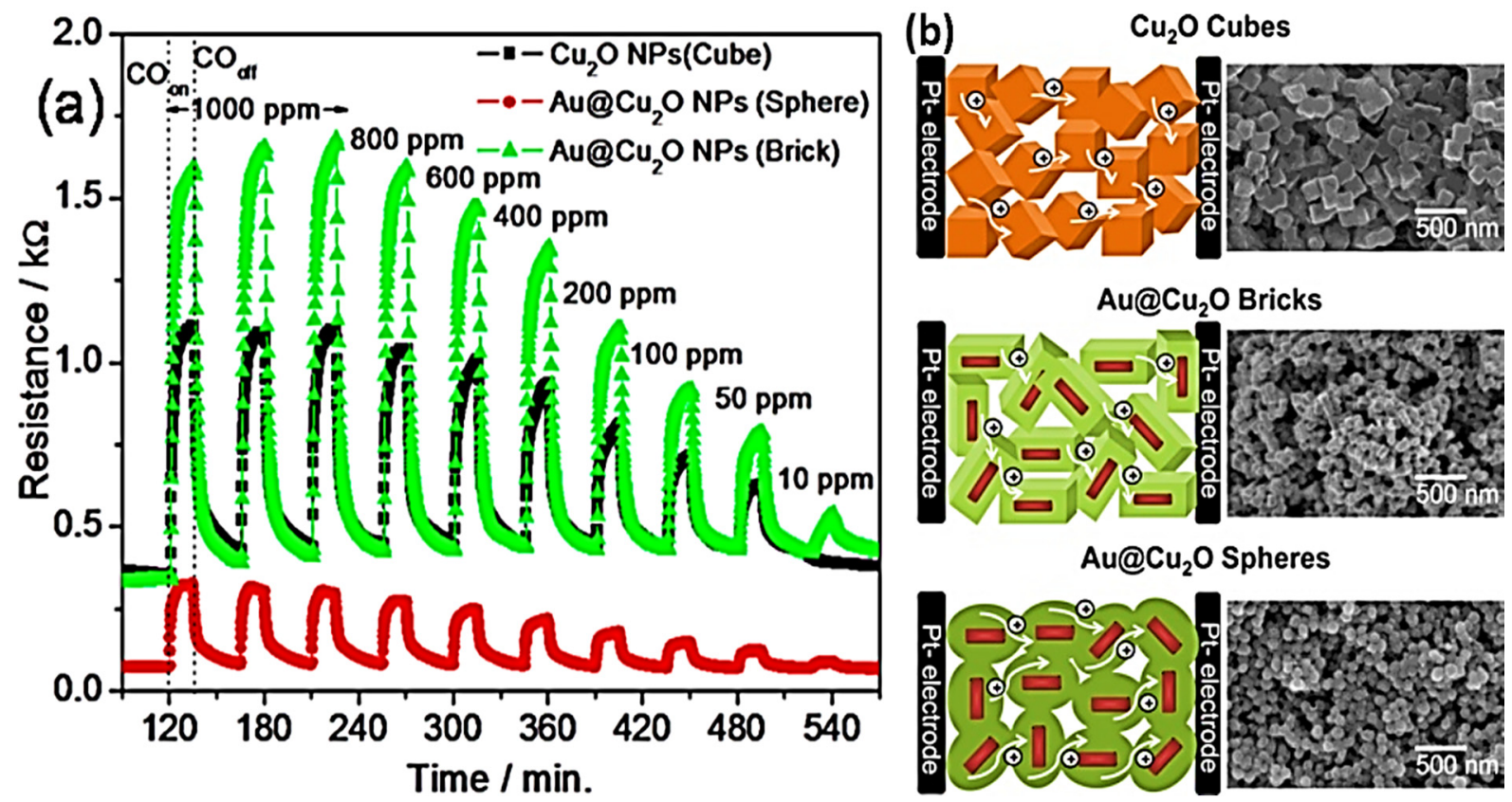

Figure 12. (a) Dynamic resistance curves of different $\mathrm{Cu}_{2} \mathrm{O}$ gas sensors for $\mathrm{CO}$ gas and (b) the sensing mechanism of different gas sensors. Reproduced from [89] with the permission of Elsevier.

The same authors further examined the $\mathrm{H}_{2}$ gas-sensing properties of Au-ZnO C-S NPs [90]. Au-ZnO C-S NPs were synthesized using a low-temperature hydrothermal method (Figure 13a-d). The NP size of Au-ZnO C-S was 50-70 nm, together with a size 10-15 nm of the Au NPs encapsulated inside the materials. The sensors exhibited the highest response $\left(R_{a} / R_{g}=103.9\right)$ in comparison to pristine ZnO NPs (12.7) with a rapid response time of $75 \mathrm{~s}$ and a low detection limit of $500 \mathrm{ppb}$. The sensor also showed good reproducibility and stability toward $\mathrm{H}_{2}$ gas when tested in repeated cycles. The enhanced sensing properties were attributed to the electronic and CS effects of the Au NPs (Figure 13((a-1)-(b-2))) [96].
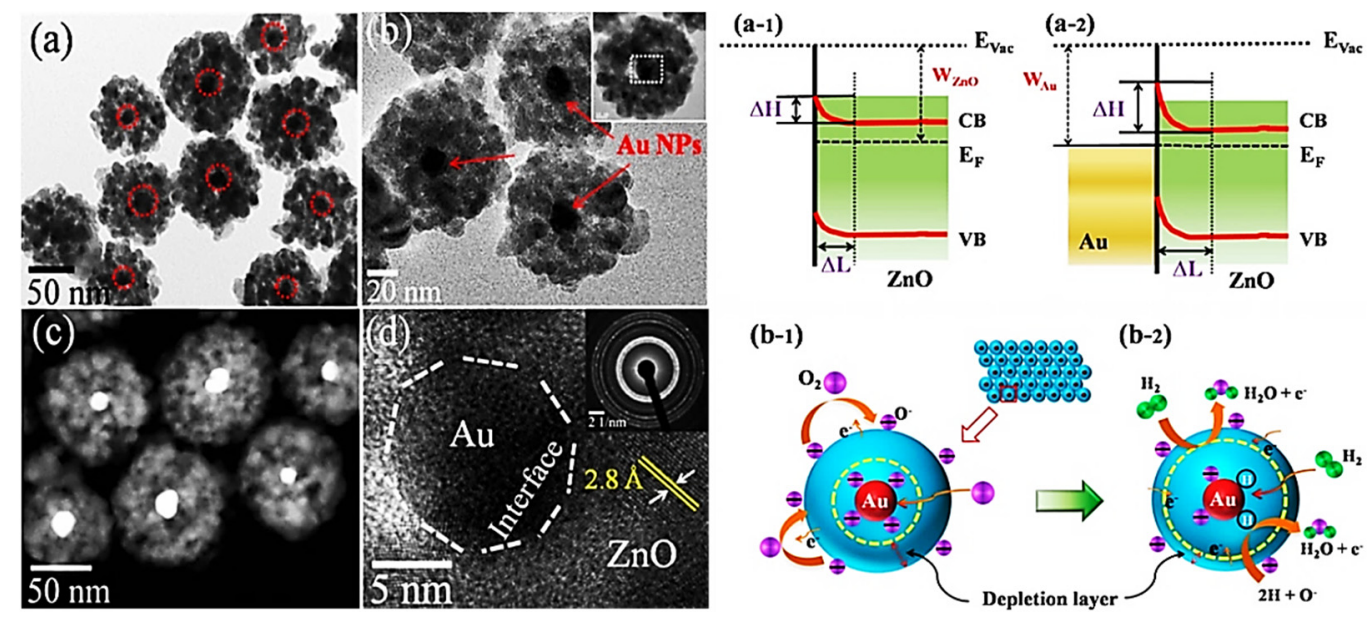

Figure 13. (a-d). TEM images of Au-ZnO C-S NPs and ((a-1)-(b-2)) the corresponding $\mathrm{H}_{2}$ gas-sensing mechanism of Au-ZnO C-S NPs. Reproduced from [90] with the permission of Elsevier.

Majhi et al. [91] further synthesized $p$-type Au-NiO-based C-S NPs and investigated their ethanol $\left(\mathrm{C}_{2} \mathrm{H}_{5} \mathrm{OH}\right)$-sensing properties at low temperatures. The highest response of Au-NiO C-S NPs toward $100 \mathrm{ppm} \mathrm{C}_{2} \mathrm{H}_{5} \mathrm{OH}$ was 2.54 in comparison to 1.88 for pristine $\mathrm{NiO}$ NPs. The operating temperature of Au-NiO C-S NPs was lower $\left(200^{\circ} \mathrm{C}\right)$ than that of 
the pristine $\mathrm{NiO} \mathrm{NPs}\left(300^{\circ} \mathrm{C}\right)$. The formation of $\mathrm{Au}-\mathrm{NiO}$ heterojunctions was responsible for the enhanced response to $\mathrm{C}_{2} \mathrm{H}_{5} \mathrm{OH}$ gas (Figure 14c). Majhi et al. [92] also reported a $p-n$ heterojunction based on PdO-ZnO C-S NPs for acetaldehyde gas sensing. The asprepared $\mathrm{PdO}-\mathrm{ZnO} p-n$ heterojunction C-S NPs were tested for many gases, and the highest sensing response of $76\left(R_{a} / R_{g}\right)$ was observed for $100 \mathrm{ppm}$ acetaldehyde gas at $350{ }^{\circ} \mathrm{C}$ in comparison to that for pristine ZnO NPs $\left(R_{a} / R_{g}=18\right)$. The enhanced sensitivity of PdO-ZnO C-S NPs was attributed to the formation of a $p-n$ heterojunction structure, the catalytic effect of PdO NPs, and the high surface area of the obtained materials. Recently, $\mathrm{Yu}$ et al. investigated the sensing properties of noble metal alloy-based metal-oxide C-S NPs [94]. The authors synthesized AuPd ${ }_{\text {alloy }} @ Z n O C-S$ NPs and examined their $\mathrm{H}_{2}$ gassensing properties. Different compositions of $\mathrm{AuPd}$ alloys, such as $\mathrm{Pd}_{20} \mathrm{Au}_{80}, \mathrm{Pd}_{35} \mathrm{Au}_{65}$, and $\mathrm{Pd}_{50} \mathrm{Au}_{50}$, were individually used to prepare C-S NPs. When tested for different gases, the $\mathrm{Pd}_{35} \mathrm{Au}_{65}-\mathrm{ZnO} \mathrm{C}-\mathrm{S} \mathrm{NP}$-based sensor showed an enhanced response toward $100 \mathrm{ppm} \mathrm{H}_{2}$, among other gases, with a high selectivity at $300^{\circ} \mathrm{C}$. This was attributed to the synergistic effect of the AuPd alloy and $\mathrm{ZnO}$ with the ES effect and the formation of the $\mathrm{PdH}_{\mathrm{x}}$ component due to the reaction with dissociated hydrogen atoms [94].

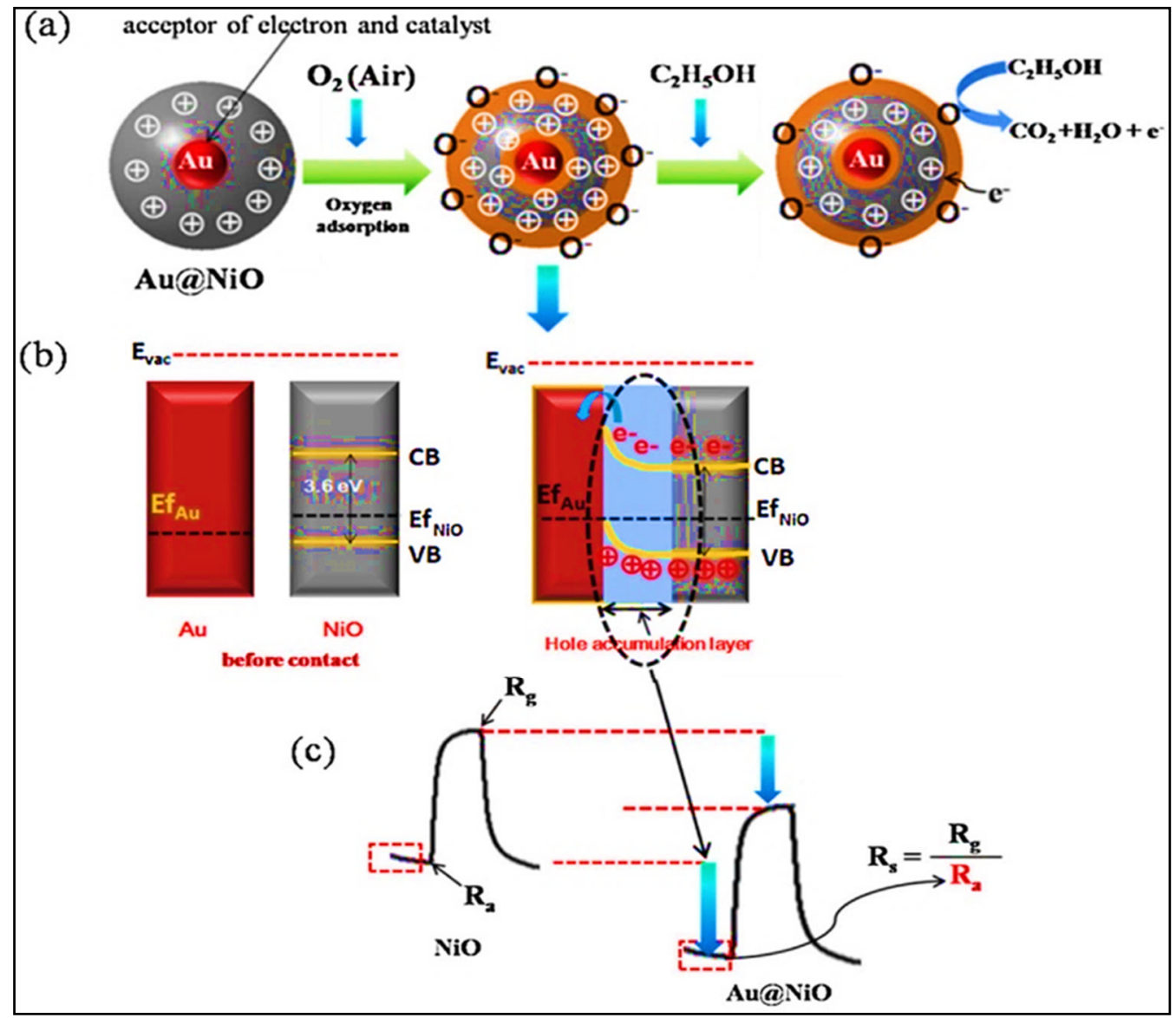

Figure 14. (a) $\mathrm{C} 2 \mathrm{H} 5 \mathrm{OH}$-sensing mechanism of Au-NiO C-S NPs. (b) Formation of heterojunctions between $\mathrm{Au}$ and $\mathrm{Ni}$ (c) comparison of sensor signal in NiO and Au-NiO C-S NP gas sensors. Reproduced from [91] with the permission of Elsevier.

Another research group from Korea University studied the gas-sensing applications of different C-S and yolk-shell NPs [97,98]. For example, Rai et al. reported a yolk-shell-type structure based on $\mathrm{Pd} @ \mathrm{In}_{2} \mathrm{O}_{3}$ and studied its $\mathrm{C}_{2} \mathrm{H}_{5} \mathrm{OH}$ gas-sensing properties. The highest response of 159.02 toward $5 \mathrm{ppm} \mathrm{C}_{2} \mathrm{H}_{5} \mathrm{OH}$ was observed at $350^{\circ} \mathrm{C}$, which was 10 times higher than that of pristine $\operatorname{In}_{2} \mathrm{O}_{3}$ NPs. Similarly, the same group reported the synthesis of an additional type of $p$-type Au-NiO yolk-shell NPs and studied their gas-sensing 
properties toward $\mathrm{H}_{2} \mathrm{~S}$ gas [99]. The response of $\mathrm{Au}-\mathrm{NiO}$ yolk-shell NPs to 5 ppm $\mathrm{H}_{2} \mathrm{~S}$ was 108.92, which was almost four times higher than that of pristine NiO hollow nanospheres. The improved performance was attributed to the unique hollow structures of the Au-NiO yolk-shell NPs, which facilitated the accessibility of Au NPs. The $\mathrm{H}_{2} \mathrm{~S}$ adsorption on $\mathrm{Au}$ NPs resulted in the formation of a sulfide layer, which likely decreased the work function of the $\mathrm{Au}-\mathrm{NiO}$ yolk-shell NPs. As a result, electron transfer occurred from $\mathrm{Au}$ to $\mathrm{NiO}$ rather than $\mathrm{NiO}$ to $\mathrm{Au}$, which increased the resistance of the sensor and response to $\mathrm{H}_{2} \mathrm{~S}$. Rai et al. [97] further investigated C-S NPs based on Ag-SnO 2 NPs. The Ag-SnO 2 C-S NPs were synthesized using a microwave-assisted hydrothermal method. The as-prepared sensor exhibited a high response of $16.17\left(R_{a} / R_{g}\right)$ to $5 \mathrm{ppm} p$-xylene among other interfering gases, whereas the response of pristine $\mathrm{SnO}_{2}$ NPs was only 10.79. The enhanced $p$-xylene-sensing performance of $\mathrm{Ag}-\mathrm{SnO}_{2} \mathrm{C}-\mathrm{S}$ NPs was correlated to the electronic and CS effects of the Ag NPs. Therefore, it is concluded that the functionalization or encapsulation of noble metal NPs has a significant role in enhancing the sensing performance.

\section{Self-Heated Gas Sensors}

The major feature of self-heating gas sensors is the application of an appropriate voltage. The Joule heating effect is mainly caused by small-scale heat dissipation. Any obstacle that leads to electron deviation from its pathway may result in the production of heat. Heat is generated within the sensor owing to the Joule heating process, which results in an increase in its temperature [100]. In the case of Joule heating, heat is generated owing to the kinetic energy loss of the electrons through collisions between the lattice atoms and moving electrons [101]. Operation at room temperature is one of the major advantages of self-heated gas sensors. In the following section, the results of the most relevant papers in the field of self-heated gas sensors published by the laboratories of Professors Hyoun Woo Kim and Sang Sub Kim are discussed.

$\mathrm{Pd}$ is mostly utilized as a $\mathrm{C}_{6} \mathrm{H}_{6}$-sensing agent owing to its good catalytic activity [102]. In addition, NW-type one-dimensional morphologies are highly favored for self-heating studies [103]. Kim et al. [104] utilized Pd-functionalized $\mathrm{SnO}_{2}-\mathrm{ZnO}$ C-S NWs (C-S NWs) for sensing $\mathrm{C}_{6} \mathrm{H}_{6}$ gas in the self-heating mode. A high response of 71 at $100 \mathrm{ppb}$ of $\mathrm{C}_{6} \mathrm{H}_{6}$ gas was attained under $20 \mathrm{~V}$ applied voltage. Figure 15 shows a schematic of a threestep synthesis method comprising the growth of $\mathrm{SnO}_{2}$ NWs via the VLS mechanism, subsequent $\mathrm{ZnO}$ deposition by the ALD technique, followed by gamma ray irradiation for Pd deposition.

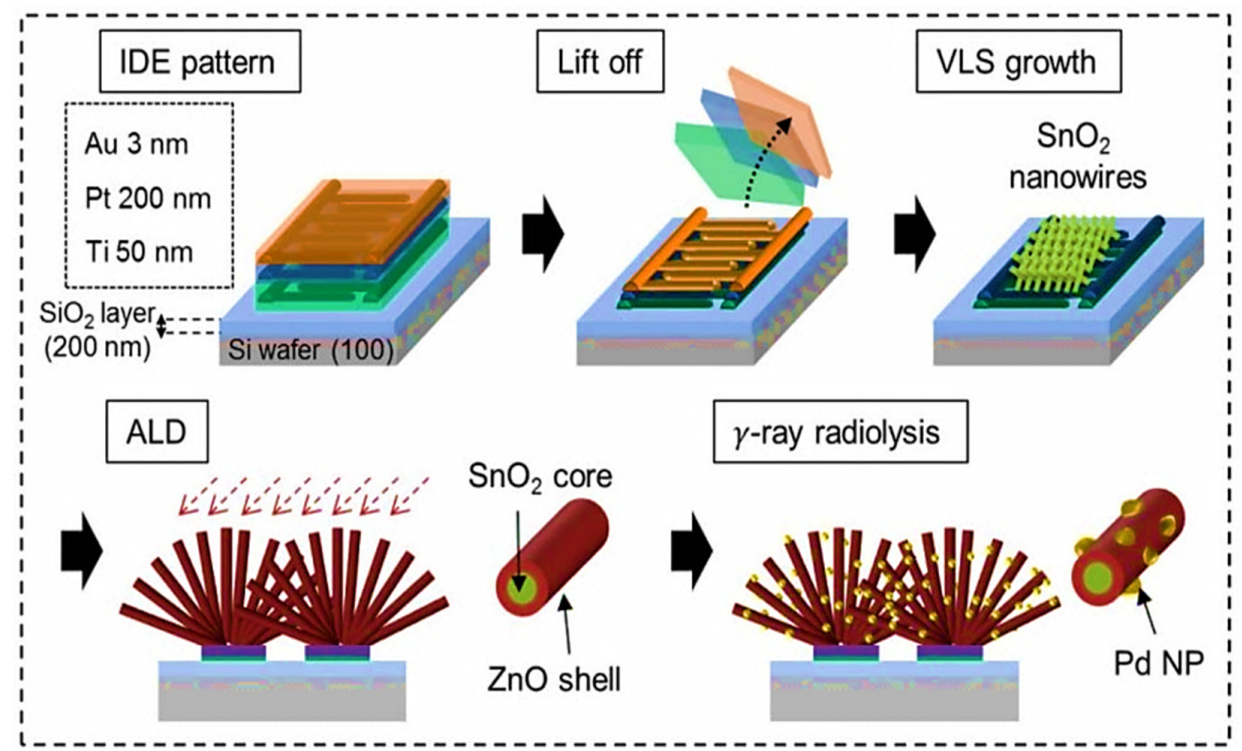

Figure 15. Schematic of the synthesis of Pd-decorated $\mathrm{SnO}_{2}-\mathrm{ZnO}$ C-S NWs. Reproduced from [104] with the permission of Elsevier. 
The as-fabricated sensors exhibited an improved $\mathrm{C}_{6} \mathrm{H}_{6}$ response in the self-heating mode. An enhanced response of 71-100 ppb of $\mathrm{C}_{6} \mathrm{H}_{6}$ gas was obtained at an applied voltage of $20 \mathrm{~V}$. The three Joule heating sources in the sensors included the (i) electron collisions with one another and with $\mathrm{Zn}$ and $\mathrm{O}$ atoms in the $\mathrm{ZnO}$ grain, (ii) the collision of electrons and $\mathrm{ZnO}$ grain boundaries, and (iii) kinetic energy loss of electrons in $\mathrm{ZnO}-\mathrm{ZnO}$ homojunctions, whose structure was dense and tangled. As a result of the different work functions of $\mathrm{ZnO}, \mathrm{SnO}_{2}, \mathrm{Pd}$, and $\mathrm{PdO}$, potential barriers were developed at the interfaces between these materials (Figure 16a-d), which acted as a source of the resistance within the gas sensor upon exposure to $\mathrm{C}_{6} \mathrm{H}_{6}$ gas. Furthermore, $\mathrm{Pd}$ NPs exhibited promotional effects on the gas detection properties of $\mathrm{C}_{6} \mathrm{H}_{6}$ gas. In CS, Pd initiated the dissociation of molecular oxygen in the atomic form. Accordingly, $\mathrm{Pd}$ increased the reaction rate of the $\mathrm{C}_{6} \mathrm{H}_{6}$ gas molecules. Through the spillover effect, $\mathrm{C}_{6} \mathrm{H}_{6}$ molecules were primarily adsorbed onto the Pd NP surface and then transferred to the $\mathrm{ZnO}$ surface to respond with the chemisorbed species. Therefore, further reactions resulted in a higher $\mathrm{C}_{6} \mathrm{H}_{6}$ response.

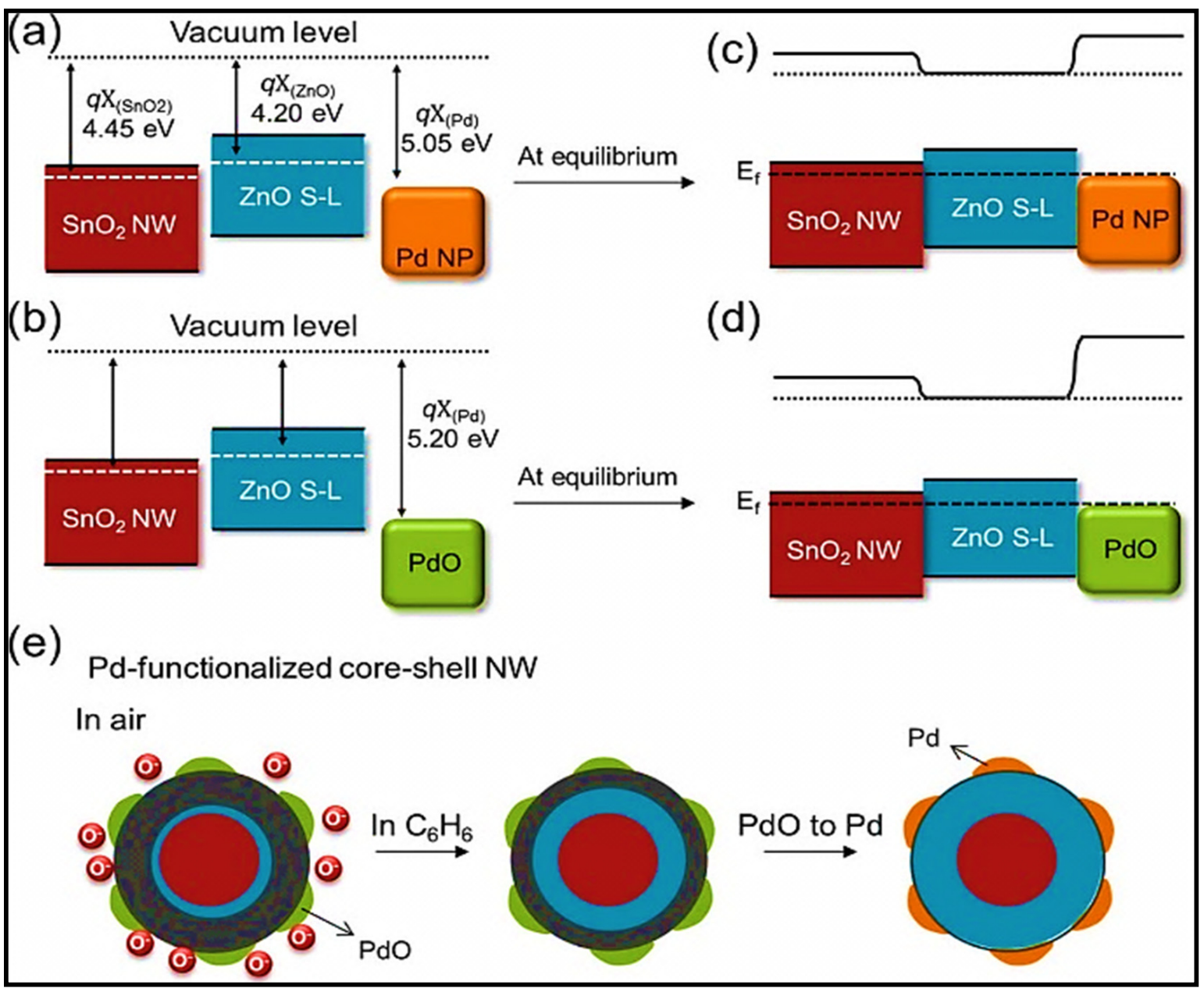

Figure 16. (a-d) Schematic of the energy levels of $\mathrm{SnO}_{2}-\mathrm{ZnO}-\mathrm{Pd}$ and $\mathrm{SnO}_{2}-\mathrm{ZnO}-\mathrm{PdO}$ systems and the development of heterojunction barriers. (e) Change in depletion layer width in the presence of Pd. Reproduced from [104] with the permission of Elsevier.

Tungsten disulfide $\left(\mathrm{WS}_{2}\right)$ is one of the most important members of the $2 D$ transition metal dichalcogenides (TMDs) and has unique properties such as low cost, good thermal stability, and tunable band structure. In addition, the weak van der Waals forces attach the vertically stacked layers in $\mathrm{WS}_{2}$, which simplifies the diffusion of target gases between the layers [105]. Nonetheless, gas sensors based on pure $\mathrm{WS}_{2}$ exhibit poor selectivity, low sensitivity, and long recovery time, which limits their applications for realistic pur- 
poses [106]. Kim et al. [107] described the CO gas-sensing features of Au-functionalized 2D $\mathrm{WS}_{2}$ nanoflakes in the self-heating mode (1-5 V), where Au was deposited over $\mathrm{WS}_{2}$ using UV light for different durations of irradiation. One of the objectives was to investigate the amount of $\mathrm{Au}$ on the $\mathrm{WS}_{2}$ surface for $\mathrm{CO}$ gas detection in the self-heating mode. The developed sensor exhibited a greater response toward $\mathrm{CO}$ in relation to other gases at room temperature at an applied voltage of $2 \mathrm{~V}$. The response to $50 \mathrm{ppm}$ CO gas was 1.48. Catalytically active Au NPs can enhance the number of chemisorbed oxygen ions when $\mathrm{Au}$ NPs are well-dispersed onto the $\mathrm{WS}_{2}$ surface, leading to further reactions among the $\mathrm{CO}$ molecules and chemisorbed species and an increase in the detection activities in terms of spillover effects. Additionally, Schottky barriers developed at the interfaces between Au and $\mathrm{WS}_{2}$, which acted as a probable source of resistance modulation in the presence of $\mathrm{CO}$ gas. An optimum amount of Au loading was necessary to achieve the maximum response to $\mathrm{CO}$ gas. A small amount of Au functionalization led to a deficiency in the number of $\mathrm{Au}$ NPs involved in the gas detection process, whereas high amounts of Au decreased the number of sites available for target gas adsorption. When the quantity of Au was less than the optimum value (irradiated for $15 \mathrm{~s}$ ), the gas sensor resistance increased with an increase in $\mathrm{Au}$ quantity because of the development of further Schottky barriers between Au and $\mathrm{WS}_{2}$, and more electrons were consequently moved from $\mathrm{WS}_{2}$ to Au NPs. However, the $\mathrm{Au}$ NPs were partially interconnected when the Au quantity was greater than the optimum value, which considerably decreased the baseline sensor resistance, and the number of adsorption sites accessible for $\mathrm{CO}$ was also decreased, resulting in a low $\mathrm{CO}$ response.

In another study, Lee et al. [108] reported the $\mathrm{CO}$ and $\mathrm{NO}_{2}$ gas sensitivities of $\mathrm{SnO}_{2}$ quantum dots (QDs) with $\mathrm{TiO}_{2}$ layers in the self-heating mode. The $\mathrm{TiO}_{2}$ layer was deposited via ALD by controlling the number of ALD cycles, where the $\mathrm{TiO}_{2}$ layer thickness was set to 10,30, and $60 \mathrm{~nm}$ to determine the impact of shell thickness on the gas response of the sensor. The sensor with a shell thickness of $30 \mathrm{~nm}$ showed the maximum response to $\mathrm{CO}$ gas $\left(\Delta \mathrm{R} / \mathrm{R}_{\mathrm{a}}=0.45\right.$ to $1 \mathrm{ppm} \mathrm{CO}$ gas at $\left.20 \mathrm{~V}\right)$. For QD sensors with the thinnest $\mathrm{TiO}_{2}(10 \mathrm{~nm})$, the $\mathrm{TiO}_{2}$ electrons were reduced not only by the flow of electrons to $\mathrm{SnO}_{2}$ but also by the adsorbed oxygen species. As a result, the entire layer of $\mathrm{TiO}_{2}$ became electron-depleted, and holes were also created (Figure 17a). Upon CO exposure, the electrons returned to the $\mathrm{TiO}_{2}$ conduction band. Moreover, the holes were initially created when the oxygen molecules were adsorbed onto the $\mathrm{TiO}_{2}$ surface, and the number of electrons delivered through the $\mathrm{CO}$ gas was utilized to neutralize the formed holes. The remaining electrons were used as charge carriers for resistance modulation. Consequently, only a part of the inserted electrons contributed to resistance modulation (Figure $17 \mathrm{~b}$ ). $\mathrm{The}^{\mathrm{TiO}} 2$ layer was completely depleted in air at a thickness of $30 \mathrm{~nm}$ (Figure 17b). The introduction of electrons through the $\mathrm{CO}$ gas resulted in significant resistance modulation, and the modified QD sensors exhibited the maximum response to $\mathrm{CO}$ gas at a thickness of $30 \mathrm{~nm}$. For a large thickness of $60 \mathrm{~nm}$, the initial depletion layer in ambient air was comparatively smaller than the entire layer thickness, and $\mathrm{CO}$ adsorption/desorption radial modulation did not result in a significant increase in the sensor response (Figure 17c). In contrast, $\mathrm{NO}_{2}$ sensitivity was the highest for pure $\mathrm{SnO}_{2}$ QDs. It was assumed that the ability of $\mathrm{NO}_{2}$ gas to extract electrons from the surface of $\mathrm{SnO}_{2}$ was higher than that of the $\mathrm{TiO}_{2}$ layer. Additionally, the electron transfer capability of $\mathrm{NO}_{2}$ gas with the $\mathrm{SnO}_{2}$ surface was higher than that of $\mathrm{CO}$ gas. For a thinner layer of $\mathrm{TiO}_{2}(10-30 \mathrm{~nm})$, for which the lowest $\mathrm{NO}_{2}$ response was observed, the entire layer of $\mathrm{TiO}_{2}$ was electron-depleted upon close contact between $\mathrm{TiO}_{2}$ and $\mathrm{SnO}_{2}$. Hence, no electrons were extracted by the $\mathrm{NO}_{2}$ gas molecules when $\mathrm{NO}_{2}$ gas was present. With an increase in the thickness of $\mathrm{TiO}_{2}$ to $60 \mathrm{~nm}$, it became partially electron-depleted, and electrons were present in the $\mathrm{TiO}_{2}$ layer that had to be adsorbed by $\mathrm{NO}_{2}$ gas molecules when $\mathrm{NO}_{2}$ gas was present. Any further increase in thickness decreased the sensor response, as the $\mathrm{TiO}_{2}$ layer was partially depleted by the injection of $\mathrm{NO}_{2}$. The region/volume of the initial conduction increased, and the relative change in the electron concentration of the $\mathrm{TiO}_{2}$ layer at the time of the introduction/removal of $\mathrm{NO}_{2}$ species decreased, eventually decreasing the $\mathrm{NO}_{2}$ response. 


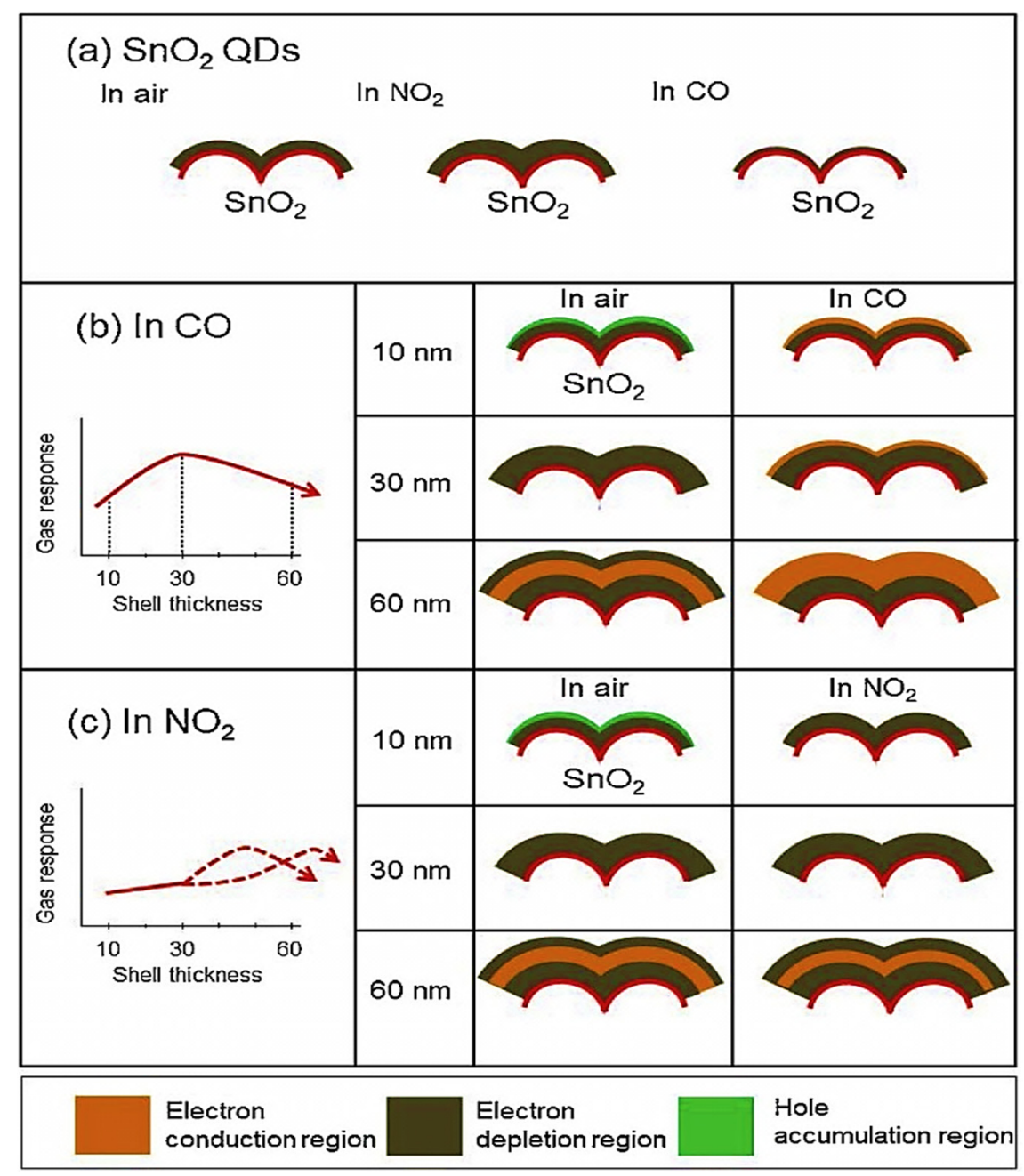

Figure 17. Schematic of the $\mathrm{NO}_{2}$ and $\mathrm{CO}$-sensing mechanism for (a) pristine $\mathrm{SnO}_{2}$ QDs and (b,c) $\mathrm{TiO}_{2}-$ layer-modified $\mathrm{SnO}_{2}$ QDs with different layer thicknesses. Reproduced from [108] with the permission of Elsevier.

In another study, Kim et al. [109] investigated the CO gas-sensing characteristics of bare, $\mathrm{Au}, \mathrm{SnO}_{2}$, and $\mathrm{Au}-\mathrm{SnO}_{2}$-co-decorated $\mathrm{WS}_{2}$ nanosheets (NSs) in the self-heating mode. The Au-SnO ${ }_{2}$-co-decorated $\mathrm{WS}_{2} \mathrm{NSs}$ exhibited a maximum response of 3.687 to $50 \mathrm{ppm}$ $\mathrm{CO}$ gas at $4.7 \mathrm{~V}$. The $\mathrm{WS}_{2}$ NSs possessed intrinsic resistance, leading to heat generation within the $\mathrm{WS}_{2} \mathrm{NSs}$ through voltage application. Joule heating may produce heat within the $\mathrm{WS}_{2} \mathrm{NS}$ grains and at the homojunctions of $\mathrm{WS}_{2}-\mathrm{WS}_{2}$. Furthermore, $\mathrm{Au} / \mathrm{SnO}_{2}$ and $\mathrm{Au} / \mathrm{WS}_{2}$ are considered as resistance sources at the interfaces between $\mathrm{SnO}_{2}$ and $\mathrm{WS}_{2}$, which are additional sources of Joule heating. For the $\mathrm{Au}-\mathrm{SnO}_{2}$-co-decorated $\mathrm{WS}_{2}$ gas sensor, in addition to the catalytic activities of $\mathrm{Au}$, the development of Schottky barriers among $\mathrm{Au} / \mathrm{WS}_{2}$ and $\mathrm{Au} / \mathrm{SnO}_{2}$, the heterojunctions of $\mathrm{SnO}_{2}-\mathrm{WS}_{2}$, and heterojunctions between $\mathrm{Au} / \mathrm{SnO}_{2} / \mathrm{WS}_{2}$ afforded numerous resistance heterojunctions for the gas sensor.

In a different study, Kim et al. [110] investigated the $\mathrm{H}_{2} \mathrm{~S}$-sensing activities of pristine and Pd-decorated $\mathrm{CuO}$ NWs in the self-heating mode. In this study, a VLS method was used to synthesize $\mathrm{CuO}$ NWs, and subsequent Pd functionalization was performed via UV irradiation. Under the applied voltage, heat was produced due to the Joule heating effect. At $5 \mathrm{~V}$, the sensor exhibited the highest response $\left(R_{g} / R_{a}=1.89\right.$ to $100 \mathrm{ppm} \mathrm{H}_{2} \mathrm{~S}$ gas$)$ under self-heating conditions because a significant amount of heat was produced in the gas sensor. Through CS, Pd dissociated and moved the oxygen molecules and target gases via the spillover effect. Thus, more gas molecules reached the sensor surface, resulting in a greater response. Figure 18a,b show that the electrons travel from $\mathrm{CuO}$ to $\mathrm{Pd} / \mathrm{PdO}$ because 
of the lower work function of $\mathrm{CuO}$ in comparison to those of $\mathrm{Pd}$ and $\mathrm{PdO}$, which lead to the formation of $\mathrm{HAL}$ on the $\mathrm{CuO}$ side.

(a)
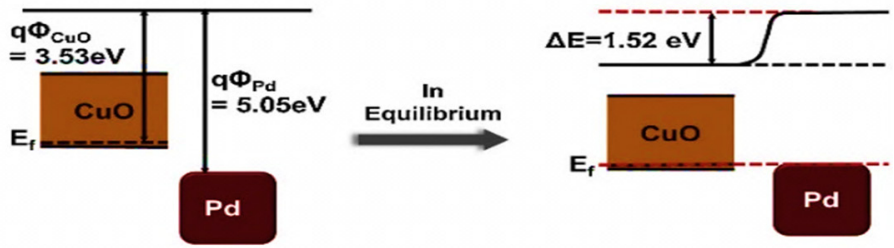

(b)
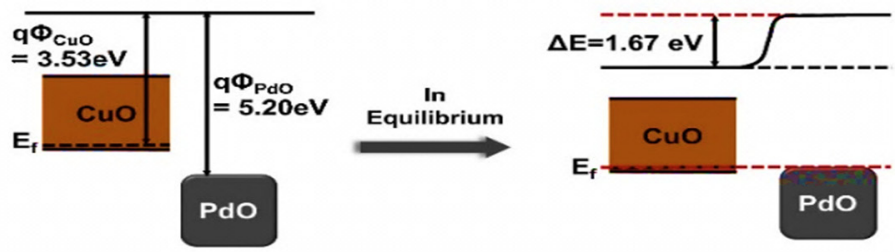

(c)
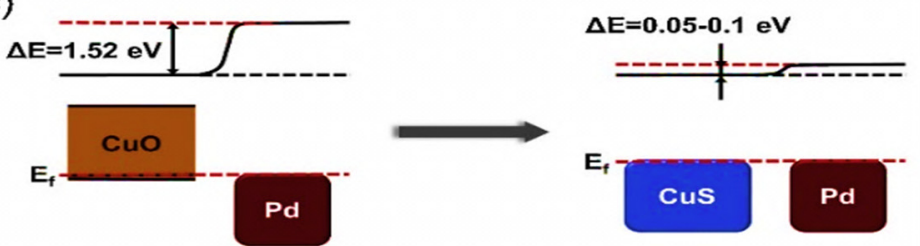

(In air)

(In $\mathrm{H}_{2} \mathrm{~S}$ )

(d)
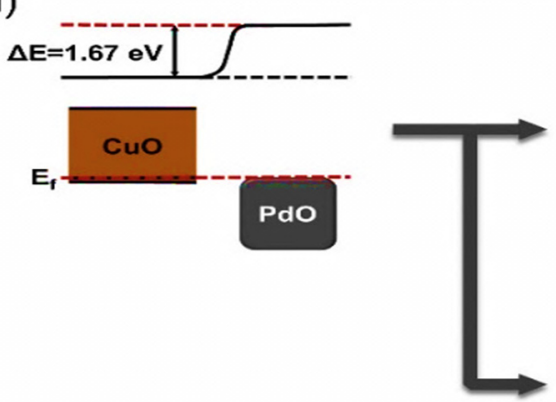

$\Delta E=0.05-0.1 \mathrm{eV}$
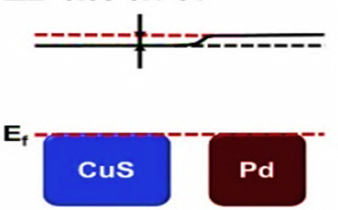

$\Delta E=0.2-0.25 \mathrm{eV}$
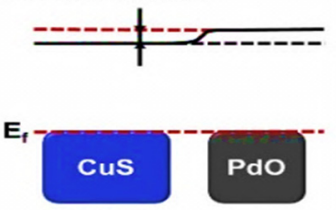

(In air)

(In $\mathrm{H}_{2} \mathrm{~S}$ )

Figure 18. Schematics of the energy levels of (a) $\mathrm{CuO} / \mathrm{Pd}$ and $(\mathbf{b}) \mathrm{CuO} / \mathrm{PdO}$ with the development of heterojunction barriers. Variations in the energy levels of (c) $\mathrm{CuO} / \mathrm{Pd}$ and (d) $\mathrm{CuO} / \mathrm{PdO}$ heterostructures in the presence of $\mathrm{H}_{2} \mathrm{~S}$ gas. Reproduced from [110] with the permission of Elsevier.

When exposed to reducing gases, the width of $\mathrm{HAL}$ in $\mathrm{CuO}$ decreased. This indicated that the number of holes on the $\mathrm{CuO}$ surface decreased. As the original volume of the hole area increased due to the heterojunctions, the decrease in a similar number of holes by injecting the reduction gas resulted in a low response to reducing gases. In the case of $\mathrm{H}_{2} \mathrm{~S}$ gas, in addition to the modification of the original resistance induced by the heterojunction, an alternative mechanism was speculated to impact the sensing. When exposed to $\mathrm{H}_{2} \mathrm{~S}$, $\mathrm{CuO}$ was converted into $\mathrm{CuS}$ with a conductivity similar to that of the metal, affording a strong resistance modulation within the heterojunctions. As shown in Figure 18c,d, the potential barriers of the $\mathrm{CuO} / \mathrm{Pd}$ and $\mathrm{CuO} / \mathrm{PdO}$ heterojunctions are destroyed upon the 
transformation of $\mathrm{CuO}$ to $\mathrm{CuS}$. Consequently, fewer electrons intersect from $\mathrm{CuS}$ to $\mathrm{Pd}$ than from $\mathrm{CuO}$, which results in a higher concentration of electrons in the detection layer $(\mathrm{CuO} / \mathrm{CuS})$ than in the pure detection layer.

Kim et al. [111] described the $\mathrm{CO}$ and $\mathrm{NO}_{2}$-sensing capacities of pure and Au-functionalized $\mathrm{ZnO}$ NWs in the self-heating mode. The electron-electron collisions, heterojunctions, grain boundaries, and homojunctions acted as different heat-generating sources. The sensor fabricated with the Au-functionalized $\mathrm{ZnO}$ NWs showed a maximum response of 2.87 toward 10 ppm CO gas at $7 \mathrm{~V}$ (applied voltage) and afforded a significantly higher response in comparison to that of pure $\mathrm{ZnO}$ NWs. Heat dissipation into the substrate or contacts decreased the efficiency of self-heating for voltages above $7 \mathrm{~V}$. As a result, a decrease in the sensor response at higher applied voltages $(>7 \mathrm{~V})$ was related to the high power dissipation to the substrate and a loss of sensor response. Schottky barriers developed at the $\mathrm{Au} / \mathrm{ZnO}$ interfaces because of the different work functions of $\mathrm{Au}$ and $\mathrm{ZnO}$. In addition, Au showed excellent catalytic capability for gases and efficiently adsorbed the target gases on its surfaces and transported these to the sensing material surfaces via the spillover mechanism. Consequently, more gas was adsorbed onto the ZnO NW surface in the case of sensors based on Au-ZnO NWs, leading to a high resistance modulation. Kim et al. [112] fabricated Pt-functionalized $\mathrm{SnO}_{2}-\mathrm{ZnO}$ C-S NWs for $\mathrm{C}_{7} \mathrm{H}_{8}$ gas sensing under self-heating conditions. The optimal gas sensor showed a response of 3 to $50 \mathrm{ppm} \mathrm{C}_{7} \mathrm{H}_{8}$ gas under $20 \mathrm{~V}$ applied voltage. The thermographs of C-S NWs are shown in Figure 19. The temperature increased with an increase in shell thickness from 10 to $85 \mathrm{~nm}$. Negligible self-heating was observed for the $10 \mathrm{~nm}$-thick shell sensors based on C-S NWs, whereas it was relatively apparent for a shell thickness of $85 \mathrm{~nm}$. Pt NPs were more effective for $\mathrm{C}_{7} \mathrm{H}_{8}$ adsorption and dissociation than other reducing gases. Additionally, the methyl group of $\mathrm{C}_{7} \mathrm{H}_{8}$, through which it adsorbed onto the surface, contributed toward improved adsorption onto the surface. To modulate electron depletion in C-S NWs, electrical transport could occur in both the shell and regions of the core near the shell (smearing effect) when the shell thickness was less than the $\lambda_{\mathrm{D}}$. For the sensors with a $10 \mathrm{~nm}$-thick $\mathrm{ZnO}$ layer, the complete layer of the $\mathrm{ZnO}$ region was electron-depleted with the possibility of generating a $\mathrm{SnO}_{2}$ depletion region near the interfaces. In addition, via the adsorption of $\mathrm{C}_{7} \mathrm{H}_{8}$ gas molecules, it was expected that the free electrons introduced by the $\mathrm{C}_{7} \mathrm{H}_{8}$ gas could drift through the ZnO-depleted region with no carriers, across the $\mathrm{ZnO} / \mathrm{SnO}_{2}$ heterojunction, and move into the electron depletion region of the $\mathrm{SnO}_{2}$ core.

There were no electronic barriers between $\mathrm{ZnO}$ and $\mathrm{SnO}_{2}$ (Figure 20a). As electric current passed primarily through the $\mathrm{SnO}_{2}$ core with a diameter of $<50 \mathrm{~nm}$, the resistance changed accordingly. In contrast, for an 85 nm-thick $\mathrm{ZnO}$ layer, a substantial depth of the non-depleted region existed in the $\mathrm{ZnO}$ shell despite the depletion region created by chemisorbed oxygen. As a result, the free electrons introduced by the $\mathrm{C}_{7} \mathrm{H}_{8}$ gas could drift into the $\mathrm{ZnO}$ shell layer via the adsorption of $\mathrm{C}_{7} \mathrm{H}_{8}$ molecules, thereby decreasing the thickness or increasing the concentration of electrons. Meanwhile, the main conduction volume was expected to change from the $\mathrm{ZnO}$ shell to the $\mathrm{SnO}_{2}$ core with an increase in the shell thickness. The decrease in the thickness of the $\mathrm{ZnO}$ shell did not decrease the initial resistance by decreasing the conduction volume and increasing the sensor response.

Furthermore, Pt NPs display catalytic characteristics through the spillover effect, which allow the adsorption of $\mathrm{C}_{7} \mathrm{H}_{8}$ molecules and the transfer of gas molecules to the adjacent $\mathrm{ZnO}$ surface (Figure 20b). For NWs with thick shells, the main current passed through the $\mathrm{ZnO}$ shell, which was in the vicinity of the surface and Pt NPs. Thus, Pt significantly enhanced the sensing activities. In addition, for thin-shell NWs, the main current flowed across the $\mathrm{SnO}_{2}$ core, which was away from the surface and Pt NPs. Consequently, Pt catalysts did not significantly improve the sensing performance. 


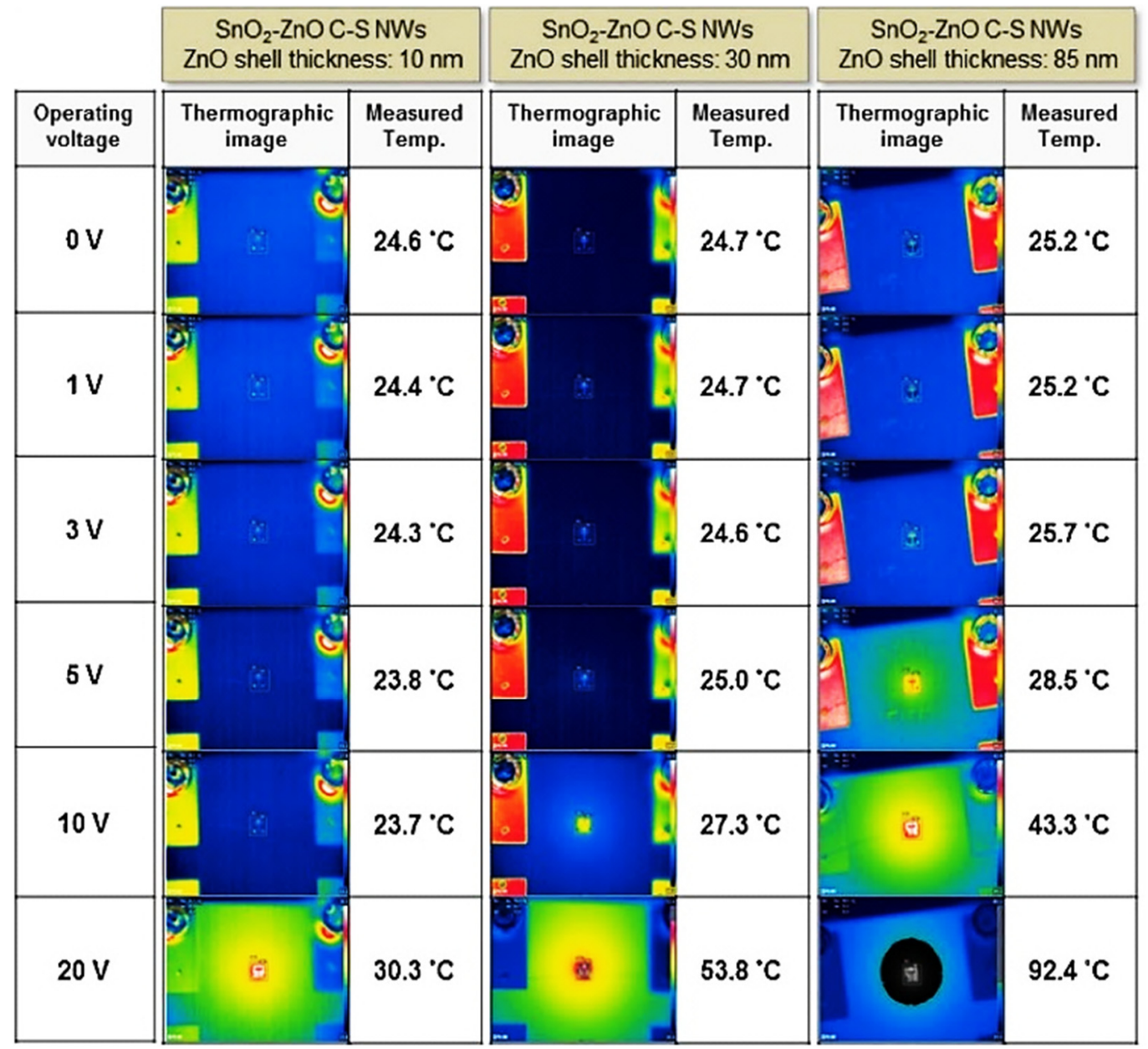

Figure 19. Thermographs of the $\mathrm{Pt} / \mathrm{SnO}_{2}-\mathrm{ZnO} \mathrm{C}-\mathrm{S} \mathrm{NW}$ sensor with various shell thicknesses at different applied voltages. Reproduced from [112] with the permission of Elsevier.

As a highly toxic gas, CO does not have odor, taste, or color [113]. Therefore, the design of sensitive $\mathrm{CO}$ gas sensors is important to prevent the hazardous effects of $\mathrm{CO}$ gas on the human body. Kim et al. [114] performed CO gas-sensing studies of $\mathrm{WS}_{2}-\mathrm{SnO}_{2}$ C-S NSs, where $\mathrm{SnO}_{2}$ shells with various thicknesses $(0-30 \mathrm{~nm})$ were deposited on $\mathrm{WS}_{2}$ by varying the number of ALD cycles. The sensor designed with a $15 \mathrm{~nm}$-thick shell was capable of detecting $\mathrm{CO}$ gas at $3.4 \mathrm{~V}$ under self-heating conditions. For $\mathrm{NO}_{2}$ gas detection, although $\mathrm{NO}_{2}$ sensitivity increased with an increase in the shell thickness (up to 1.4), it was very low in relation to the $\mathrm{CO}$ sensitivity. For a $30 \mathrm{~nm}$-thick shell layer, the response $\left(R_{a} / R_{g}=1.4\right.$ to $50 \mathrm{ppm}$ CO gas) was not different from that of the pristine $\mathrm{WS}_{2}\left(R_{g} / R_{a}=1.3\right)$. The pristine sensor had numerous homojunctions, which were attributed to the sensing signal (Figure 21a). For C-S NSs, other mechanisms were observed in addition to the modulation of resistance at the homojunctions (Figure 21b) because of the different work functions of the $\mathrm{WS}_{2}$ core and $\mathrm{SnO}_{2}$ shell. As a result, both sides were electron-depleted in the case of $\mathrm{SnO}_{2}$ shell; one side was electron-depleted because of exposure to air and the other side was depleted due to electron flow toward $\mathrm{WS}_{2}$. Based on the shell thickness, the thickness of the electron depletion layer changed relative to the entire $\mathrm{SnO}_{2}$ shell thickness. When the shell thickness was $\leq \lambda_{\mathrm{D}}$ of $\mathrm{SnO}_{2}$, the entire shell was depleted of electrons when exposed to air. Upon $\mathrm{CO}$ exposure, the electrons returned to the gas sensor surface, and considerable resistance modulation occurred, which resulted in a high $\mathrm{CO}$ response (Figure 21c). However, for shells thicker than $15 \mathrm{~nm}$, only a fraction of the shell layer became electron-depleted (Figure 21d). When more electrons were accessible in the shell layer, a larger number of electrons were removed by the $\mathrm{NO}_{2}$ gas. This led to a high sensing 
signal for $\mathrm{NO}_{2}$ gas. As a result, only a fraction of the shell layer was electron-depleted when the shell was thicker. For a sensor with a $30 \mathrm{~nm}$-thick shell, the highest response was observed to $\mathrm{NO}_{2}$ gas.

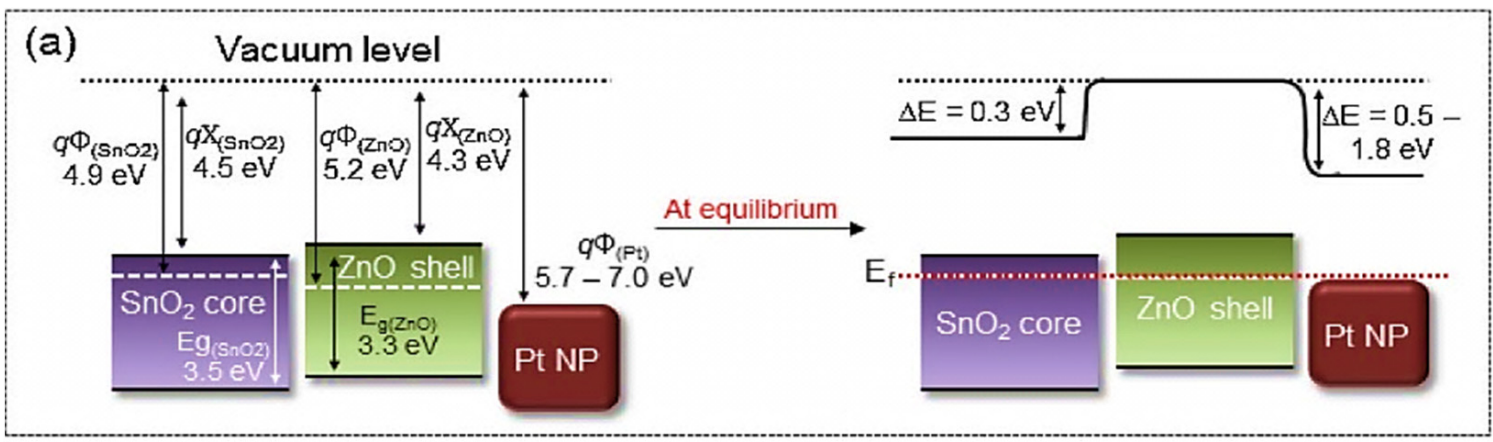

(b) Thin shell layer $(\sim 10 \mathrm{~nm})$

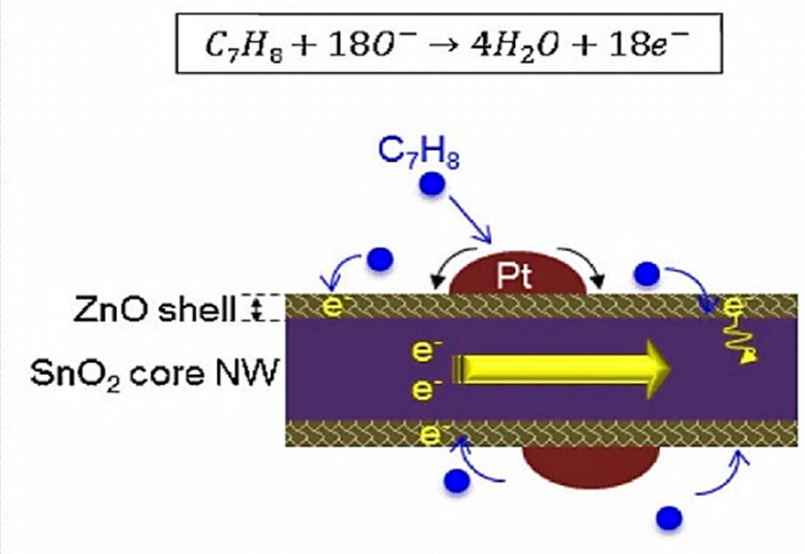

Thick shell layer $(\sim 85 \mathrm{~nm})$

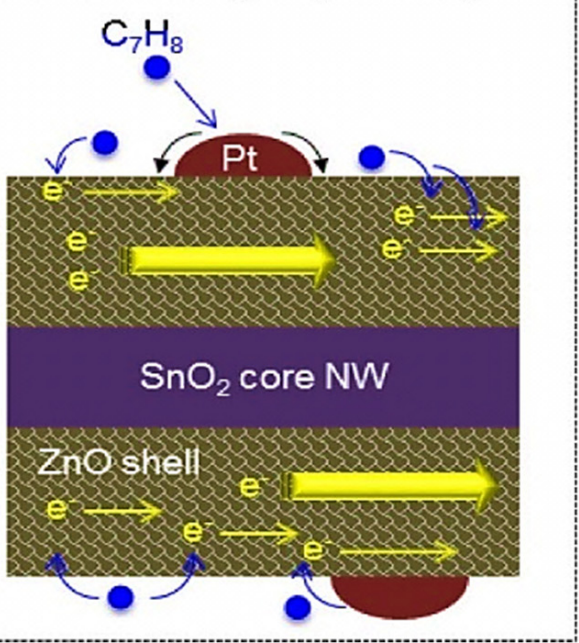

Figure 20. Schematic of $\mathrm{C}_{6} \mathrm{H}_{6}$ gas-sensing mechanisms of Pt-functionalized $\mathrm{SnO}_{2}-\mathrm{ZnO} \mathrm{C}-\mathrm{S}$ NWs . (a) Energy band diagrams and (b) Pt catalytic effect on different shell thicknesses. Reproduced from [112] with the permission of Elsevier.

Kim et al. [115] fabricated an innovative self-heated $\mathrm{CO}$ gas sensor using a Aufunctionalized network of $\mathrm{SnO}_{2}-\mathrm{ZnO}$ C-S NWs. The thicknesses of the $\mathrm{ZnO}$ shells deposited using the ALD technique were 10,30, and $80 \mathrm{~nm}$. The sensor with a shell of $80 \mathrm{~nm}$-thick showed the highest response of 1.7 to $50 \mathrm{ppm} C \mathrm{C}$ gas under $20 \mathrm{~V}$ applied voltage.

The TEM images of a Au-functionalized network of $\mathrm{SnO}_{2}-\mathrm{ZnO}$ C-S NWs are shown in Figure 22, indicating the successful formation of the expected products. As shown in Figure 23, the temperature increases with an increase in the applied voltage. Owing to the different $\mathrm{SnO}_{2}$ and $\mathrm{ZnO}$ work functions, some $\mathrm{ZnO}$ electrons in the vicinity of the interfaces moved toward the $\mathrm{SnO}_{2}$ side. In addition, $\mathrm{Au}$ NP-functionalization introduced two features: the development of $\mathrm{Au} / \mathrm{ZnO}$ nano-Schottky junctions and chemical effects of Au. In addition, the Au NPs catalytically dissociated molecular oxygen species and accordingly enhanced the reaction rate between oxygen and $\mathrm{CO}$ gas. 

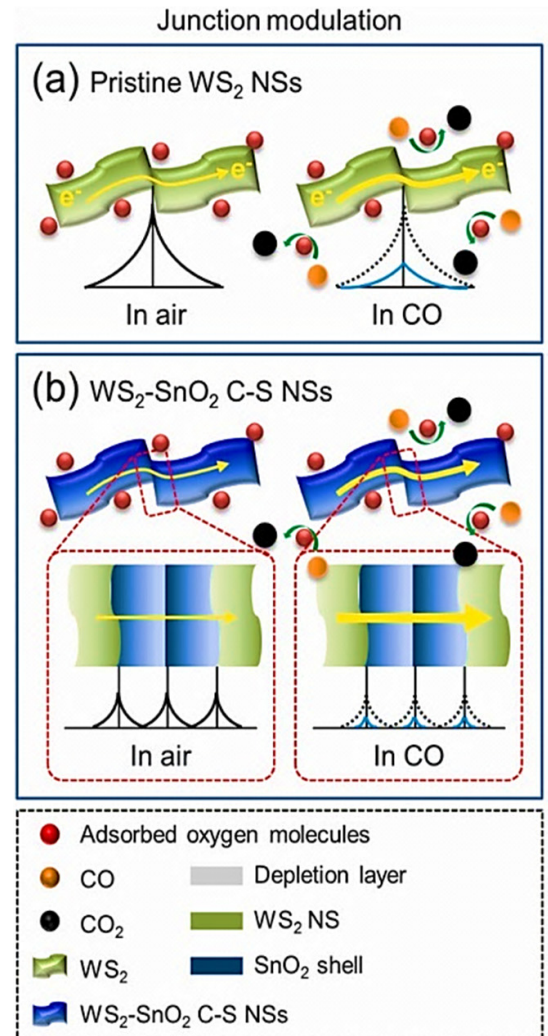

Radial modulation

(C) $\mathrm{SnO}_{2}$ shell layer thickness $\leq \lambda_{D}$ In air

In $\mathrm{CO}$
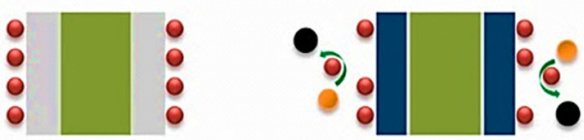

Fully depleted region

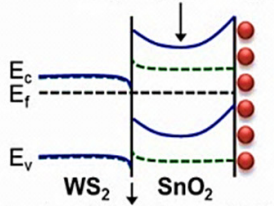

Heterojunction between $\mathrm{SnO}_{2}$ shell and WS $\mathrm{W}_{2}$ core

(d) $\mathrm{SnO}_{2}$ shell layer thickness $>\lambda_{\mathrm{D}}$

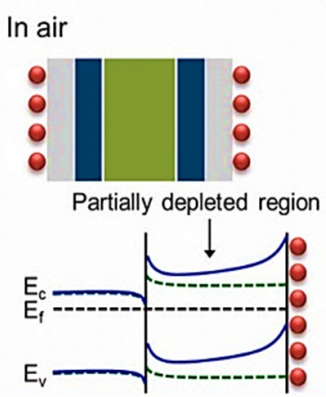

In $\mathrm{CO}$

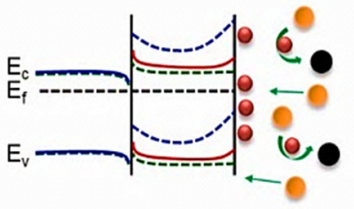

Figure 21. Schematic of the modulation of homojunction in (a) pure $\mathrm{WS}_{2} \mathrm{NSs}$ and (b) $\mathrm{WS}_{2}-\mathrm{SnO}_{2} \mathrm{C}-\mathrm{S}$ NSs. Radial modulation in the sensors with shell thicknesses of $(\mathbf{c})<\lambda_{\mathrm{D}}$ and $(\mathbf{d})>\lambda_{\mathrm{D}}$. Reproduced from [114] with the permission of Elsevier.
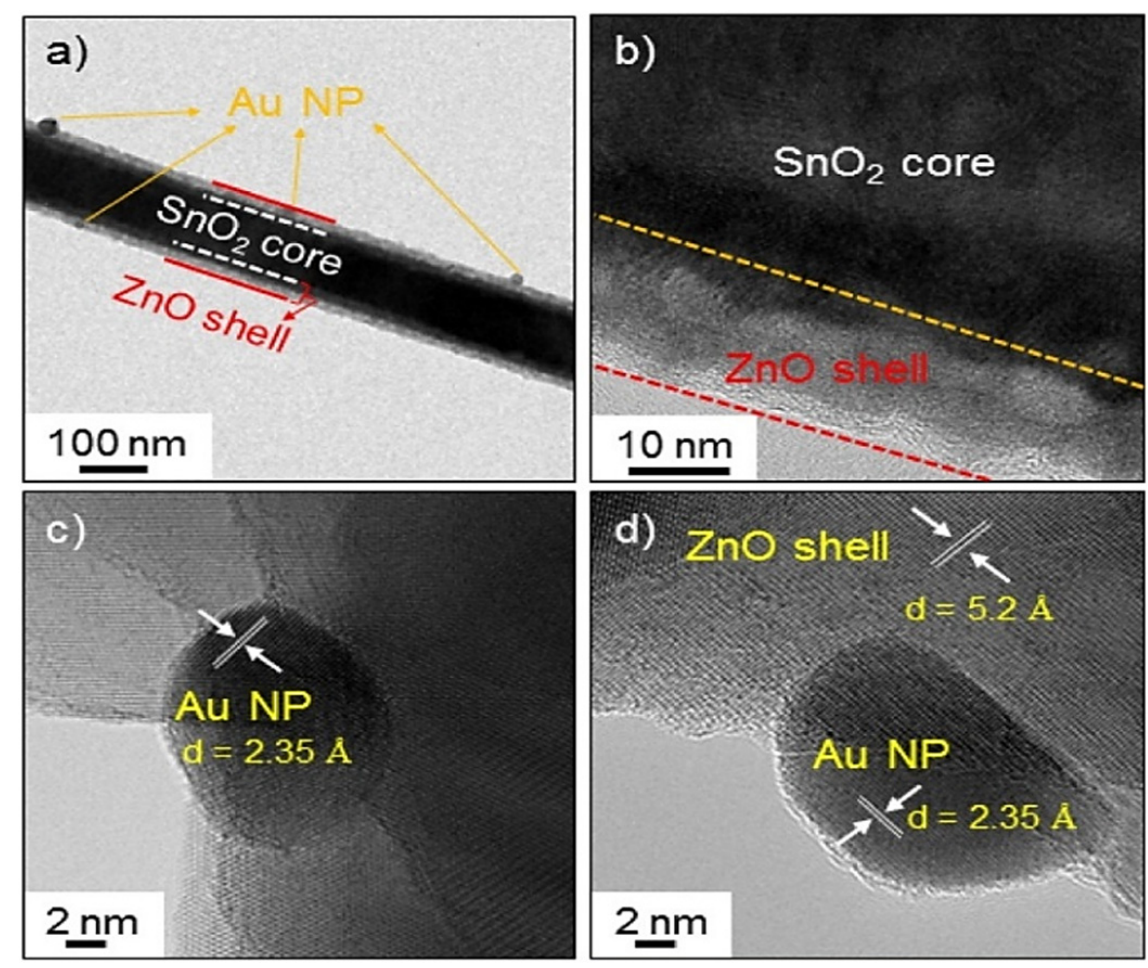

Figure 22. (a) TEM images of $\mathrm{Au} / \mathrm{SnO}_{2}-\mathrm{ZnO}$ C-S NW, (b) HR-TEM image of $\mathrm{SnO}_{2}-\mathrm{ZnO}$ C-S NW, and $(\mathbf{c}, \mathbf{d})$ the corresponding HR-TEM images. Reproduced from [115] with the permission of Elsevier. 


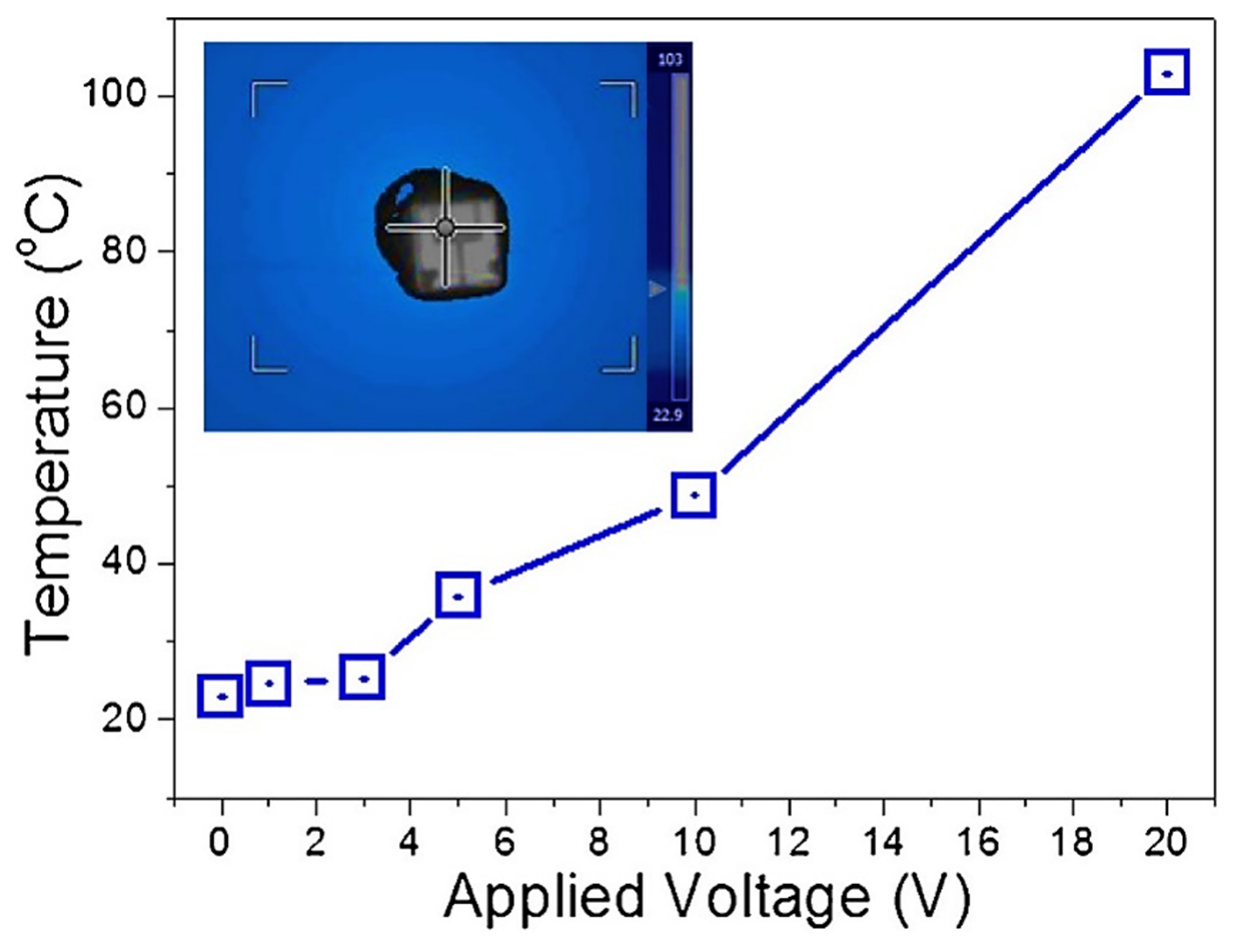

Figure 23. Variation in the generated temperature of the $\mathrm{SnO}_{2}-\mathrm{ZnO} \mathrm{C}-\mathrm{S} \mathrm{NW}$ sensor with $80 \mathrm{~nm}$ thick shell of $\mathrm{ZnO}$ as a function of the voltage applied (inset: thermograph of the sensor at $20 \mathrm{~V}$ ). Reproduced from [115] with the permission of Elsevier.

Benzene and toluene are toxic volatile organic compounds (VOCs). Benzene is a carcinogen, and its high level of exposure affects the blood, which may cause leukemia. Additionally, toluene may have an adverse effect on the nervous system, such as disrupting the brain function and impairing the ability to see, hear, and speak. It can also damage the kidneys and liver. From a medical perspective, toluene is considered a biomarker for lung cancer; unusually high toluene levels (10-100 ppb) in exhaled breath may be a sign of lung cancer. Benzene is an inert gas, and benzene rings generally exhibit low reactivity. Toluene is slightly more reactive than benzene owing to its electron-donating methyl $\left(-\mathrm{CH}_{3}\right)$ group. Consequently, the development of selective gas sensors for detecting benzene and toluene gases is important [116]. Kim et al. [117] investigated the VOC-sensing properties of Pt- and Pd-functionalized $\mathrm{ZnO}$ NWs in the self-heating mode. The thickness of the initial sputtered metal layer (5 and $10 \mathrm{~nm}$ ) and annealing temperature $\left(500-750{ }^{\circ} \mathrm{C}\right)$ were varied to optimize Pt NP formation, while the UV irradiation time was modulated to obtain isolated Pd NPs on the $\mathrm{ZnO} \mathrm{NW}$ surface. The sensors decorated with Pd and Pt showed an enhanced response to benzene and toluene gases, respectively. The response of the Pd-decorated gas sensor to 50 ppm $\mathrm{C}_{6} \mathrm{H}_{6}$ was 2.3 under $20 \mathrm{~V}$ applied voltage, and the response of the Pt-decorated gas sensor to $50 \mathrm{ppm}_{7} \mathrm{H}_{8}$ was 2.2 under $20 \mathrm{~V}$ applied voltage. The sensing mechanism is shown in Figure 24. For toluene sensing with $\mathrm{Pt} / \mathrm{ZnO}$, toluene is initially chemisorbed onto the surface sites of $\mathrm{Pt} / \mathrm{ZnO}$ and reacts with the chemisorbed oxygen to form benzaldehyde, which is then transformed into benzoate species. The increased decomposition of benzoate species is a major contributor to the catalytic activity of Pt during toluene oxidation. Thereafter, the benzoate species were broken down into carboxylates and carboxylic acids, which were then transformed into anhydrides and carboxylates. 


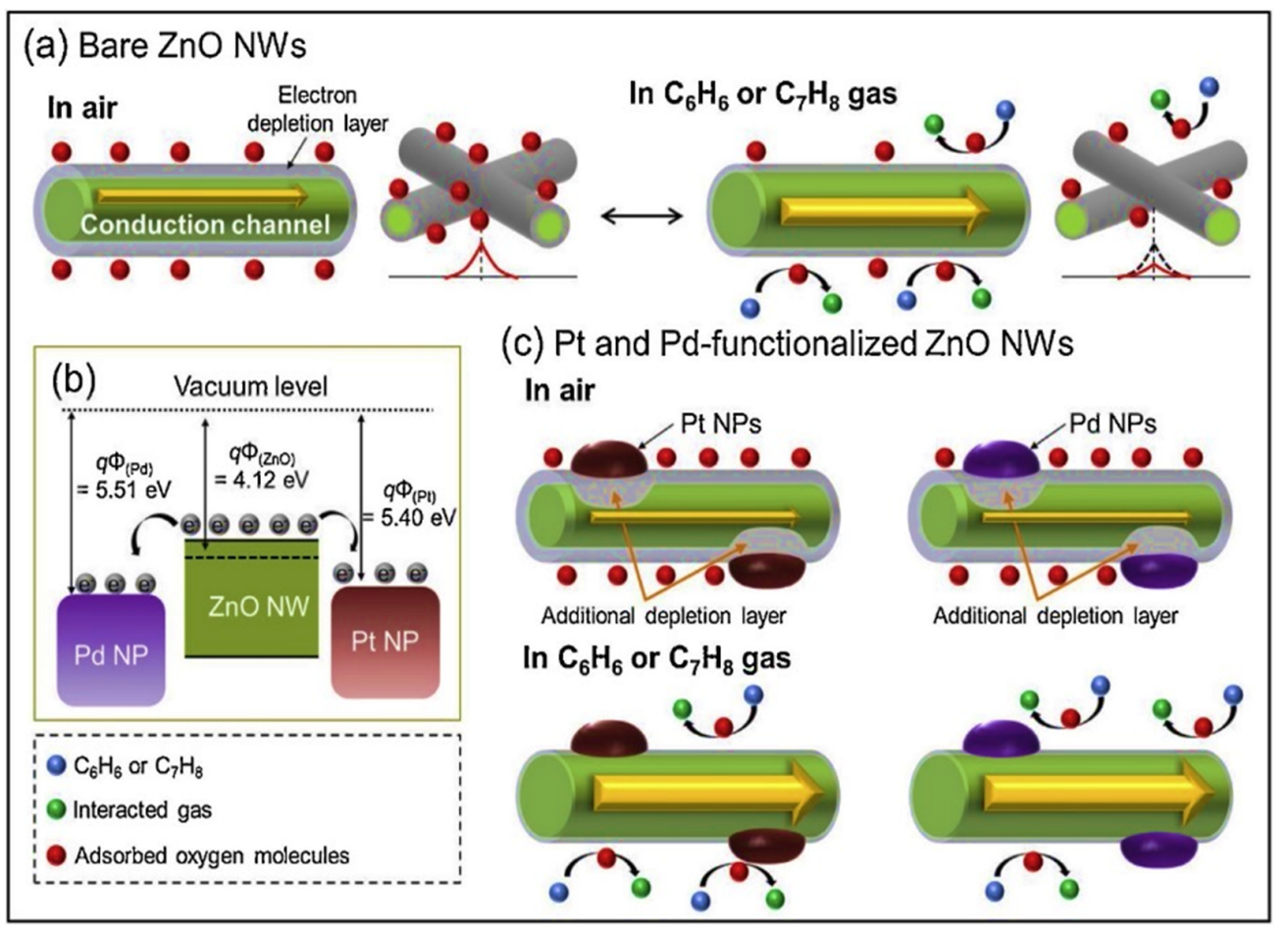

Figure 24. (a) Sensing mechanism of pristine $\mathrm{ZnO}$ NWs, (b) work functions of $\mathrm{ZnO}, \mathrm{Pd}$, and Pt/Pdfunctionalized $\mathrm{ZnO}$ NWs, and (c) sensing mechanism of Pt- and Pd-functionalized ZnO NWs. Reproduced from [117] with the permission of Elsevier.

Anhydrides were further converted into adsorbed $\mathrm{H}_{2} \mathrm{O}$ and $\mathrm{CO}$ species, and the latter could react with adsorbed oxygen to produce $\mathrm{CO}_{2}$. The presence of $-\mathrm{CH}_{3}$ plays an important role in the detection of toluene, as toluene can adsorb on the surface through this group [118]. Kim et al. [119] reported the $\mathrm{H}_{2} \mathrm{~S}$ gas-sensing properties of $\mathrm{CuO}$-decorated $\mathrm{SnO}_{2}-\mathrm{ZnO}$ C-S NWs with different shell thicknesses in the self-heating mode. The sensor with an $80 \mathrm{~nm}$-thick shell showed better detection capability than sensors based on thin shells. The maximum response was 1.8 to $10 \mathrm{ppm}_{2} \mathrm{~S}$ under $5 \mathrm{~V}$ applied voltage. In addition to the development of various heterojunctions between $\mathrm{SnO}_{2}-\mathrm{ZnO}$ and $\mathrm{ZnO}-\mathrm{CuO}$, together with the $\mathrm{ZnO}-\mathrm{ZnO}$ homojunction, the transformation of $\mathrm{CuO}$ to $\mathrm{CuS}$ should also be considered. Upon $\mathrm{H}_{2} \mathrm{~S}$ exposure, $\mathrm{CuO}$ reacted with $\mathrm{H}_{2} \mathrm{~S}$ to form an intermetallic CuS compound with a conductivity similar to that of the metal. In this manner, the $p-n$ heterojunction was destroyed, and the sensor resistance was decreased significantly. For a $\mathrm{ZnO}$ shell thickness of $80 \mathrm{~nm}$ in the $\mathrm{C}-\mathrm{S} \mathrm{NWs}$, a substantial depth of the non-depleted region was observed in the $\mathrm{ZnO}$ shell even though the depletion region was formed due to oxygen chemisorption. Upon $\mathrm{H}_{2} \mathrm{~S}$ introduction, $\mathrm{CuO}$ was transformed into $\mathrm{CuS}$ by destruction of the $\mathrm{ZnO}-\mathrm{CuO}$ heterojunctions, and the sensor resistance decreased significantly. A low response was observed for the sensor based on pristine $\mathrm{SnO}_{2} \mathrm{NWs}$, which was attributed to the low self-heating effect of the pure $\mathrm{SnO}_{2}$ gas sensor.

\section{Irradiated Gas Sensors}

There are various approaches to improve the gas detection properties of the sensing materials. One of the post-treatment (change in morphology or chemical composition after synthesis) strategies involves the use of low- to high-energy irradiation techniques such as ion-beam irradiation [120], laser irradiation [121], gamma ray irradiation [122], electron-beam (e-beam) irradiation, and UV light irradiation [123]. The research groups of Professors Hyoun Woo Kim and Sang Sub Kim applied high-energy irradiation to the sensing materials. The application of high-energy irradiation is promising as it can change the physicochemical properties of the sensing materials. When high-energy beams 
interact with the sensing material, they can modify the molecular and structural properties of the materials, including the ionization and development of various types of defects such as interstitial atoms and vacancies [124]. In this manner, irradiation modifies the structure of the sensing material and may therefore alter its detection capability. The degree of modification is determined by the radiation energy, radiation dose, and material properties [125]. Among various irradiation techniques, e-beam irradiation is one of the common irradiation techniques that may induce defects in the sensing materials [126]. Kim et al. [127] designed highly sensitive $\mathrm{ZnO}$ NFs for $\mathrm{H}_{2}$ sensing via e-beam irradiation $(1 \mathrm{MeV})$ and investigated the effect of e-beam doses (50, 100, and $150 \mathrm{kGy})$ on the sensing characteristics. Figure 25 shows the schematics of the synthesis, irradiation, and sensor fabrication processes of the $\mathrm{ZnO}$ NFs.

(a) Preparation of Viscous $\mathrm{Zn}^{+2}$ solution
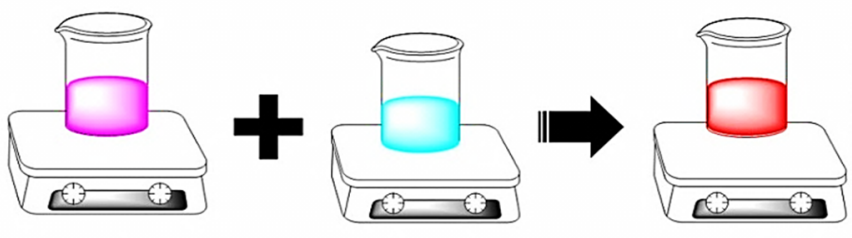

$\left.\mathrm{Zn}\left(\left(\mathrm{CH}_{3} \mathrm{CO}_{2}\right)_{2}\right)\right)$ Distilled Water PVA (Poly Vinyl Alcohol)

PVA solution $\mathrm{Zn}^{+2}$ solution Viscous $\mathrm{Zn}^{+2}$ solution

(b) Electrospinning of $\mathrm{ZnO} \mathrm{NFs}$

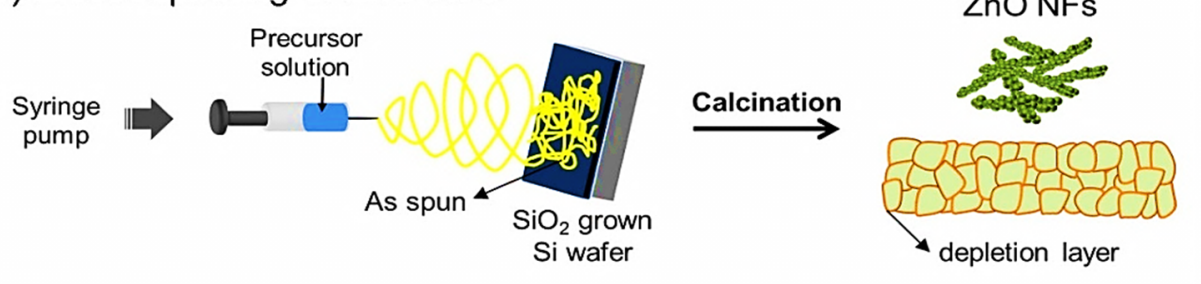

(c) e-beam irradiation (1 MeV)

Electron beam (50 kGy)

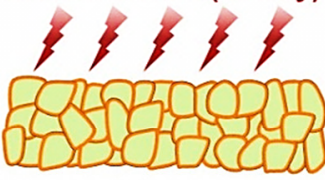

Irradiation time: $18 \mathrm{~s}$

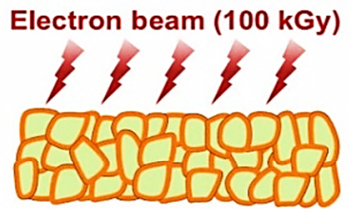

Irradiation time: $36 \mathrm{~s}$
Electron beam (150 kGy)

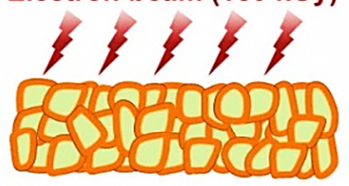

Irradiation time: $54 \mathrm{~s}$

(d) Sensor devices

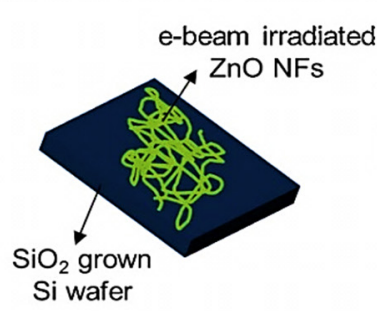

Deposition of $\mathrm{Ti}(50 \mathrm{~nm})$,

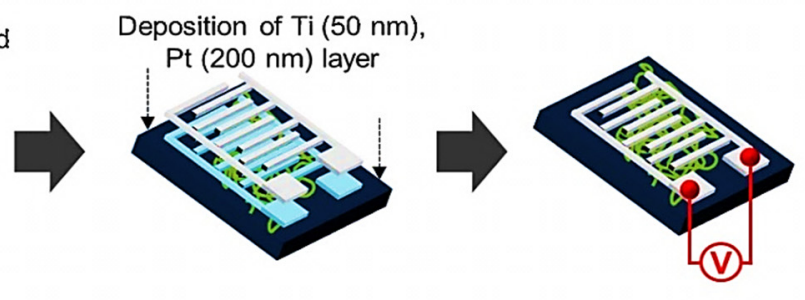

Figure 25. Illustration of (a-b) the synthesis of $\mathrm{ZnO} N F s$, (c) e-beam irradiation, and (d) sensor fabrication. Reproduced from [127] with the permission of Elsevier.

The sensor fabricated using $50 \mathrm{kGy}$ irradiation exhibited sensing properties comparable to those of the unirradiated sensor, as the e-beam dose was inadequate to generate structural defects in the sensor. In contrast, the sensors irradiated at 100 and $150 \mathrm{kGy}$ afforded excellent sensing properties. The highest response was observed for the $150 \mathrm{kGy}$ irradiated gas sensor with a value of 150 to $10 \mathrm{ppm} \mathrm{H}_{2}$ gas at $350{ }^{\circ} \mathrm{C}$. The gas detection mechanism of $\mathrm{ZnO}$ NFs was associated with radial modulation, grain boundary modula- 
tion, metallization effect of $\mathrm{ZnO}$ (reduction of $\mathrm{ZnO}$ to metallic $\mathrm{Zn}$ ), and radiation-induced oxygen defects (Figure 26a-d). In particular, the high responses to the sensors irradiated at $100 \mathrm{kGy}$ and $150 \mathrm{kGy}$ were attributed to the development of defects, as indicated by the photoluminescence (PL) studies. The irradiated sensor with a high e-beam dose exhibited higher levels of structural defects with oxygen vacancies. Oxygen vacancies acted as favorable adsorption sites for oxygen molecules, leading to more reactions between the adsorbed oxygen species and incoming $\mathrm{H}_{2}$ gas molecules.

a) Radial modulation

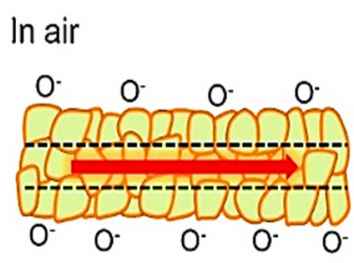

c) e-beam effect

Non e-beam irradiation

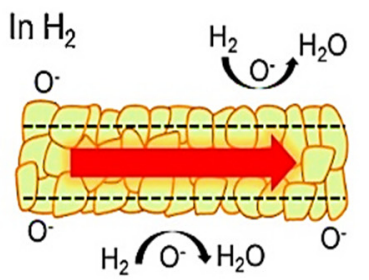

$\mathrm{H}_{2} / \mathrm{O}^{-}+\mathrm{H}_{2} \mathrm{O}$

\section{b) Grain boundary modulation}
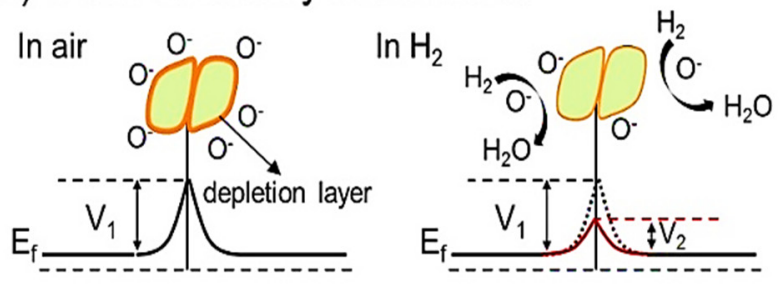

\section{d) Metallization effect}

In air

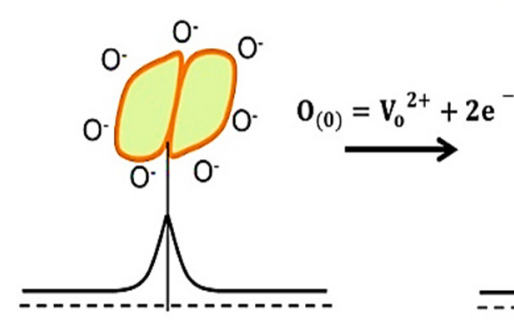

e-beam irradiation
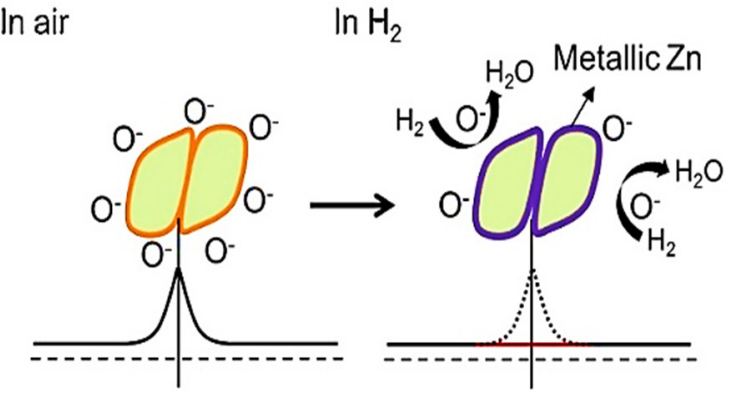

Figure 26. Schematic of the $\mathrm{H}_{2}$-sensing mechanism of the e-beam-irradiated $\mathrm{ZnO} \mathrm{NF}$ sensor. (a) Radial modulation, (b) grain boundary modulation, (c) effect of e-beam, and (d) effect of $\mathrm{ZnO}$ metallization. Reproduced from [127] with the permission of Elsevier.

Kim et al. [128] reported the $\mathrm{H}_{2}$-sensing characteristics of Pd-loaded ZnO NFs with respect to e-beam irradiation, where the optimized sensor irradiated at $150 \mathrm{kGy}$ exhibited an excellent response of 74.7 toward $100 \mathrm{ppb} \mathrm{H}_{2}$ at $350{ }^{\circ} \mathrm{C}$. Pd acted as a strong catalyst for oxygen molecules, resulting in a rapid and greater removal of electrons from the $\mathrm{ZnO}$ surface through oxygen species. Additionally, hydrogen molecules were divided into hydrogen atoms and shifted toward the $\mathrm{ZnO}$ surface (through the "spillover" effect), where they interacted strongly with the previously adsorbed oxygen species, thereby releasing the electrons back to the sensor surface. In ambient air, oxygen interacted with the trapped electrons at the $\mathrm{Pd} / \mathrm{ZnO}$ heterojunctions. In an $\mathrm{H}_{2}$ environment, $\mathrm{Pd} \mathrm{NPs}$ could absorb atomic hydrogen to form $\mathrm{PdH}_{\mathrm{x}}$. The work function of $\mathrm{PdH}_{x}$ may be sufficiently high to accept other $\mathrm{ZnO}$ electrons and decrease the original number of electrons in $\mathrm{ZnO}$, thereby increasing the sensor response. In addition, Pd NPs could act as electron scattering points, and the variation in electron scattering produced by hydrogen adsorption resulted in additional changes in resistance. Thus, Pd-loaded sensors exhibited higher responses relative to the pristine $\mathrm{ZnO} \mathrm{NF}$ sensor due to Pd effects.

Kwon et al. [129] enhanced the $\mathrm{NO}_{2}$-sensing properties of reduced graphene oxide (rGO) by e-beam irradiation (100 and $500 \mathrm{kGy}$ ). The sensor irradiated with a higher dose showed a higher response, decreased response time, and increased recovery time due to enhanced $\mathrm{NO}_{2}$ adsorption through defect formation and functional oxygen groups. The observed structural defects and functional oxygen groups were responsible for the beaminduced variations in the sensing performances. For an irradiation of $100 \mathrm{kGy}$, oxygen functional groups were created between the graphene nanosheets. The oxygen functional 
groups could provide additional surface adsorption sites to the target gases, resulting in higher modulation of the resistance of the e-beam-irradiated rGO films. Therefore, an improvement in the sensing performance through e-beam irradiation of $100 \mathrm{kGy}$ was related to the production of oxygen functional groups. However, the d-spacing and oxygen content decreased with an increase in the irradiation dose from 100 to $500 \mathrm{kGy}$. As a result, at a high dose of $500 \mathrm{kGy}$, the quantity of generated oxygen functional groups was lower at $100 \mathrm{kGy}$. Thus, non-oxygenated defects played an important role in improving the sensing performance. Choi et al. [130] reported the effect of e-beam irradiation (0, 100, and $500 \mathrm{kGy}$ ) on the $\mathrm{NO}_{2}$-sensing features of Pd-functionalized rGO. The response of the unirradiated sensor and the sensor irradiated at doses of 100 and $500 \mathrm{kGy}$ to $10 \mathrm{ppm} \mathrm{\textrm {NO } _ { 2 }}$ were 1.027, 1.045, and 1.047, respectively. The response times of Pd-RGO, Pd-RGO-100 kGy, and Pd-RGO $500 \mathrm{kGy}$ to 10 ppm $\mathrm{NO}_{2}$ gas were 389, 335, and $345 \mathrm{~s}$, respectively. Thus, the sensor developed with the highest irradiation dose exhibited the maximum $\mathrm{NO}_{2}$ response. The corresponding recovery times for these sensors were 808, 766, and 816 s, respectively. For the sensor irradiated at $100 \mathrm{kGy}$, the quantity of oxygen decreased, and the amount of carbon increased with respect to the non-irradiated sensor. As a result, the improvement in the gas response was attributed to a high number of oxygen vacancies or functional oxygen groups in this sensor with additional adsorption sites for the target gas molecules. For the sensor irradiated with a higher dose, the oxygen content of rGO increased due to e-beam irradiation. These sites were capable of adsorbing large quantities of oxygenated functional groups. Moreover, non-oxygen related defects, including carbon vacancies and 5-8-5 defects, could be produced after irradiation at $500 \mathrm{kGy}$ with a potential impact on the response to $\mathrm{NO}_{2}$.

Ion implantation is a method for injecting atoms/ions into the host solids at the desired depth of the host material, which allowed the alteration of the surface properties of the solids. This process allowed the precise placement of ions at the preferred depth of the solid as a function of energy, ion mass, and implantation angle. In contrast to other techniques, the implantation of ions for doping affords several advantages, such as excellent reproducibility and the ability to embed any atom into any solid material without limitations due to diffusion, precipitation, and segregation solid solubility. The interactions between the electrons and nuclei of the host material occur via ion implantation. At low energies, the incident ions lose their energy primarily because of the elastic collisions with solid nuclei (nuclear energy loss). The properties mainly change according to the characteristics and quantity of the incident atoms, their diffusion characteristics, and the number and types of defects. At high energies, electron excitation/ionization occurs (electronic energy loss) due to inelastic collisions [131-133]. Kwon et al. [134] irradiated $\mathrm{SnO}_{2} \mathrm{NWs}$ with He ions (45 MeV) through different ionic fluences, where the $\mathrm{NO}_{2}$ response of the sensor increased considerably with an increase in the ion fluence. The highest response was achieved under an ion fluence of $1 \times 10^{16}$ ions $/ \mathrm{cm}^{2}$. PL studies demonstrated the generation of structural defects and/or tin interstitials upon irradiation. In addition, the ionic ratio of $\mathrm{Sn}^{2+} / \mathrm{Sn}^{4+}$ increased upon ion-beam irradiation, indicating the development of surface $\mathrm{Sn}$ interstitials. Accordingly, the increased $\mathrm{NO}_{2}$ response was associated with the development of surface defects, which were made up of Sn interstitials. In another study, Kim et al. [135] described the $\mathrm{NO}_{2}$-sensing characteristics of Sb-ion-implanted (30 keV) $\mathrm{SnO}_{2}$ NWs at various irradiation doses $\left(2 \times 10^{13}, 2 \times 10^{14}\right.$, and $2 \times 10^{15}$ ions $\left./ \mathrm{cm}^{2}\right)$. The sensor designed with the lowest dose of $2 \times 10^{13}$ ions $/ \mathrm{cm}^{2}$ exhibited an excellent sensing performance. It showed a high response of 118 to 1 ppm $\mathrm{NO}_{2}$ gas at $300{ }^{\circ} \mathrm{C}$. Electron paramagnetic resonance (EPR) studies supported the generation of a large number of oxygen vacancies upon $\mathrm{Sb}$ implantation, which not only improved oxygen adsorption but also provided a large number of electrons to the $\mathrm{SnO}_{2}$ conduction band. Surface defects facilitated oxygen adsorption, thereby increasing the resistance following implantation. Contrarily, for high doses, the initial sensor resistance decreased because of the development of $\mathrm{Sn}$ interstitials, where these created a donor level within the $\mathrm{SnO}_{2}$ conduction band. The surface defects developed not only because of the various ionic sizes of $\mathrm{Sb}^{5+}$ and 
$\mathrm{Sn}^{4+}$ but also because of the high energy of the ion-implantation process. In the case of high implantation doses for which low responses were observed, more defect clusters were formed, which decreased the number of gas adsorption sites on the sensor surface. Furthermore, for the sensor developed using a low irradiation dose, more oxygen vacancies were generated, which promoted $\mathrm{NO}_{2}$ gas adsorption.

Kim et al. [136] fabricated $\mathrm{SnO}_{2}$ NWs and implanted indium ions (30 keV) using irradiation doses of $2 \times 10^{14}$ and $1.8 \times 10^{15} \mathrm{ion} / \mathrm{cm}^{2}$ for the sensing of reducing and oxidizing gases. The sensor irradiated with a lower dose showed a response of 19 to $1 \mathrm{ppm} \mathrm{NO}_{2}$ gas at $300^{\circ} \mathrm{C}$. The TEM-EDS color mapping images of the low-dose implanted $\mathrm{SnO}_{2} \mathrm{NW}$ sensor are shown in Figure 27a-c. A diameter of $\approx 50 \mathrm{~nm}$ for the $\mathrm{SnO}_{2} \mathrm{NW}$ was observed with In ions diffused up to a depth of $\approx 6 \mathrm{~nm}$. The TEM-EDS color mapping images of the high-dose-implanted $\mathrm{SnO}_{2} \mathrm{NW}$ sensor with an In-implanted depth of $\approx 10 \mathrm{~nm}$ is shown in Figure 27d-f. Notably, In diffused to certain depths in both cases. Consequently, a homo-core (the deeper region inside the $\mathrm{SnO}_{2} \mathrm{NWs}$ )-shell (implanted region) structure was developed due to implantation. The implanted gas sensors exhibited higher responses relative to those of the pristine sensor, and the sensor fabricated with a lower dose showed the highest response among the implanted sensors. The sensing mechanism of the $\mathrm{SnO}_{2}$ NWs was elucidated through a homo-C-S structure (Figure 28). For sensors implanted at low doses, $\mathrm{In}^{3+}$ species were deeply diffused into the $\mathrm{SnO}_{2} \mathrm{NWs}$, where the conduction channel of the $\mathrm{SnO}_{2} \mathrm{NWs}$ (highlighted in green) formed the core. In contrast, the In-implanted region (highlighted in yellow) formed the shell, which consisted of fewer electrons. Accordingly, the electrons traveled from the core region to the shell region, and two additional electron depletion layers were formed at the interface between the $\mathrm{SnO}_{2}$ conduction channel and the implanted area. Consequently, various sources of resistance modulation were established, and a significant resistance modulation was observed when exposed to $\mathrm{NO}_{2}$ gas. For the sensors implanted at higher doses, the electrons in the core $\mathrm{SnO}_{2}$ region did not flow toward the shell layer as the shell region had many free electrons; accordingly, the electron depletion layers were not formed between $\mathrm{In}^{3+}$ and the $\mathrm{SnO}_{2}$ conduction channel interfaces. Thus, there were few adsorbed oxygen ions at the sensor surface, which affected the sensor response.
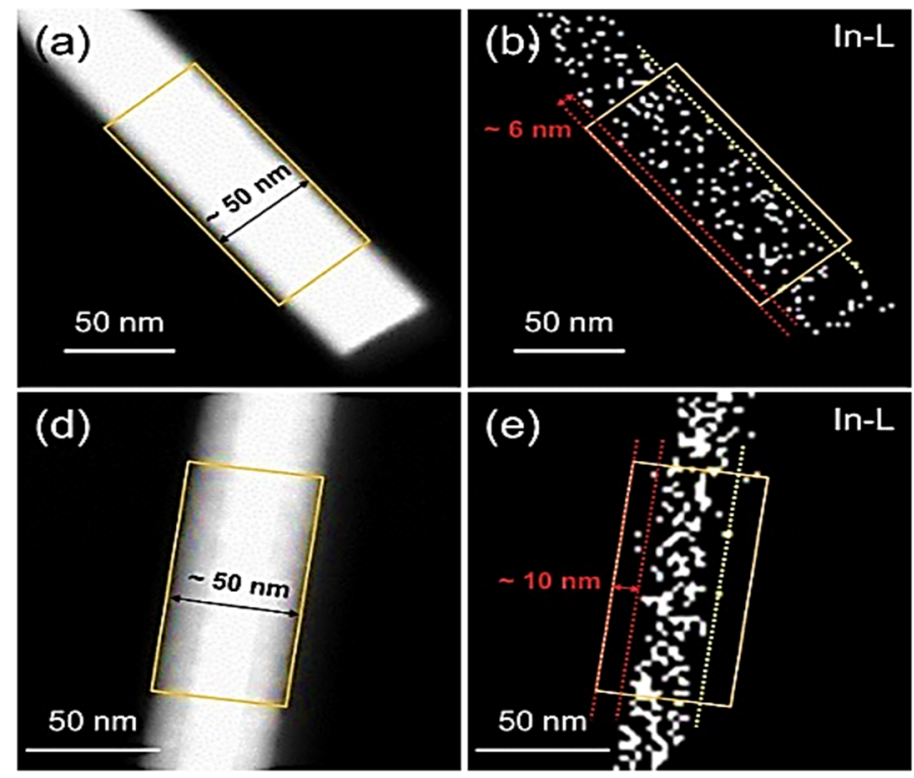
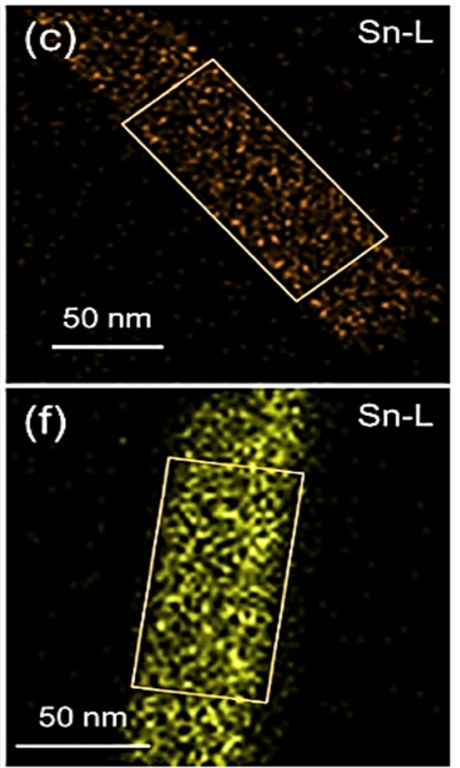

Figure 27. EDS color mapping images showing distribution of In and Sn elements of In-implanted $\mathrm{SnO}_{2}$ NWs at a dose of $(\mathbf{a}-\mathbf{c}) 2 \times 10^{14} \mathrm{ion} / \mathrm{cm}^{2}$ and $(\mathbf{d}-\mathbf{f}) 1.8 \times 10^{15} \mathrm{ion} / \mathrm{cm}^{2}$ Reproduced from [136] with the permission of Elsevier. 


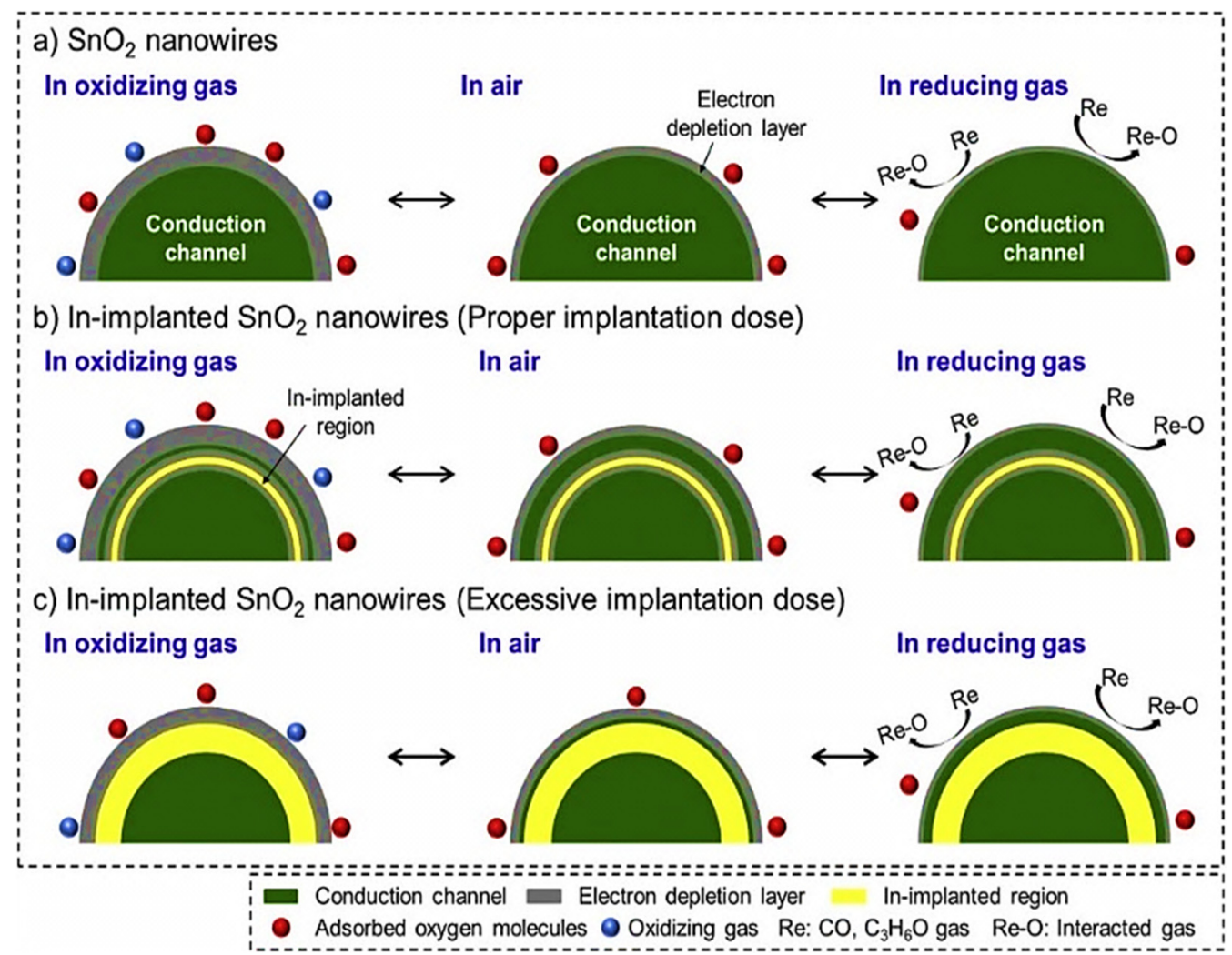

Figure 28. Schematic of the gas-sensing mechanisms of (a) $\mathrm{SnO}_{2} \mathrm{NWs}$ without implantation and Inimplanted $\mathrm{SnO}_{2}$ NWs with (b) optimal and (c) excessive implantation doses. Reproduced from [136] with the permission of Elsevier.

\section{Flexible Gas Sensors}

Considering the types of substrates utilized in gas sensor fabrication, the gas sensors are divided into flexible and non-flexible (rigid) sensors. Non-flexible sensors are fabricated on rigid substrates. A gas sensor should be flexible in the terms of mechanical deformations and have properties that make it suitable for wear. Flexible gas sensors are fabricated on flexible substrates, and their properties should not significantly change upon titling, stretching, and bending [137]. Flexible gas sensors with low cost, low weight, high stretchability, high flexibility, and high conformability may provide a good platform for wearable gas sensors and are important for ambient atmosphere monitoring at room temperature [138-140]. Various flexible substrates such as polyethylene terephthalate (PET) [141], polyimide (PI) [142], and Kapton [143] can be used for the fabrication of wearable sensors. An ideal smart sensor capable of being integrated into electronics should have properties such as (i) flexibility and transparency, (ii) room temperature operation, (iii) rapid response/recovery, (iv) low detection limit, high sensitivity, low cost, and eco-friendliness [144].

The selection of the flexible substrate and sensing material is the main challenge faced in developing a flexible gas-sensing platform. Some sensing layers may crack or separate from the substrate when strained [145]. An overview of some of the most relevant research articles based on flexible gas sensors published by various Korean research groups in recent years is included below. Two-dimensional TMDs are among the most suitable materials for the realization of flexible sensors [146]. Kim et al. [107] reported the CO gas-sensing properties of pristine and Au-functionalized (UV-irradiated for $15 \mathrm{~s}$ ) $\mathrm{WS}_{2}$ nanoflakes on flexible PI substrates under self-heating conditions. Au-decorated $\mathrm{WS}_{2}$ nanoflakes demonstrated outstanding CO selectivity and excellent flexibility (Figure 29). 
(a)

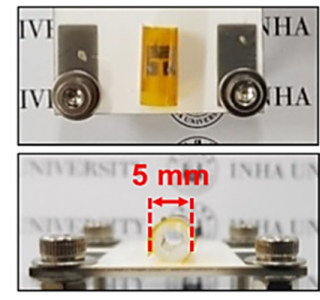

(b) Bending test

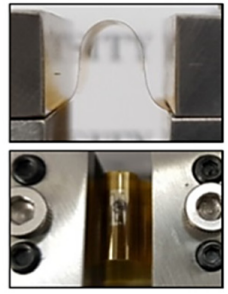

(c) Stretching test

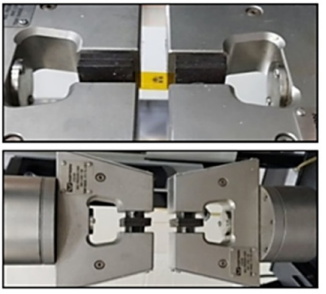

(d) Tilting test

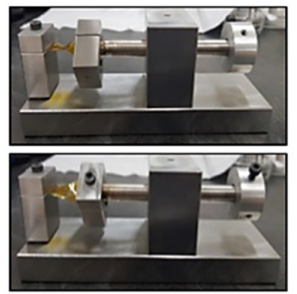

Figure 29. Digital photographs showing the (a) radius of curvature, (b) bending test, (c) stretching tests, and (d) tilting test. Reproduced from [107] with the permission of Elsevier.

Figure 30a-d show different states such as bending and stretching, in which the sensor on the PI substrate is tested under an applied voltage of $2 \mathrm{~V}$ for a response toward the $\mathrm{CO}$ gas. The sensor response was almost unaffected even after bending 1000 times.
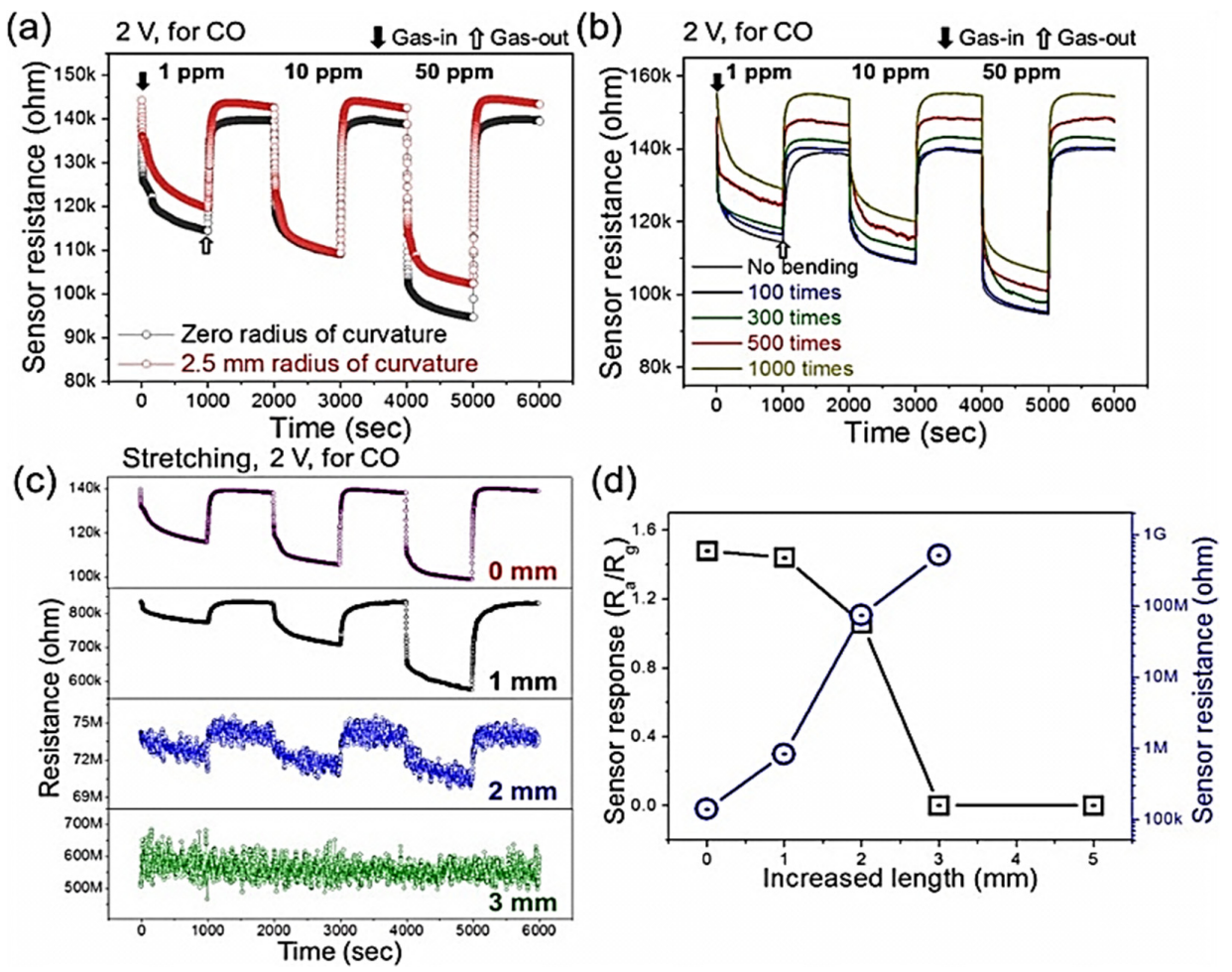

Figure 30. Curves showing resistance as a function of time for the sensor based on Au-functionalized $\mathrm{WS}_{2}$ for response toward $50 \mathrm{ppm} \mathrm{CO}$ at $2 \mathrm{~V}$ without bending and with bending at the radii of curvature of (a) $2.5 \mathrm{~mm}$ and (b) $4 \mathrm{~mm}$ for several bending cycles. (c) Resistance curves of the sensor with Au-functionalized $\mathrm{WS}_{2}$ nanoflakes stretched for different lengths. (d) Response and resistance of $\mathrm{Au}-\mathrm{WS}_{2}$ gas sensor (irradiated for $15 \mathrm{~s}$ ) with increased length (toward 50 ppm CO gas at $2 \mathrm{~V}$ ). All the gas-sensing tests were performed at room temperature $\left(25^{\circ} \mathrm{C}\right)$. Reproduced from [107] with the permission of Elsevier.

The gas responses at 1, 10, and 50 ppm levels of $\mathrm{CO}$ after bending 1000 times were $1.202,1.290$, and 1.463, respectively, indicating good flexibility, stability, and repeatability of the developed sensor. It was concluded that the sensor could be operated under bending and stretching conditions, demonstrating its high flexibility for practical applications.

In a different study, Kim et al. [109] reported the CO gas-sensing properties of $\mathrm{Au}$ $\mathrm{SnO}_{2}$-co-decorated $\mathrm{WS}_{2}$ nanosheets, where the maximum response of 3.687 was observed for 50 ppm $\mathrm{CO}$ at $4.7 \mathrm{~V}$. Digital photographs of $\mathrm{Au}-\mathrm{SnO}_{2}$-co-decorated $\mathrm{WS}_{2} \mathrm{NS}$ sensor under bending, tilting, and stretching conditions are shown in Figure 31. Gas detection 
tests were performed under various mechanical conditions to confirm the flexibility of the designed gas sensor. As shown in Figure 32a-f, the optimized gas sensor shows excellent flexibility upon tilting, bending, and stretching. Even after 10,000 bending cycles, tilting 10,000 times, and stretching up to $1 \mathrm{~mm}$, the performance of the gas sensor did not change, confirming the high flexibility of the sensor owing to the use of a PI substrate and the $2 D$ structure of the sensing layer.

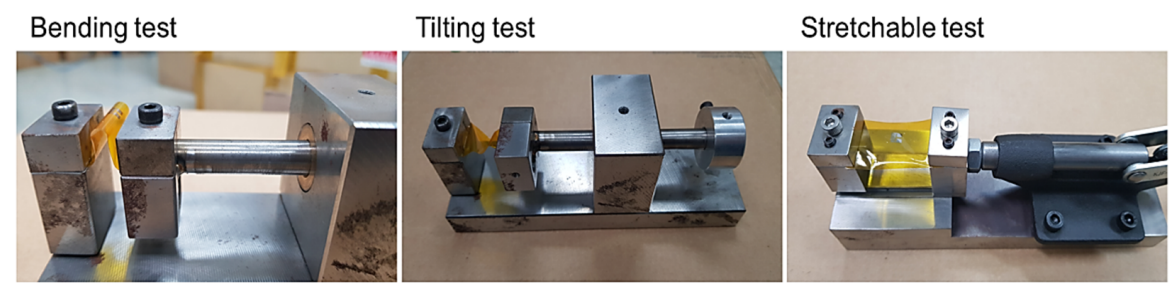

Figure 31. Digital photographs of the Au-SnO 2 -co-decorated $\mathrm{WS}_{2} \mathrm{NS}$ sensor upon bending, tilting, and stretching. Reproduced from [109] with the permission of Elsevier.

(a) Bending test

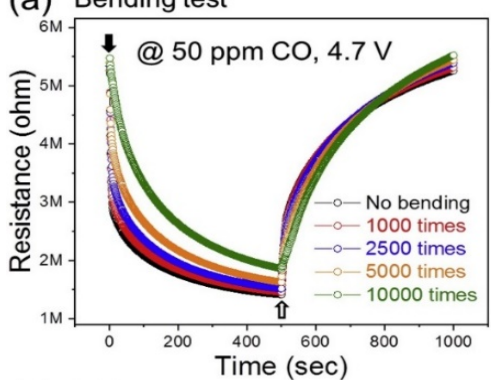

(c) Tilting test

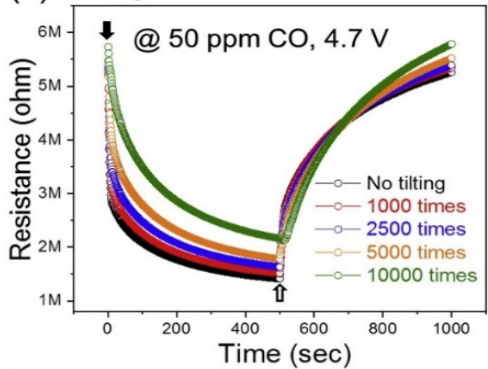

(e) Stretchable test

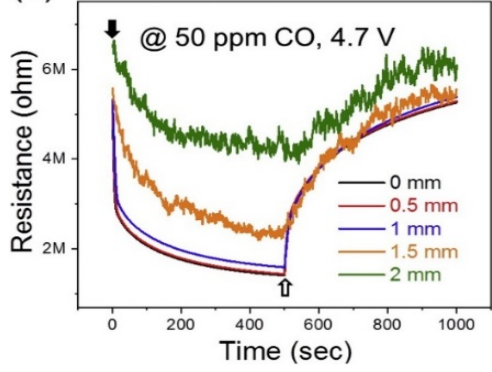

(b)

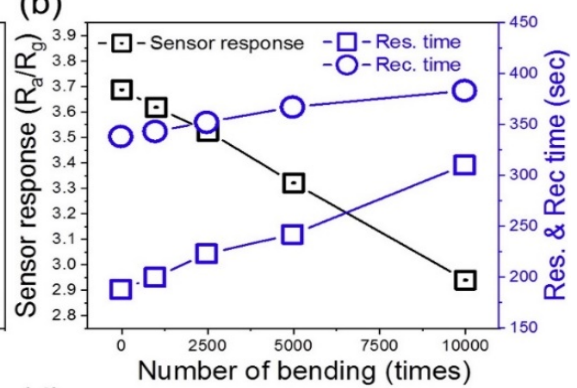

(d)
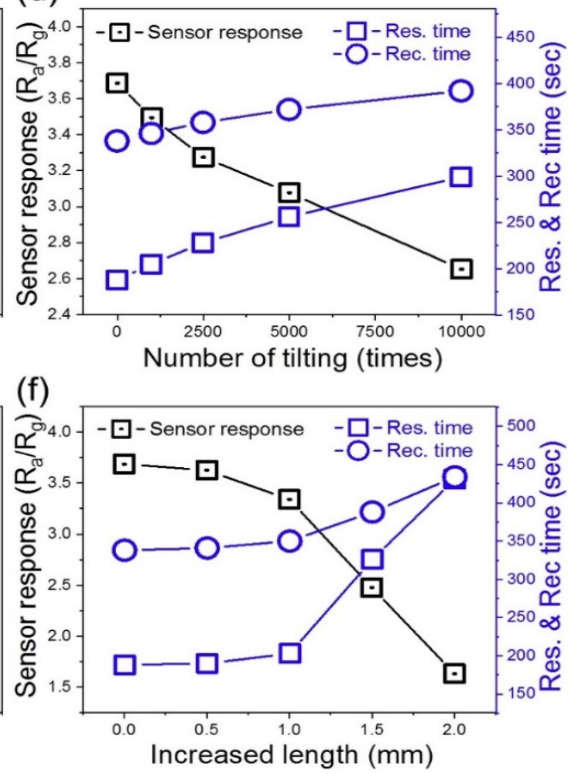

Figure 32. (a) Resistance plot of $\mathrm{Au}-\mathrm{SnO}_{2}$ co-decorated $\mathrm{WS}_{2}$ sensor for response to $50 \mathrm{ppm} \mathrm{CO}$ gas upon 10,000 bending cycles. (b) Corresponding response of the sensor and response/recovery times upon variation in the number of bending cycles. (c) Resistance plot of the sensor based on $\mathrm{Au}-\mathrm{SnO}_{2}$ co-decorated $\mathrm{WS}_{2} \mathrm{NS}$ upon exposure to $50 \mathrm{ppm} \mathrm{CO}$ gas with different tilting cycles. (d) Corresponding response of the sensor and response/recovery time as a function of a change in the number of tilting cycles. (e) Resistance plots of the $\mathrm{Au}-\mathrm{SnO}_{2}$ co-decorated $\mathrm{WS}_{2}$ sensor considering its response to $50 \mathrm{ppm} \mathrm{CO}$ gas with variation of the stretching amount. (f) Equivalent sensor parameters as a function of increased length. All the sensing tests were performed at room temperature $\left(24^{\circ} \mathrm{C}\right)$. Reproduced from [109] with the permission of Elsevier. 
rGO affords various advantages such as excellent electrical conductivity, high mechanical flexibility, high chemical and thermal stability, and low weight. Park et al. [147] developed a flexible $\mathrm{NO}_{2}$-gas-sensor-based $\mathrm{rGO}$ nanofibrous mesh fabric. Figure 33 shows a schematic illustration of the synthesis. At room temperature, the absolute response values were $\approx 23.9 \%$ toward $8 \mathrm{ppm} \mathrm{NO} \mathrm{NO}_{2}$ gas for the flat gas sensor and $26.5 \%$ for the bent RGONMF gas sensor. This result showed that the sensor performance well at an extreme radius of curvature $(R=1.0 \mathrm{~mm})$.
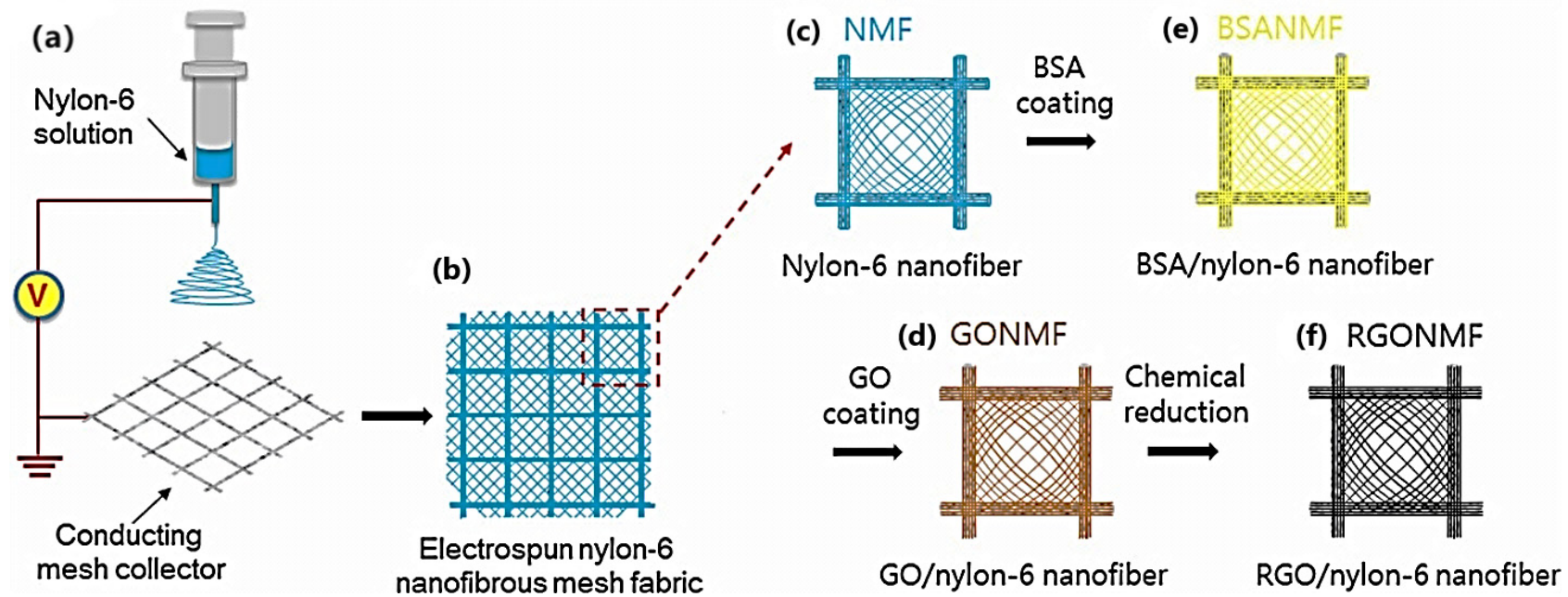

Figure 33. Schematic of the preparation of RGO/nylon-6 nanofiber. (a) electrospinning of nylon-6 solution (b) electrospun nylon-6 fabric (c) nylon-6 nanofiber (d) BSA-nylon-6 nanofiber (e) GO coating (f) RGO-nylon-6 nanofiber. Reproduced from [147] with the permission of Elsevier.

Jang et al. [148] synthesized $\mathrm{TiO}_{2}$ nanotubes (TNTs) directly on titanium thin films deposited on plastic substrates. The fabricated gas sensor was used for CO-sensing applications. With a minimum bending radius of $6 \mathrm{~mm}$, the gas sensor showed no electrical failure or repetitive bending deformation for up to 20 cycles, demonstrating the high flexibility and stability of the gas sensor. $\mathrm{Yi}$ et al. [149] prepared vertically aligned $\mathrm{ZnO}$ nanorods and graphene hybrid architectures for the realization of flexible and highly sensitive $\mathrm{C}_{2} \mathrm{H}_{5} \mathrm{OH}$ gas sensors. Repeated bending-unbending cyclic experiments confirmed that the sensor resistance changed by $\approx 0.2 \pm 0.01 \%$ upon bending the substrate to a radius of curvature of $<0.8 \mathrm{~cm}$. Furthermore, sensor resistance fully recovered to its original value when the substrate returned to its release state after 100 cycles. Uddin et al. [150] fabricated a flexible $\mathrm{C}_{2} \mathrm{H}_{2}$ sensor for the first time (Figure 34). Ag-loaded vertical $\mathrm{ZnO}$ NRs $(6,8$, and $10 \mathrm{~s}$ ) were synthesized by the hydrothermal RF magnetron sputtering method.
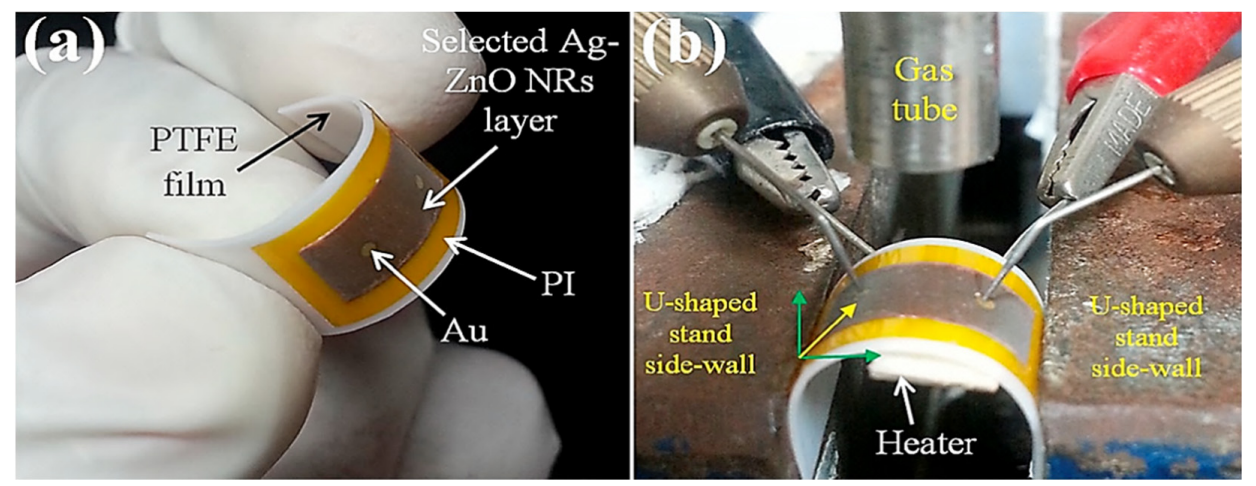

Figure 34. Optical images of (a) flexible ZnO NRs gas sensor and (b) experimental setup at specific bending angles. Reproduced from [150] with the permission of Elsevier. 
To investigate mechanical flexibility, bending tests were performed for the fabricated sensors at various curvature angles ranging from $0^{\circ}$ to $90^{\circ}$ using a U-shaped support stand for different $\mathrm{C}_{2} \mathrm{H}_{2}$ concentrations at $200{ }^{\circ} \mathrm{C}$. With an increase in bending, the strain between the PI substrate and sensing layer resulted in a minor change in the surface resistance. The initial response magnitudes (unbent or $\theta_{c}=0^{\circ}$ ) for $100 \mathrm{ppm} \mathrm{C}_{2} \mathrm{H}_{2}$ were 9.33, 13.8, and 9.57 for the 6, 8, and $10 \mathrm{~s}$ Ag-loaded sensor, respectively. The response magnitudes of all samples were retained without a significant degradation up to a bending angle of $\theta_{c}=30^{\circ}$ (bending radius of $\approx 12 \mathrm{~mm}$ ). With an increase in the bending angle, the sensor exhibited a negligible response decrease of $1.3 \%$ for $\theta_{c}=45^{\circ}, 1.7 \%$ for $\theta_{c}=60^{\circ}$, and $2.1 \%$ for $\theta_{c}=90^{\circ}$, which was because of the low binding energy and low charge transfer between the strained sensing layer atoms and target gas molecules at large bending angles. Moreover, for a large bending state, the ohmic contact distance increased, resulting in a slight increase in resistance and a low drop in the response value. Kang et al. [151] developed a flexible gas sensor based on the $2 \mathrm{D}$ layer assembly of Pt-ZnO NPs on $\mathrm{rGO}$ for $\mathrm{NO}_{2}$ gas sensing. To demonstrate its stable and reliable operation as a wearable sensor, the $\mathrm{NO}_{2}$-sensing characteristics of the sensors were investigated upon the application of external mechanical stress. Therefore, mechanical bending tests were performed directly on the flexible sensor on the PI substrate. The dynamic resistance curves obtained during 450 bending cycles were evaluated, with each cycle having a bending angle of $90^{\circ}$. Interestingly, a stable baseline resistance was observed with a negligible resistance drift (1.73\% increase) even after 450 bending cycles. The scattered resistances in the first 50 bending cycles were mainly owing to the stabilization of the mechanical stress and partial detachment of the drop-coated sensing layer. The synthesis of perovskite oxides such as $\mathrm{SrTiO}_{3}$ requires long calcination at elevated temperatures, which limits their application to flexible electronics. Duy et al. [152] reported an effective laser-assisted sol-gel method to obtain $\mathrm{SrTiO}_{3} \mathrm{NPs}_{\text {in }}$ selective areas on PI substrates. The violet laser power was only $1 \mathrm{~W}$ but was sufficient to crystallize the material in a short period (a few seconds). The authors used it together with the CNTs to detect changes in humidity at room temperature. The sensor in the resistive mode with a lower power usage (approximately $0.2 \mu \mathrm{W}$ ) was used for the long-term monitoring of humidity of $\geq 2 \% \mathrm{RH}$. The performance of the flexible sensor was maintained after 5000 bending cycles at a $1.5 \mathrm{~cm}$ radius.

In another study, Kim et al. [153] used micropatternable double-faced ZnO NFs for the realization of flexible gas sensors on a PI substrate with SWCNTs as the electrode. The response of the sensor to $500 \mathrm{ppm} \mathrm{NO}$ at $270{ }^{\circ} \mathrm{C}$ increased from 202.2 to 297.6 after 10,000 cycles. Moreover, the characteristic times improved. The response and recovery times decreased from 36.0 to $19.2 \mathrm{~s}$ and 20.3 to $11.5 \mathrm{~s}$, respectively. Furthermore, the recovery increased from $89.4 \%$ to $94.8 \%$. Overall, the characteristics of the gas sensor improved with an increase in the number of bending cycles from 0 to 10,000. However, despite an increase in the numerical values during the evaluation of sensor characteristics, the resistance gradually increased under the same conditions, with significant fluctuations. This behavior indicated the deterioration of the sensor. After flexibility tests comprising 10,000 cycles, the NRs appeared bent, indicating that a constant strain was applied to the NRs during the repetitive flexibility test. Due to repetitive strain, the breakaway of the NRs from the shells occurred, and this was the first sign of device failure. In contrast, the shells appeared to maintain their structures, and cracked shells were rarely observed. In addition, Kim et al. [154] used 2D $\mathrm{MoS}_{2}$ on a plastic substrate to realize a flexible gas sensor for the detection of $\mathrm{NO}_{2}$ and $\mathrm{NH}_{3}$ gases. The flexibility of the $\mathrm{MoS}_{2}$-based gas sensor was evaluated after 2000, 4000, and 6000 bending cycles. The gas responses of the flexible gas sensors were maintained without any significant degradation and even showed some enhancement. This increased response at less than 4000 bending cycles was likely attributed to the formation of microcracks induced by the strain generated during the bending test. Microcracks and defects created more edge sites than those present in the initial $2 \mathrm{D} \mathrm{MoS}_{2}$, which led to increased gas adsorption. 


\section{Other Resistive-Based Gas Sensors (Glass/Silicon/MOF-Based Gas Sensors)}

In addition to the above-mentioned strategies, other types of chemiresistive gassensing devices, such as glass, silicon, and MOF-based gas sensors, have been investigated by the Korean groups in the past few years. In the following section, some of the key research papers on glass-, silicon-, and MOF-based gas sensors are reviewed.

\subsection{Glass Gas Sensors}

Glass is a cheap material and can be modified via simple procedures. In addition, glass can be simultaneously used as a substrate and detecting layer [155]. However, there are limited studies on the use of glass as a sensing material. To employ its sensing characteristics, glass should be significantly enriched with alkalis. As the sensing response includes diffusion, the operating temperature can be decreased by the increased doping of mobile Li instead of Na. The polarization of glass is essential and should be performed prior to the sensing test. The polarization voltage can be calibrated to ensure that the accumulated charge is accurately determined prior to sensing. This allows the baseline current to be set to zero, thereby significantly increasing the resistance-based sensing response. To ensure long-term stability, it is necessary to re-polarize the glass once the basement current drifts below zero [156]. The origin of the gas-sensing mechanism is different from the mechanism used to detect metal oxides, which is attributed to the development and thickness of either an electron depletion layer or an HAL in the $n$ - and $p$-type metal oxides, respectively. In the case of a soda-lime glass gas sensor, the primary detection mechanism is the development of surface impurity phases when the glass sensor is exposed to target gases [156,157]. Sophia et al. [156] reported that soda-lime glass is an active electrochemical material with significant gas detection characteristics toward various oxidizing and reducing gases such as $\mathrm{NO}_{2}, \mathrm{C}_{6} \mathrm{H}_{6}, \mathrm{C}_{6} \mathrm{H}_{12}$, and $\mathrm{CO}$ at high temperatures $\left(300-500{ }^{\circ} \mathrm{C}\right)$. A chemically inert $\mathrm{CO}_{2}$ gas was also detected at a $1 \mathrm{~V}$ DC bias.

Alkali ions doped into the silica glass matrix were positively charged, and as a result, these were sensitive to the electric field. Alkali ions were compensated by the less mobile, negatively charged, and non-bridging oxygen units. By providing sufficient ionic mobility via thermal activation, the cations could be rearranged under an external electric field by setting a concentration gradient responsible for the macroscopic polarization of glass (Figure 35a). Once the interdigitated metal electrodes were deposited onto the sodalime glass slides (Figure 35c), an electrochemical cell could be created where the glass slide acted as an electrolyte because of its high ionic conductivity. The corresponding schematic of an electrochemical cell (Randles circuit) constituted a parallel combination of a double-layer capacitor $C$ and resistor $R_{2}$, which were connected in series to resistor $R_{1}$ (Figure 35d). When the soda-lime sample was electrically coupled to the DC voltage source, the external electric field induced the redistribution of $\mathrm{Na}^{+}$(Figure $35 \mathrm{~b}$ ), thereby charging capacitor $\mathrm{C}$. The electrochemical cell was completely charged, and the current attained its asymptotic minimum within an infinite time limit. As the target gas entered the air, its surface phase composition could be modified through the development of carbonates and/or hydroxides of the alkali elements, resulting in a change in the dielectric characteristics. Furthermore, $\mathrm{Na}_{2} \mathrm{CO}_{3}$ formation as a chemical reaction product between $\mathrm{Na}^{+}$and atmospheric $\mathrm{CO}_{2}$ could passivate the charged $\mathrm{Na}^{+}$species, thereby decreasing the electric charge of the polarized soda-lime glass sample because of the greater content of the reactive alkali ions near the cathode. Additional phases of impurities such as $\mathrm{NaNO}_{3}$ and $\mathrm{NaOH}$ could also form due to the reaction of glass with other gases $\left(\mathrm{NO}_{2}\right.$ and $\left.\mathrm{H}_{2} \mathrm{O}\right)$. Furthermore, the variation in the oxygen concentration could change the concentration of non-bridging oxygen units, which changed the concentration of compensated $\mathrm{Na}^{+}$species, thereby changing the accumulated charge. Notably, both the changes in the dielectric constant and passivation of $\mathrm{Na}^{+}$were attributable to the development of impurity phases, indicating the total current recorded throughout the sensing tests, which was dependent on the accumulated charge and capacitance. Similarly, the phases of impurities could also alter the conductivity of the soda-lime glass by decreasing the diffusion of $\mathrm{Na}^{+}$or 
because of the development of free conducting electrons/holes. These effects afforded a chemiresistive gas-sensing response and the development of surface impurity phases when exposed to target gases, which was the primary reason for the gas-sensing characteristics of soda-lime glass.
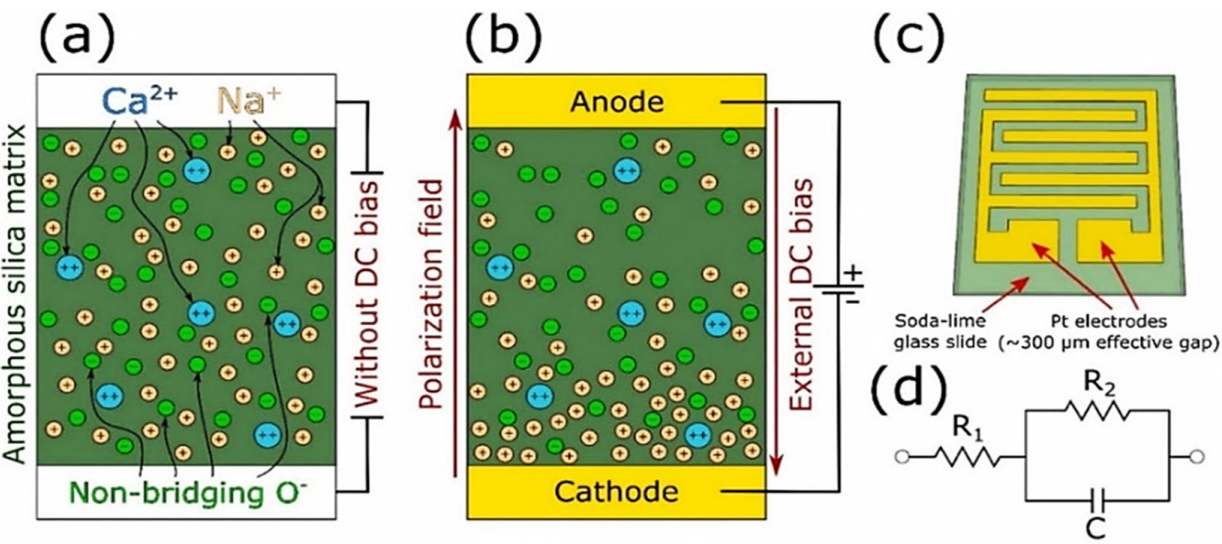

Figure 35. Schematic of the structures of (a) unbiased and (b) DC-biased soda-lime glass, (c) testing device design, and (d) the corresponding structure of an electrochemical cell (Randles circuit). Reproduced from [156] with the permission of Elsevier.

In another study, Kim et al. [157] described the gas-sensing characteristics of Pd-, Pt-, and Au-functionalized glass sensors. In this study, Pd, Pt, and $\mathrm{Au}$ functionalization revealed high selectivity toward $\mathrm{C}_{6} \mathrm{H}_{6}, \mathrm{C}_{7} \mathrm{H}_{8}$, and $\mathrm{CO}$ gases, respectively. The response $\left(I_{g} / I_{a}\right)$ of $\mathrm{Pd}-$, $\mathrm{Pt}-$, and $\mathrm{Au}$-functionalized glass sensors toward $\mathrm{C}_{6} \mathrm{H}_{6}(10 \mathrm{ppm}), \mathrm{C}_{7} \mathrm{H}_{8}(10 \mathrm{ppm})$, and $\mathrm{CO}$ (500 ppm) gases was 5, 2.5, and 1.3, respectively. A schematic of a glass sensor with various ions is shown in Figure 36a. Generally, positively charged alkali ions are doped into the silica glass matrix and electrically compensated through negatively charged non-bridging oxygens with significantly low mobility. During thermal activation that was achieved via the sensing temperature, cations could show adequate mobility and reorganize themselves under the effect of a large external electric field. This resulted in a cationic concentration gradient that was responsible for the macroscopic polarization of glass. A glass gas sensor with metallic electrodes could be considered as an electrochemical cell in which the glass slide with high ionic conductivity acted as an electrolyte. $\mathrm{Na}^{+}$with high mobility were redistributed via the effect of an external electric field, thereby charging the capacitor. Then, the total current attained its minimum value. By injecting the target gas into the gas chamber, the electrical properties of the glass sensor could be favorably modified owing to changes in its surface composition due to carbonate formation and mobile cation hydroxides. Since the dielectric properties of silica glasses depend on its surface composition, they could be modified with the development of surface impurity phases. Owing to the high alkaline ion concentration near the cathode, the chemical reactions between $\mathrm{Na}^{+}$and target gases formed compounds that could passivate $\mathrm{Na}^{+}$species, thereby decreasing the polarization of the soda-lime glass gas sensor; this phenomenon increased the overall current. Phases of impurities, such as $\mathrm{NaCO}$ and $\mathrm{NaC}_{\mathrm{x}} \mathrm{H}_{\mathrm{y}}$, could develop due to the reaction of $\mathrm{Na}^{+}$with $\mathrm{CO}, \mathrm{C}_{6} \mathrm{H}_{6}$, and $\mathrm{C}_{7} \mathrm{H}_{8}$ gases. In addition, impurities could affect the conductivity of the soda-lime glass sensor by decreasing the diffusivity of $\mathrm{Na}^{+}$or hampering the development of free electrons, which could result in a resistive-gas sensing response. In noble-metalfunctionalized gas sensors, noble metals may act as catalysts for the decomposition of target gases (Figure 36b). Owing to the catalytic activities of noble metals, many decomposed target gases could reach the glass sensor surfaces, resulting in a high response toward a specific target gas. As each metal preferred to attract a specific gas, the metal catalyst promoted selective sensing. 

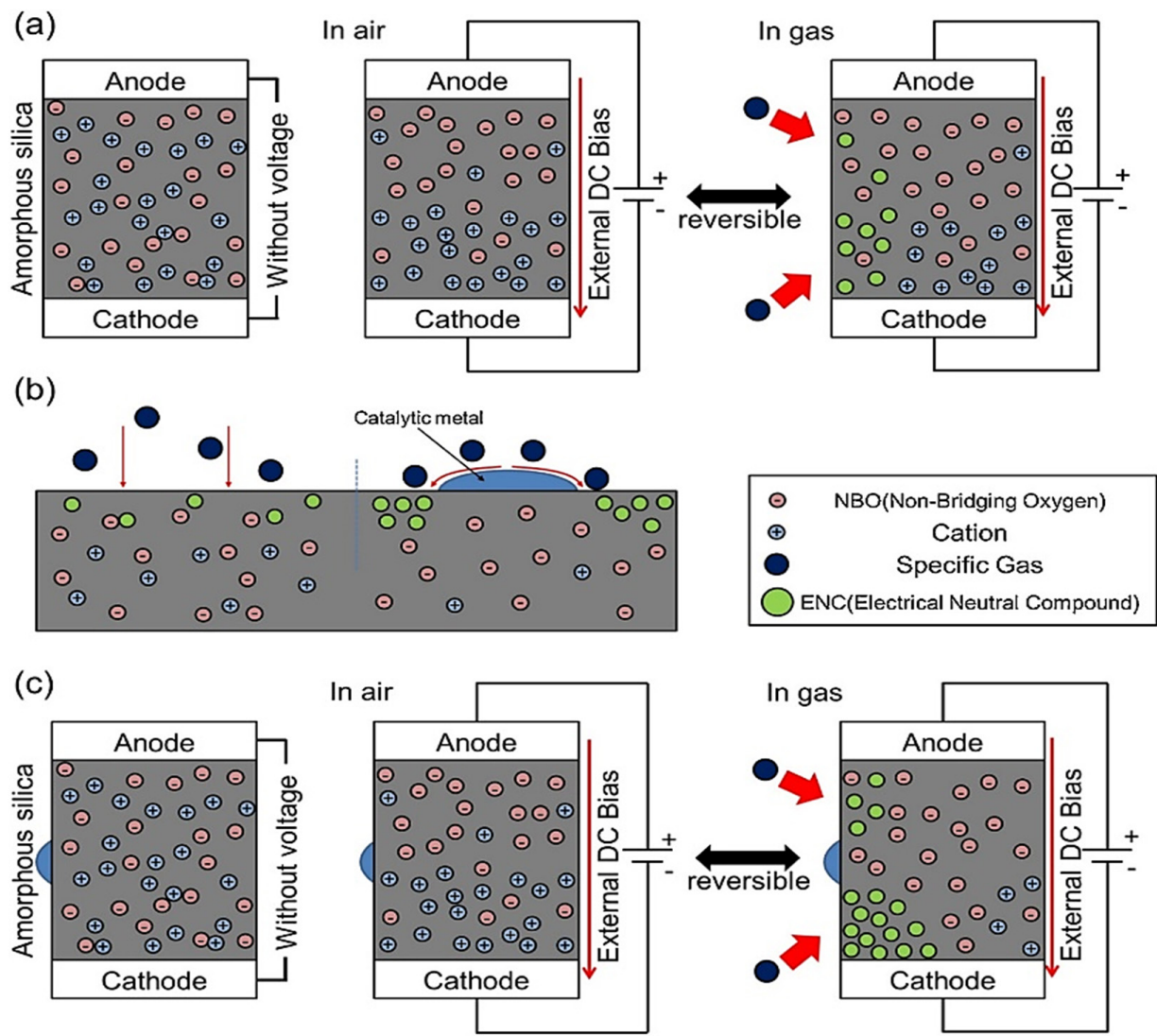

Figure 36. Schematic demonstrating the detection mechanism of noble-metal-functionalized sodalime glass. (a) Reversible change in soda-lime glass upon the introduction and removal of target gas. (b) Spillover effect due to metal functionalization. (c) Reversible change in the metal-functionalized soda-lime glass by the introduction and removal of the target gas. Reproduced from [157] with the permission of Elsevier.

Kim et al. [158] investigated a Pd-functionalized soda-lime glass sensor using machine learning algorithms to accurately identify the $\mathrm{VOC}\left(\mathrm{C}_{2} \mathrm{H}_{5} \mathrm{OH}, \mathrm{CH}_{3} \mathrm{COCH}_{3}, \mathrm{C}_{6} \mathrm{H}_{6}\right.$, and $\mathrm{C}_{7} \mathrm{H}_{8}$ ) and estimate the VOC concentrations. Pd played a catalytic role in facilitating the decomposition of target gas molecules and producing the spillover effect, leading to more surface reactions. To overcome the main limitation of this type of sensor (lack of selectivity due to the one-dimensional output signal), a new approach was applied, which merged the sensor response values at different working temperatures. The responses obtained at five different temperatures $\left(300-500^{\circ} \mathrm{C}\right)$ that were combined into five-dimensional points were analyzed using a support vector machine. After calibration using a training dataset, the detection system could accurately identify the gas and estimate its concentration. The results showed that the sensing system afforded accurate classification $(100 \%)$ and a good estimation of the concentrations of the tested gases (average error of $<19 \%$ in the $1-30 \mathrm{ppm}$ range). Therefore, using this approach (different temperatures and machine learning), a single resistive sensor made of glass could achieve good selectivity and accurate quantification while retaining features such as simplicity, smaller size, and lower cost compared to those of an electronic nose.

\subsection{Si-Based Gas Sensors}

A large amount of $\mathrm{Si}$ is present on Earth. It is highly stable, non-toxic, has high carrier mobility, and allows the use of automatized manufacturing methods. The Si NWs affords a large surface area-to-volume ratio, relative ease of fabrication, the possibility of functionalization, and environmentally friendly properties, which are beneficial for gassensing studies [159-162]. Mirzaei et al. [163] reported a novel top electrode configuration 
for vertically aligned silicon NWs synthesized via metal-assisted chemical etching (MACE) using $\mathrm{Ag}$ as the catalyst for $\mathrm{H}_{2}$ gas sensing. The sensor showed a response of 17.1 to $100 \mathrm{ppm} \mathrm{H}_{2}$ gas at $100{ }^{\circ} \mathrm{C}$. In MACE, which is an electrodeless chemical reaction, the shapes and pathways of the noble metal NPs determine the final morphology of silicon. If the noble metal NPs form a continuous porous nanometer-scale thin film on the Si substrate, Si NWs can be successfully obtained [164]. After immersion of the Si substrate in the $\mathrm{HF} / \mathrm{AgNO}$ solution, the $\mathrm{Ag}^{+}$species captured electrons from $\mathrm{Si}$, resulting in the Ag nucleation. As the reaction progressed, the nucleated Ag gradually grew into Ag NPs, and as Ag has a higher electronegativity than $\mathrm{Si}$, Ag NPs directly captured electrons from Si and formed an accumulation of holes beneath the catalyst. Subsequently, the reduction of $\mathrm{H}_{2} \mathrm{O}_{2}$ occurred at the surfaces of the Ag NPs, and the holes were consumed by the oxidation of Si to silica, because of which HF was rapidly dissolved. The Ag NPs moved into the Si wafer with the dissolution of the silica layer; therefore, the depth of Ag NPs in the pits increased with an increase in the reaction time. Furthermore, during the MACE of Si, the reaction was highly anisotropic because the numbers of broken Si-Si bonds differed significantly in different directions [164,165]. The sensor exhibited a high response of 17.1 to $50 \mathrm{ppm}_{2}$ at $100{ }^{\circ} \mathrm{C}$. The high $\mathrm{H}_{2}$ selectivity of the $\mathrm{Si}$ NW sensor was associated with the high chemical reactivity of $\mathrm{H}_{2}$ and the lower bond energy of $\mathrm{H}-\mathrm{H}$ in comparison to those of other tested gas molecules. Furthermore, $\mathrm{H}_{2}$ easily decomposed at the sensing temperature.

Porous $\mathrm{Si}$ is a promising material for low-temperature gas-sensing applications [166]. Bang et al. [167] developed heterojunctions based on porous $\mathrm{Si}$ and $\mathrm{SnO}_{2} \mathrm{NWs}_{\text {for low- }}$ temperature $\left(100{ }^{\circ} \mathrm{C}\right) \mathrm{H}_{2} \mathrm{~S}$ gas-sensing applications. Porous $\mathrm{Si}$ was obtained from $p$-Si wafers via electrochemical etching, and a VLS route was employed for the synthesis of $\mathrm{SnO}_{2} \mathrm{NWs}$. The porous $\mathrm{Si} / \mathrm{SnO}_{2} \mathrm{NW}$ sensor showed better sensing properties toward $\mathrm{H}_{2} \mathrm{~S}$ than the porous $\mathrm{Si}$ sensor. The porous $\mathrm{Si} / \mathrm{SnO}_{2} \mathrm{NW}$ gas sensor showed a response of 3.2 to 50 ppm $\mathrm{H}_{2} \mathrm{~S}$ gas at $100{ }^{\circ} \mathrm{C}$. For heterojunctions made of porous $\mathrm{Si} / \mathrm{SnO}_{2} \mathrm{NWs}$, the available surface area for the adsorption of $\mathrm{H}_{2} \mathrm{~S}$ gas increased owing to the presence of $\mathrm{SnO}_{2} \mathrm{NWs}$, which eventually led to a higher sensing response. In addition, a potential barrier developed due to the transfer of electrons from $\mathrm{SnO}_{2}$ to $\mathrm{Si}$, as $p$-Si had a higher work function than $n-\mathrm{SnO}_{2}$. Accordingly, the HAL in Si was reversed to form a hole-depletion layer (HDL), and the original sensor resistance was enhanced owing to the main sensing currents flowing through the $p$-type porous Si structures. Thus, the initial hole conduction volume in porous $\mathrm{Si}$ decreased. In the $\mathrm{H}_{2} \mathrm{~S}$ gas atmosphere, the gas molecules removed holes from porous $\mathrm{Si}$, and the hole resistance increased. Additionally, for an insignificant initial hole conduction volume, the decrease in the hole concentration induced by $\mathrm{H}_{2} \mathrm{~S}$ gas led to a high response. Furthermore, crystallographic defects at the interfaces between $\mathrm{Si}$ and $\mathrm{SnO}_{2}$ were formed owing to the lattice mismatch between $\mathrm{Si}$ and $\mathrm{SnO}_{2}$. The dangling bonds and defects at the interfaces between $\mathrm{Si}$ and $\mathrm{SnO}_{2}$ afforded an improved response owing to the provision of preferred adsorption sites. The difference in the lattice constants of $\mathrm{Si}$ and $\mathrm{SnO}_{2}$ resulted in the formation of dangling bonds at the interfaces, resulting in more available adsorption sites and an improved gas response.

Lee et al. [168] investigated the $\mathrm{H}_{2}$-sensing properties of Pd-decorated Si nanohorns (NHs). Si-NHs were synthesized using a simple chemical etching method, which was followed by Pd decoration using a UV irradiation technique. The optimized gas sensor could detect as low as 0.1 ppm $\mathrm{H}_{2}$ gas. It showed a very high response of 2300 to $10 \mathrm{ppm}$ $\mathrm{H}_{2}$ gas at $400{ }^{\circ} \mathrm{C}$. When the sensor was exposed to air, a greater concentration of holes was observed at the surfaces of the Si-NHs. When the $\mathrm{Si} \mathrm{NH}$ sensor was exposed to $\mathrm{H}_{2}$, it reacted with the already adsorbed oxygen ions, resulting in the release of electrons and subsequent combination with holes, decreasing the hole concentration as well as the thickness of the HAL.

Figure 37a shows the sensing mechanism of the pristine Si NH gas sensor. For the Pd-decorated Si-NHs shown in Figure 37b, electrons flowed from Si to Pd upon intimate contact of Pd and Si in air. This led to the expansion of the HAL at the interfaces between $\mathrm{Pd}$ and $\mathrm{Si}$. In $\mathrm{H}_{2}$ atmosphere, the released electrons resulted in the narrowing of the HAL, 
thereby contributing to the sensing mechanism. Furthermore, the catalytic activity of Pd NPs increased the surface reaction rates by dissociating $\mathrm{H}_{2}$ into active hydrogen atoms $(\mathrm{H})$ and transporting atomic hydrogen to the Si NH surface. Consequently, in the presence of $\mathrm{Pd}$, atomic $\mathrm{H}$ could easily react with chemisorbed oxygen, leading to a high response to $\mathrm{H}_{2}$ gas. In addition, the kinetic diameter of $\mathrm{H}_{2}$ molecules $(2.9 \AA)$ was very small, resulting in diffusion to the deep parts of the gas sensor. In the case of $\mathrm{NO}_{2}$ gas, there were insufficient electrons for adsorption by $\mathrm{NO}_{2}$ gas due to the formation of $\mathrm{Pd} / \mathrm{Si}$ heterojunctions and the flow of electrons from $\mathrm{Si}$ to $\mathrm{Pd}$, resulting in a low response.

\section{(a) Bare Si NHs}

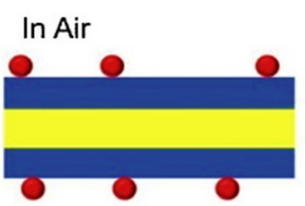

In $\mathrm{H}_{2}$

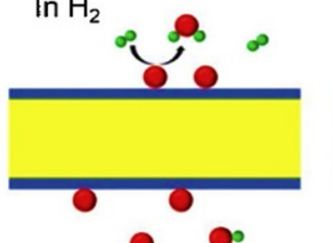

ค. $8^{\circ}$

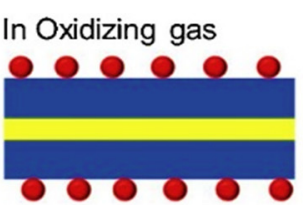

In Reducing gas

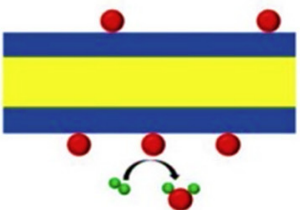

Hole Accumulation Layer

$\mathrm{O}^{2-} \odot \mathrm{H}_{2}$

\section{(b) Pd-decorated Si NHs}

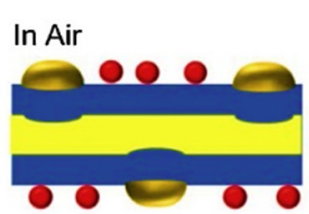

In Oxidizing gas

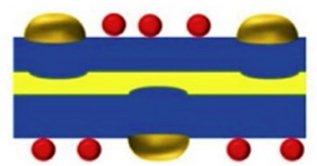

In Reducing gas
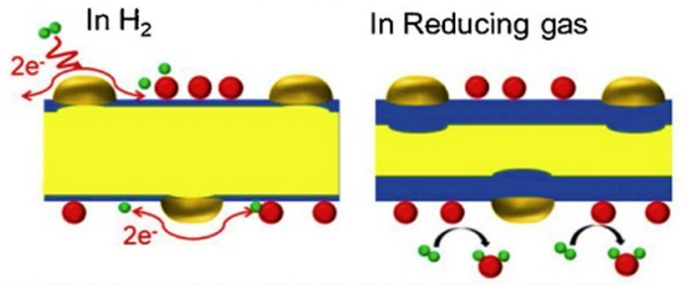

Electron Dominant Layer

$\mathrm{H}_{2} \mathrm{O}$

Pd

Figure 37. Schematics of the sensing mechanisms of (a) pristine Si-NHs and (b) Pd-decorated Si-NHs. Reproduced from [168] with the permission of Elsevier.

\subsection{Metal-Organic Framework (MOF)-Based Gas Sensors}

MOFs are a distinct type of emergent materials that can be produced by connecting metal centers with organic linkers [169]. Owing to their unique properties, such as high surface area, ready chemical modification, structural flexibility, and tunable pore size, these have attracted significant attention for different applications [170-172]. In particular, MOFs have been used for chemical sensors because of their unique porous morphology, which allows the adsorption and diffusion of target gaseous molecules [173]. Drobek et al. [174] described a general approach to enhance the selectivity of NW gas sensors to $\mathrm{H}_{2}$ gas based on the coverage of $\mathrm{ZnO} N W s$ with a thin zeolitic imidazolate framework (ZIF) and ZIF-8 molecular sieve membranes. ZIF structures are a subfamily of MOFs with ultra-high porosity, structural/chemical tunability, structural flexibility, and large core surface areas. The synthetic approach involved the ALD of $\mathrm{ZnO}$ thin films and their successive conversion into ZIF-8 using a 2-methylimidazole/methanol solution under solvothermal conditions. The methodology was based on the use of ZnO NWs as the only zinc source, which was then used to grow a thin layer of ZIF-8 onto the NW surfaces. This method allowed the uniform coverage of ZnO NWs with a ZIF-8 selective barrier (membrane) with ultra-high specific surface area and molecular sieving characteristics. Owing to the molecular sieving effect of the thin ZIF-8 membrane, the ZIF-8-encapsulated $\mathrm{ZnO} \mathrm{NW}$ sensor afforded significantly enhanced $\mathrm{H}_{2}$ selectivity in comparison to the sensor based on pristine $\mathrm{ZnO}$ NWs. The sensor showed a response of 1.44 to $50 \mathrm{ppm}_{2}$ gas at $300{ }^{\circ} \mathrm{C}$, which was higher than the response to $\mathrm{C}_{7} \mathrm{H}_{8}(\approx 1)$ and $\mathrm{C}_{6} \mathrm{H}_{6}(\approx 1)$ gases. The large porous structures of ZIFs improved species uptake (preconcentration), and the precise pore structures of MOFs allowed molecular sieving. Both these effects likely improved the sensitivity (preconcentration effect) and selectivity (size/shape exclusion effect). Drobek et al. [175] described the synthesis of a ZnO-based sensor coated with a SIM-1 (substituted imidazolate material-1) membrane layer. SIM-1 is a material that is isostructural with ZIF-8 
with a cage size of $\approx 0.8 \mathrm{~nm}$ and an expected pore aperture of $<0.34 \mathrm{~nm}[176,177]$. The $\mathrm{H}_{2}$ selective membrane of SIM-1 was used as an effective layer for molecular sieving. ZnO NWs with an optimized SIM-1 coating exhibited outstanding $\mathrm{H}_{2}$ selectivity at high temperatures $\left(300^{\circ} \mathrm{C}\right)$ when the interfering gases were present, confirming the effectiveness of these sensors in detecting $\mathrm{H}_{2}$. It showed a response of 2.6 to $50 \mathrm{ppm}_{2}$ gas at $300{ }^{\circ} \mathrm{C}$, with almost no response to interfering gases. As the SIM-1 membrane did not exhibit semiconducting properties and simply acted as a molecular sieve to block the transportation of interference gases, $\mathrm{ZnO} \mathrm{NWs}$ were responsible for the electron transport channels.

Weber et al. [178] built upon the previous studies by fabricating $\mathrm{H}_{2}$ gas sensors with improved sensitivity and outstanding selectivity using a combination of ZnO NWs decorated with Pd NPs and ZIF-8 as a molecular sieve. Three stages were involved in the fabrication of the desired materials: (i) growth of $\mathrm{ZnO} \mathrm{NWs}$ via the VLS process, (ii) decoration of Pd by ALD, and (iii) partial solvothermal conversion of the tuned NW surface into the ZIF-8 nanomembrane. The Pd NPs improved the $\mathrm{H}_{2}$ sensitivity, and the ZIF-8 overcoat enhanced the sensor selectivity. The sensor showed a response value of 9 to $50 \mathrm{ppm} \mathrm{H}_{2}$ gas at $200{ }^{\circ} \mathrm{C}$. Gases with higher kinetic diameters than ZIF-8 windows cannot pass through and reach the surface of the metal-oxide. Therefore, interfering gas molecules (all greater than $\mathrm{H}_{2}$ ) could not pass through the ZIF-8 overcoat, and no response signal was obtained from the sensor. Owing to the presence of a molecular sieve membrane, the $\mathrm{H}_{2}$ gas molecules reached the sensor surface. The diffusion of $\mathrm{H}_{2}$ by the ultra-microporous ZIF-8 network involves a thermally activated transport mechanism, which is promising for the design of a sensitive and selective high-temperature $\left(200-300{ }^{\circ} \mathrm{C}\right) \mathrm{H}_{2}$ sensor. Owing to the existence of Pd NPs, the depth of the depletion layer of electrons increased at the contact area between $\mathrm{Pd}$ and $\mathrm{ZnO}$, which resulted in a higher resistance of the $\mathrm{Pd} / \mathrm{ZnO}$ $\mathrm{NW}$ sensor in comparison to that of the sensor based on pure $\mathrm{ZnO} \mathrm{NWs}$. When exposed to $\mathrm{H}_{2}$ gas, $\mathrm{Pd}$ was converted into $\mathrm{PdH}_{\mathrm{x}}$, and a part of the $\mathrm{ZnO}$ (surface) was transformed into metallic Zn. Both mechanisms afforded high conductivities, thereby contributing to the sensor response. By selecting an appropriate MOF overcoat, the pore sizes could be tailored, and this approach could also be applied to the selective sensing of other gases. ZIF-8 is a comparatively rigid but open crystalline framework with significant potential for extracting $\mathrm{H}_{2}$ from gas mixtures [179]. Nguyn et al. [180] investigated the CO gas-sensing characteristics of two different types of MOFs, namely Ni-VNU-74-I and Ni-VNU-74-II (Figure $38 \mathrm{a}-\mathrm{c}$ ), with different pore sizes and surface areas. The as-synthesized Ni-VNU74-I and Ni-VNU-74-II exhibited high crystallinity and thermal stability, together with ultra-high specific surface areas. The gas sensor fabricated using Ni-VNU-74-II with an ultra-high surface area of $2350 \mathrm{~m}^{2} / \mathrm{g}$ exhibited the maximum response $\left(R_{a} / R_{g}=1.7\right)$ toward 50 ppm CO gas in comparison to other gases at a working temperature of $200{ }^{\circ} \mathrm{C}$. The excellent sensing activity of the Ni-VNU-74-II sensor in comparison to that of the Ni-VNU$74-I$ sensor with a surface area of $2020 \mathrm{~m}^{2} \mathrm{~g}^{-1}$ was attributed to the enhanced interactions between the open $\mathrm{Ni}$ sites and $\mathrm{CO}$ gas molecules in the unique Ni-VNU-74-II structure with smaller pores, larger surface area, and higher concentration of $\mathrm{Ni}^{2+}$ sites. In addition, the observed CO selectivities of both the Ni-VNU-74-I and Ni-VNU-74-II sensors were attributed to the special structures presented in Figure 38.

The MOFs comprised a partial charge of open metal Ni sites that could afford strong interactions with $\mathrm{CO}$ gas molecules. The higher density of the open metal $\mathrm{Ni}^{2+}$ sites resulted in a high probability of $\mathrm{CO}$ gas attachment. Additionally, the metal $\mathrm{Ni}^{2+}$ species had smaller ionic radii, and because the $\mathrm{CO}$ molecules were adjacent to $\mathrm{Ni}^{2+}$, the shorter distances of $\mathrm{Ni}^{2+}+\mathrm{O}$ allowed enhanced interactions with the oxygen atoms and $\mathrm{CO}$ gas molecules. Consequently, the $\mathrm{CO}-\mathrm{Ni}^{2+}$ interaction increased because of the highly cooperative effects between the $\mathrm{MOF}$ framework and $\mathrm{CO}$ gas molecules. Furthermore, the smaller $\mathrm{Ni}^{2+}$ radius facilitated the release of its electrons owing to the interaction with the target gases, particularly CO gas. An MOF structure with an adequate pore size and volume should be selected when considering the kinetic properties of sensors such as response/recovery times, mostly when the MOF material is directly utilized as a sensing material rather than 
as a sieve. Lee et al. [181] investigated the $\mathrm{NO}_{2}$-sensing activities of two unique series of Mg-incorporated MOFs, which were labeled as Mg-MOF-I and Mg-MOF-II. The assynthesized iso-reticular type of Mg-MOFs afforded excellent crystallinity, good thermal stability, and needle-shaped surface morphology with ultra-high surface area, which were advantageous for gas detection applications. The higher response $\left(R_{a} / R_{g}=1.4\right.$ to $50 \mathrm{ppm}$ $\mathrm{NO}_{2}$ at $\left.200{ }^{\circ} \mathrm{C}\right)$ observed for the Mg-MOF-II sensor $\left(2900 \mathrm{~m}^{2} / \mathrm{g}\right)$ than that for Mg-MOF-I sensor $\left(2520 \mathrm{~m}^{2} / \mathrm{g}\right)$ was mainly associated with the higher surface area. A higher surface area resulted in a greater number of adsorption sites, which supported the adsorption of more target gases on the gas sensor surface, leading to a greater resistance modulation and a higher sensor response. In addition, the base resistance of the Mg-MOF-II sensor was lower because of the enhanced adsorption of oxygen gas molecules in air. Furthermore, the Mg-MOF-II sensor with a larger pore size and volume showed faster response and recovery times, indicating the importance of the porosity size on the kinetic characteristics of the sensors based on the MOFs. Furthermore, MOF-derived $\mathrm{ZnO}-\mathrm{CuO}$ [182] and $\mathrm{ZnO}-$ $\mathrm{Co}_{3} \mathrm{O}_{4}$ [183] nanocomposites with high surface areas resulting from MOFs were reported recently for enhanced sensing of $\mathrm{H}_{2} \mathrm{~S}$ and $\mathrm{C}_{2} \mathrm{H}_{5} \mathrm{OH}$ gases, respectively.

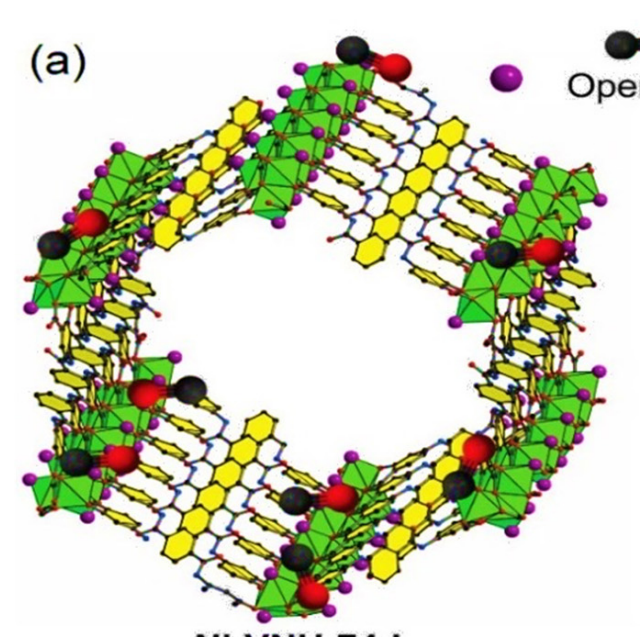

Ni-VNU-74-I
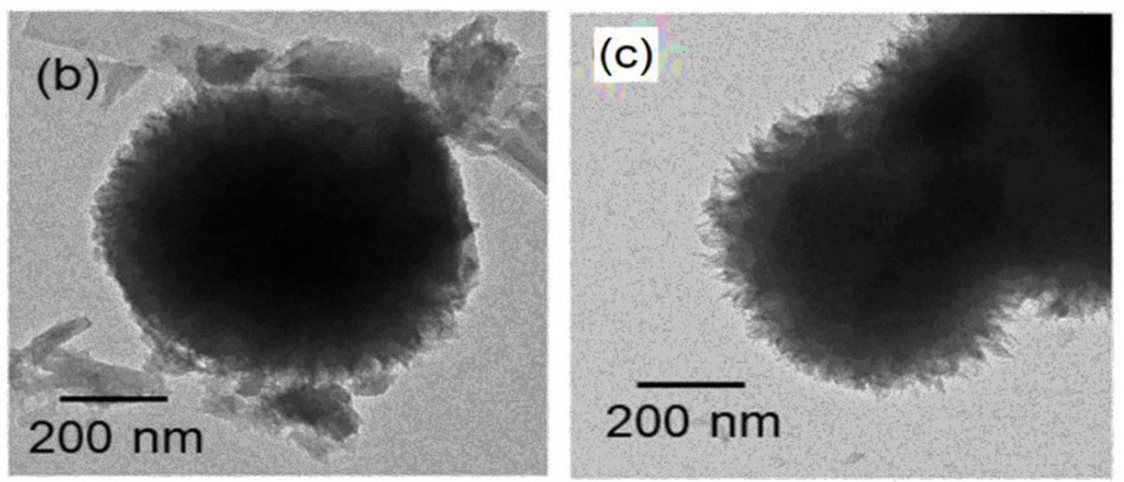

Figure 38. (a) Structures of Ni-VNU-74-I and-II. TEM images of (b) Ni-VNU-74-I and (c) Ni-VNU-74II. Reproduced from [135] with the permission of Elsevier.

Finally, we have compared the gas-sensing performances of different types of gas sensors described above with research papers published by other research groups from Korea [184-222] in Table 3. 
Table 3. Comparison of gas detection performances of different types of gas sensors reported by different research groups in Korea.

\begin{tabular}{|c|c|c|c|c|c|c|c|}
\hline Sensing Material & Target Gas & $\begin{array}{l}\text { Gas Conc. } \\
\text { (ppm) }\end{array}$ & $\begin{array}{c}\mathrm{T} \\
\left({ }^{\circ} \mathrm{C}\right)\end{array}$ & $\begin{array}{c}\text { Response }\left(R_{a} / R_{g}\right) \text { or } \\
\left(R_{g} / R_{a}\right) \text { or } \\
{\left[\left(R_{a}-R_{g}\right) / R_{a}\right]^{*} 100 \%}\end{array}$ & $\operatorname{Res}(\mathbf{s}) / \operatorname{Rec}(\mathbf{s})$ & $\begin{array}{c}\text { LDL } \\
\text { (ppm) }\end{array}$ & Ref. \\
\hline \multicolumn{8}{|c|}{ Core-shell (C-S) Gas Sensors } \\
\hline $\mathrm{SnO}_{2}-\mathrm{ZnO}$ C-S NFs & $\mathrm{NO}_{2}$ & 5 & 300 & $\sim 0.45$ & NA & 1 & {$[70]$} \\
\hline $\mathrm{ZnO}-\mathrm{SnO}_{2} \mathrm{C}-\mathrm{S} \mathrm{NWs}$ & $\mathrm{CO}$ & 10 & 300 & 42 & $9 / 57$ & 1 & [71] \\
\hline $\mathrm{SnO}_{2}-\mathrm{ZnO}$ C-S NWs & $\mathrm{NO}_{2}$ & 10 & 300 & $\sim 155$ & NA & 1 & [72] \\
\hline $\mathrm{SnO}_{2}-\mathrm{ZnO} \mathrm{C}-\mathrm{S} \mathrm{NFs}$ & $\mathrm{CO}$ & 1 & 300 & $\sim 48$ & NA & 1 & {$[73]$} \\
\hline CuO-ZnO C-S NWs & $\mathrm{C}_{6} \mathrm{H}_{6}$ & 1 & 300 & $\sim 6$ & NA & 1 & {$[74]$} \\
\hline $\mathrm{SnO}_{2}-\mathrm{Cu}_{2} \mathrm{O}$ C-S NFs & $\mathrm{CO}$ & 10 & 300 & 5 & $14 / 14$ & 1 & [75] \\
\hline $\mathrm{Pt} @ \mathrm{SnO}_{2}-\mathrm{ZnO}$ C-S NWs & $\mathrm{C}_{7} \mathrm{H}_{8}$ & 0.1 & 300 & 279 & NA & 0.1 & [76] \\
\hline $\mathrm{SnO}_{2}-\mathrm{ZrO}_{2} \mathrm{C}-\mathrm{S} \mathrm{NWs}$ & $\mathrm{NO}_{2}$ & 10 & 150 & 24.7 & NA & NA & [78] \\
\hline $\mathrm{SnO}_{2}-\mathrm{Cu}_{2} \mathrm{O}$ C-S NWs & $\mathrm{C}_{6} \mathrm{H}_{6}$ & 10 & 300 & 12.5 & $4 / 4$ & 1 & [79] \\
\hline $\mathrm{CuO}-\mathrm{TiO}_{2} \mathrm{C}-\mathrm{S} \mathrm{NWs}$ & $\mathrm{CO}$ & 10 & 300 & $\sim 16$ & NA & 1 & [80] \\
\hline CuO-ZnO C-S NFs & $\mathrm{CO}$ & 10 & 300 & $\sim 8$ & NA & 0.1 & [81] \\
\hline $\mathrm{SnO}_{2}$-ZnO C-S NFs & $\mathrm{CO}$ & 150 & 300 & $\sim 17$ & NA & 3 & [82] \\
\hline $\mathrm{Pd} @ \mathrm{SnO}_{2}-\mathrm{ZnO}$ C-S NWs & $\mathrm{C}_{6} \mathrm{H}_{6}$ & 0.1 & 300 & 71 & $33 / 114$ & 0.1 & {$[83]$} \\
\hline Au-decorated Si NW-ZnO C-S & $\mathrm{H}_{2} \mathrm{~S}$ & 50 & 300 & 11.22 & $48 / 64$ & 10 & {$[84]$} \\
\hline $\mathrm{Au} / \mathrm{SnO}_{2} \mathrm{C}-\mathrm{S} \mathrm{NPs}$ & $\mathrm{CO}$ & 1000 & 100 & $\sim 1$ & NA & NA & [85] \\
\hline $\mathrm{Au} / \mathrm{SnO}_{2} \mathrm{C}-\mathrm{S} \mathrm{NPs}$ & $\mathrm{CO}$ & 1000 & 200 & $\sim 2.2$ & NA & NA & [87] \\
\hline $\mathrm{Au} @ \mathrm{Cu}_{2} \mathrm{O}$ C-S NPs & $\mathrm{CO}$ & 1000 & 200 & $\sim 5.8$ & NA & NA & {$[88]$} \\
\hline $\mathrm{Au} @ \mathrm{Cu}_{2} \mathrm{O}$ C-S NPs & $\mathrm{CO}$ & 1000 & 250 & 5.67 & NA & 10 & [89] \\
\hline Au@ZnO C-S NPs & $\mathrm{H}_{2}$ & 100 & 300 & 103.9 & NA & 0.5 & [90] \\
\hline Au@NiO C-S NPs & $\mathrm{C}_{2} \mathrm{H}_{5} \mathrm{OH}$ & 100 & 200 & 2.54 & NA & 2 & [91] \\
\hline $\mathrm{Au} @ \mathrm{In}_{2} \mathrm{O}_{3} \mathrm{C}-\mathrm{S} \mathrm{NPs}$ & $\mathrm{H}_{2}$ & 100 & 300 & 34.38 & $31 / 600$ & 2 & [92] \\
\hline $\mathrm{AuPd}_{\text {alloy }}-\mathrm{ZnO}$ C-S NPs & $\mathrm{H}_{2}$ & 100 & 300 & 80 & $36 / 720$ & NA & [94] \\
\hline $\mathrm{Au} @ \mathrm{SnO}_{2}$ C-S NPs & $\mathrm{C}_{8} \mathrm{H}_{10}$ & 5 & 300 & 16.17 & NA & NA & [97] \\
\hline $\mathrm{Pd} @ \mathrm{In}_{2} \mathrm{O}_{3}$ yoll-shell NPs & $\mathrm{C}_{2} \mathrm{H}_{5} \mathrm{OH}$ & 5 & 350 & 159.02 & NA & NA & [98] \\
\hline $\mathrm{Au} @ \mathrm{NiO}$ yoll-shell NPs & $\mathrm{H}_{2} \mathrm{~S}$ & 5 & 300 & 108.90 & NA & 1.25 & [99] \\
\hline $\mathrm{ZnO}-\mathrm{SnO}_{2} \mathrm{C}-\mathrm{S} \mathrm{NWs}$ & $\mathrm{C}_{2} \mathrm{H}_{5} \mathrm{OH}$ & 200 & 400 & 280 & NA & 0.5 & [184] \\
\hline $\mathrm{SnO}_{2}-\mathrm{ZnO}$ C-S NWs & $\mathrm{NO}_{2}$ & 5 & 25 & 6.18 & NA & 1 & [185] \\
\hline $\mathrm{Ag}-\mathrm{Fe}_{2} \mathrm{O}_{3} \mathrm{C}-\mathrm{S} \mathrm{NPs}$ & $\mathrm{NO}_{2}$ & 4 & 150 & 3.6 & 280 & 340 & [186] \\
\hline $\mathrm{ZnO}-\mathrm{Cr}_{2} \mathrm{O}_{3} \mathrm{C}-\mathrm{S}$ nanocables & TMA & 5 & 400 & 17.8 & NA & 0.05 & [187] \\
\hline $\mathrm{Ga}_{2} \mathrm{O}_{3}-\mathrm{SnO}_{2} \mathrm{C}-\mathrm{S} \mathrm{NWs}$ & $\mathrm{C}_{2} \mathrm{H}_{5} \mathrm{OH}$ & 1000 & 400 & 66 & NA & NA & [188] \\
\hline Pd@ZnOC-S NPs & $\mathrm{H}_{2}$ & 100 & 350 & 22 & $84 / 468$ & 5 & [189] \\
\hline $\mathrm{ZnO}^{-\mathrm{TiO}_{2}} \mathrm{C}-\mathrm{S} \mathrm{NRs}$ & $\mathrm{NO}_{2}$ & 50 & RT & 7.50 & NA & NA & [190] \\
\hline $\mathrm{TeO}_{2}-\mathrm{CuO}$ C-S NRs & $\mathrm{NO}_{2}$ & 10 & 150 & $425 \%$ & NA & 0.5 & [191] \\
\hline $\mathrm{Pd} @ \mathrm{ZnO}-\mathrm{In}_{2} \mathrm{O}_{3}$ C-S NPs & $\mathrm{H}_{2}$ & 100 & 300 & 42 & $24 / 240$ & NA & [192] \\
\hline $\mathrm{Pd} @ \mathrm{~N}-\mathrm{CeO}_{2} \mathrm{C}-\mathrm{S}$ nanoflatforms & $\mathrm{H}_{2}$ & 100 & 350 & 19 & $60 / 360$ & 0.5 & [193] \\
\hline \multicolumn{8}{|c|}{ Self-Heated Gas Sensors } \\
\hline $\mathrm{Pd} @ \mathrm{SnO}_{2}-\mathrm{ZnO}$ C-S NWs & $\mathrm{C}_{6} \mathrm{H}_{6}$ & 50 & $20 \mathrm{~V}(\mathrm{RT})$ & 1.62 & NA & 0.1 & [104] \\
\hline $\mathrm{Au} @ \mathrm{WS}_{2}$ nanoflakes & $\mathrm{CO}$ & 50 & $2 \mathrm{~V}(\mathrm{RT})$ & 1.48 & $174 / 30$ & 1 & [107] \\
\hline $\mathrm{TiO}_{2}$-layer-modified $\mathrm{SnO}_{2} \mathrm{QDs}$ & $\mathrm{NO}_{2}$ & 1 & $20 \mathrm{~V}(\mathrm{RT})$ & $\sim 90 \%$ & NA & 1 & [108] \\
\hline $\mathrm{Au}-\mathrm{SnO}_{2}$-decorated $\mathrm{WS}_{2} \mathrm{NSs}$ & $\mathrm{CO}$ & 50 & $4.7 \mathrm{~V}(\mathrm{RT})$ & 3.68 & NA & 0.3 & [109] \\
\hline Pd@CuO NWs & $\mathrm{H}_{2} \mathrm{~S}$ & 100 & $5 \mathrm{~V}(\mathrm{RT})$ & 1.89 & NA & 1 & [110] \\
\hline
\end{tabular}


Table 3. Cont.

\begin{tabular}{|c|c|c|c|c|c|c|c|}
\hline Sensing Material & Target Gas & $\begin{array}{l}\text { Gas Conc. } \\
\text { (ppm) }\end{array}$ & $\begin{array}{c}\mathrm{T} \\
\left({ }^{\circ} \mathrm{C}\right)\end{array}$ & $\begin{array}{c}\text { Response }\left(R_{a} / R_{g}\right) \text { or } \\
\left(R_{g} / R_{a}\right) \text { or } \\
{\left[\left(R_{a}-R_{g}\right) / R_{a}\right]^{*} 100 \%} \\
\end{array}$ & $\operatorname{Res}(s) / \operatorname{Rec}(s)$ & $\begin{array}{l}\text { LDL } \\
(\mathrm{ppm})\end{array}$ & Ref. \\
\hline $\mathrm{Au} @ \mathrm{ZnO} \mathrm{NWs}$ & $\mathrm{NO}_{2}$ & 10 & $7 \mathrm{~V}(\mathrm{RT})$ & 3.07 & NA & 0.1 & [111] \\
\hline $\mathrm{Pt} @ \mathrm{SnO}_{2}-\mathrm{ZnO}$ C-S NWs & $\mathrm{C}_{7} \mathrm{H}_{8}$ & 50 & $20 \mathrm{~V}(\mathrm{RT})$ & 3.14 & NA & 0.1 & [112] \\
\hline $\mathrm{WS}_{2}-\mathrm{SnO}_{2} \mathrm{C}-\mathrm{S} \mathrm{NSs}$ & $\mathrm{CO}$ & 10 & $3.4 \mathrm{~V}$ & 8 & NA & NA & [114] \\
\hline $\mathrm{Au} @ \mathrm{SnO}_{2}-\mathrm{ZnO}$ C-S NWs & $\mathrm{CO}$ & 50 & $20 \mathrm{~V}(\mathrm{RT})$ & 1.62 & NA & 0.1 & [115] \\
\hline Pt@ZnO NWs & $\mathrm{C}_{7} \mathrm{H}_{8}$ & 50 & $20 \mathrm{~V}(\mathrm{RT})$ & 2.86 & NA & NA & [117] \\
\hline Pd@ZnO NWs & $\mathrm{C}_{6} \mathrm{H}_{6}$ & 50 & $20 \mathrm{~V}(\mathrm{RT})$ & 2.20 & NA & NA & [117] \\
\hline $\mathrm{CuO@SnO}{ }_{2}-\mathrm{ZnO}$ C-S NWs & $\mathrm{H}_{2} \mathrm{~S}$ & 10 & $1 \mathrm{~V}(\mathrm{RT})$ & $\sim 1.9$ & NA & 1 & [119] \\
\hline Pd@Si NWs & $\mathrm{H}_{2}$ & $0.5 \%$ & $30 \mathrm{~V}(\mathrm{RT})$ & $106 \%$ & $24 / 590$ & NA & [194] \\
\hline Pd@Si NWs & $\mathrm{H}_{2}$ & $1 \%$ & $1.7 \mathrm{~V}(\mathrm{RT})$ & $1.6 \%$ & NA & NA & [195] \\
\hline Pd@C NWs & $\mathrm{H}_{2}$ & 1000 & $6 \mathrm{~V}(\mathrm{RT})$ & $\sim 95 \%$ & NA & 10 & [196] \\
\hline Nanocolumnar $\mathrm{WO}_{3}$ thin films & $\mathrm{NO}_{2}$ & 1 & $5 \mathrm{~V}(\mathrm{RT})$ & $\sim 130$ & NA & 1 & [197] \\
\hline \multicolumn{8}{|c|}{ Irradiated Gas Sensors } \\
\hline ZnO NFs (e-beam, 150 kGy) & $\mathrm{H}_{2}$ & 10 & 350 & 150 & $23 / 114$ & 0.1 & [127] \\
\hline Pd@ZnO NFs (e-beam, 150 kGy) & $\mathrm{H}_{2}$ & 10 & 350 & 236.82 & NA & 0.1 & [128] \\
\hline RGO (e-beam, 500 kGy) & $\mathrm{NO}_{2}$ & 50 & RT & 5.280 & $84 / 1592$ & 10 & [129] \\
\hline Pd@RGO (e-beam, 500 kGy & $\mathrm{NO}_{2}$ & 10 & RT & 1.047 & $345 / 816$ & 2 & [130] \\
\hline $\mathrm{SnO}_{2} \mathrm{NWs}\left(1 \times 10^{16}\right.$ ions $\left./ \mathrm{cm}^{2}\right)$ & $\mathrm{NO}_{2}$ & 2 & 150 & $\sim 14$ & $292 / 228$ & NA & [134] \\
\hline $\begin{array}{c}\mathrm{Sb@SnO} \mathrm{SWs}_{2} \mathrm{NWs} \\
\left(2 \times 10^{13} \text { ion } / \mathrm{cm}^{2}\right)\end{array}$ & $\mathrm{NO}_{2}$ & 1 & 300 & 111.58 & NA & 0.05 & [135] \\
\hline $\begin{array}{c}\mathrm{In} @ \mathrm{SnO}_{2} \mathrm{NWs} \\
\left(2 \times 10^{14} \text { ion } / \mathrm{cm}^{2}\right)\end{array}$ & $\mathrm{NO}_{2}$ & 1 & 300 & $\sim 4.9$ & NA & 0.1 & [136] \\
\hline $\mathrm{SnO}_{2}$ NWs (e-beam, 150 kGy) & $\mathrm{NO}_{2}$ & 10 & NA & 1.03 & $16 / 230$ & NA & [198] \\
\hline $\begin{array}{c}\text { SWCNT-Sn } / \mathrm{SnO}_{2} \text { composites } \\
(1 \mathrm{KW})\end{array}$ & $\mathrm{C}_{2} \mathrm{H}_{5} \mathrm{OH}$ & 10 & RT & $\sim 6.5$ & NA & 1 & [199] \\
\hline Graphene (1000 kGy) & $\mathrm{NO}_{2}$ & 100 & RT & 40.68 & $86 / 499$ & 5 & [200] \\
\hline \multicolumn{8}{|c|}{ Flexible Gas Sensors } \\
\hline $\mathrm{Au} @ \mathrm{WS}_{2}$ nanoflakes & $\mathrm{CO}$ & 50 & RT & 1.48 & $174 / 30$ & 1 & [107] \\
\hline $\mathrm{Au}-\mathrm{SnO}_{2}$ decorated $\mathrm{WS}_{2} \mathrm{NSs}$ & $\mathrm{CO}$ & 50 & RT & 3.68 & NA & 0.3 & [109] \\
\hline RGO nanofibrous mesh fabrics & $\mathrm{NO}_{2}$ & 8 & RT & $26.5 \%$ & NA & 8 & [147] \\
\hline Titania NTs & $\mathrm{NH}_{3}$ & 200 & 350 & $\sim 80 \%$ & NA & NA & [148] \\
\hline $\mathrm{ZnO}$ NRs & $\mathrm{C}_{2} \mathrm{H}_{5} \mathrm{OH}$ & 50 & 300 & $\sim 90$ & NA & 10 & [149] \\
\hline Ag@ZnO NRs & $\mathrm{C}_{2} \mathrm{H}_{2}$ & 1000 & 200 & 27.2 & $62 / 39$ & 3 & [150] \\
\hline Pt-ZnO@RGO & $\mathrm{NO}_{2}$ & 5 & RT & $43.28 \%$ & $528 / 702$ & 0.1 & [151] \\
\hline $\mathrm{ZnO}$ nanoflowers & $\mathrm{NO}_{2}$ & 500 & 270 & 218.1 & $\sim 31 / \sim 14$ & NA & [153] \\
\hline $\mathrm{MoS}_{2}$ & $\mathrm{NO}_{2}$ & 500 & RT & $\sim 300 \%$ & NA & 25 & [154] \\
\hline CNTs/RGO flexible film & $\mathrm{NO}_{2}$ & 10 & RT & $20 \%$ & NA & 0.5 & [201] \\
\hline Flexible graphene films & $\mathrm{NO}_{2}$ & 200 & RT & $23 \%$ & NA & NA & [202] \\
\hline Flexible graphene & $\mathrm{NO}_{2}$ & 5 & RT & $13 \%$ & NA & 1 & [203] \\
\hline Flexible RGO cotton yarn & $\mathrm{NO}_{2}$ & 1.25 & RT & $12 \%$ & NA & 0.25 & [204] \\
\hline GO on cotton yarn & $\mathrm{NO}_{2}$ & 3 & RT & $65 \%$ & NA & 0.15 & [205] \\
\hline Graphene-based electronic sheet & $\mathrm{NO}_{2}$ & 100 & RT & $\sim 38 \%$ & NA & 1 & [206] \\
\hline ZnO-decorated rGO fibers & $\mathrm{H}_{2} \mathrm{~S}$ & 20 & RT & $2.68 \%$ & $404 / 275$ & 1.5 & [207] \\
\hline $\mathrm{Ti}_{3} \mathrm{C}_{2} \mathrm{Tx} /$ Graphene fibers & $\mathrm{NH}_{3}$ & 50 & RT & $6.8 \%$ & NA & 10 & [208] \\
\hline
\end{tabular}


Table 3. Cont.

\begin{tabular}{|c|c|c|c|c|c|c|c|}
\hline Sensing Material & Target Gas & $\begin{array}{l}\text { Gas Conc. } \\
\text { (ppm) }\end{array}$ & $\begin{array}{c}\mathrm{T} \\
\left({ }^{\circ} \mathrm{C}\right)\end{array}$ & $\begin{array}{c}\text { Response }\left(R_{a} / R_{g}\right) \text { or } \\
\left(R_{g} / R_{a}\right) \text { or } \\
{\left[\left(R_{a}-R_{g}\right) / R_{a}\right]^{*} 100 \%}\end{array}$ & $\operatorname{Res}(\mathbf{s}) / \operatorname{Rec}(\mathbf{s})$ & $\begin{array}{l}\text { LDL } \\
\text { (ppm) }\end{array}$ & Ref. \\
\hline $\mathrm{CeO}_{2}-\mathrm{CuBr}$ & $\mathrm{NH}_{3}$ & 5 & RT & 68 & NA & 0.02 & [209] \\
\hline RGO- $\mathrm{In}_{2} \mathrm{O}_{3}$ & $\mathrm{NO}_{2}$ & 0.5 & 150 & 22.3 & $112 / 175$ & 0.5 & [210] \\
\hline $\mathrm{WO}_{3} / \mathrm{MWCNTs}$ & $\mathrm{NO}_{2}$ & 5 & RT & 14 & $600 / 1620$ & NA & [211] \\
\hline \multicolumn{8}{|c|}{ Glass/Si/MOF-Based Gas Sensors } \\
\hline Soda-lime glass & $\mathrm{CO}_{2}$ & 4000 & 350 & 0.4 & NA & NA & [156] \\
\hline Pd@Soda-lime glass & $\mathrm{CO}_{2}$ & 100 & 350 & 8.160 & NA & 0.2 & [157] \\
\hline Si NWs & $\mathrm{H}_{2}$ & 50 & 100 & 17.1 & $505 / 150$ & 10 & [163] \\
\hline $\mathrm{Si} / \mathrm{SnO}_{2} \mathrm{NWs}$ & $\mathrm{H}_{2} \mathrm{~S}$ & 50 & 100 & 3.5 & NA & NA & [167] \\
\hline Pd@Si nanohorns & $\mathrm{H}_{2}$ & 10 & 400 & $\sim 2300$ & NA & 0.1 & [168] \\
\hline Graphene/Si NWs & $\mathrm{H}_{2}$ & NA & 25 & $1280 \%$ & $12 / 0.15$ & NA & [212] \\
\hline Pd@p-Si & $\mathrm{H}_{2} \mathrm{~S}$ & 3 & RT & $\sim 88 \%$ & NA & 0.3 & [213] \\
\hline Pd@Si NWs & $\mathrm{H}_{2}$ & 20000 & RT & $\sim 300 \%$ & NA & 5 & [214] \\
\hline ZnO@ZIF-8 MOFs & $\mathrm{H}_{2}$ & 50 & 300 & 1.44 & NA & NA & [174] \\
\hline SIM-1 nanomembrane@ZnO NWs & $\mathrm{H}_{2}$ & 50 & 300 & $\sim 2.5$ & NA & NA & [175] \\
\hline Pd@ZnO NWs & $\mathrm{H}_{2}$ & 50 & 200 & 6.7 & NA & NA & [178] \\
\hline Ni-MOFs & $\mathrm{CO}$ & 50 & 200 & 1.7 & NA & 1 & [180] \\
\hline $\mathrm{Mg}-\mathrm{MOFs}$ & $\mathrm{NO}_{2}$ & 50 & 200 & $\sim 1.35$ & $167 / 92$ & 1 & [181] \\
\hline MOF derived $\mathrm{ZnO}-\mathrm{CuO}$ & $\mathrm{H}_{2} \mathrm{~S}$ & 10 & 350 & 10.99 & $58 / 273$ & 1 & [182] \\
\hline $\begin{array}{c}\mathrm{n}-\mathrm{ZnO} / \mathrm{p}-\mathrm{Co}_{3} \mathrm{O}_{4} \text { derived from } \\
\mathrm{MOFs}\end{array}$ & $\mathrm{C}_{2} \mathrm{H}_{5} \mathrm{OH}$ & 10 & 300 & 34.9 & $57 / 235$ & 1 & [183] \\
\hline Pd@Zr-MOFs & $\mathrm{H}_{2}$ & 100 & 150 & 1.94 & NA & 10 & [215] \\
\hline Pd NWs @ZIF-8 & $\mathrm{H}_{2}$ & $0.1 \%$ & RT & $0.7 \%$ & $30 / 8$ & 0.6 & [216] \\
\hline $\begin{array}{l}\text { ZIF-67 derived } W_{2} @ \text { @arbon } \\
\text { composites }\end{array}$ & $\mathrm{NO}_{2}$ & 1 & RT & $18 \%$ & NA & 0.1 & [217] \\
\hline $\begin{array}{l}\text { ZIF-67 derived hollow } \mathrm{Co}_{3} \mathrm{O}_{4} \\
\text { nanocages }\end{array}$ & p-Xylene & 5 & 225 & 78.6 & NA & 0.25 & [218] \\
\hline Pd@ZIF-67 derived $\mathrm{PdO} @ \mathrm{Co}_{3} \mathrm{O}_{4}$ & $\mathrm{CH}_{3} \mathrm{COCH}_{3}$ & 5 & 350 & 2.51 & NA & 0.1 & [219] \\
\hline MOF derived $\mathrm{ZnO}-\mathrm{Co}_{3} \mathrm{O}_{4}$ & $\mathrm{CH}_{3} \mathrm{COCH}_{3}$ & 5 & 450 & 29 & NA & 1 & [220] \\
\hline $\mathrm{TiO}_{2}-\mathrm{SnO}_{2} / \mathrm{MWCNTs} @ \mathrm{Cu}-\mathrm{BTC}$ & $\mathrm{NH}_{3}$ & 10 & RT & 0.58 & $80 / 15$ & 0.77 & [221] \\
\hline $\mathrm{Cu}_{3}(\mathrm{HHTP})_{2} / \mathrm{Fe}_{2} \mathrm{O}_{3}$ & $\mathrm{NO}_{2}$ & 5 & 20 & $89.4 \%$ & NA & 0.2 & [222] \\
\hline
\end{tabular}

\section{Conclusions}

In this review, recent research activities of the research labs of Professors Hyoun Woo Kim and Sang Sub Kim in Korea relating the synthesis and chemiresistive gas-sensing applications of oxide- and polymer-based nanomaterials are described. In particular, this review was divided into two parts. In the Introduction section, a general viewpoint on the chemiresistive gas sensors and their limitations were described. The second section provided an overview of the different strategies for optimizing the gas detection performance, including C-S, self-heated, irradiated, flexible, Si-based, glass, and MOF-based sensors. ALD is a useful technique for suitably coating the core with a shell material with an expected shell thickness, and C-S structures with optimized shell thickness can enhance the sensing performance compared to the use of conventional nanostructures. Different $n-n$ and $p-n$ metal oxides can be used as either core or shell materials. One of the main challenges in the development of sensing systems is the realization of low-temperature gas sensors with a low energy consumption. This implies the complete integration of these devices with conventional electronic technologies to produce low-cost sensing devices. The self-heating gas-sensing approach has been successfully employed to overcome the 
high power consumption of the gas sensors. Accordingly, both $1 D$ and $2 D$ morphologies of the C-S structures have been used for self-heating studies. In addition to the metal oxides, metal sulfides, such as $\mathrm{WS}_{2}$, with high flexibility owing to their $2 D$ structures are highly promising for the realization of flexible gas sensors that can operate at low working temperatures. Another effective strategy to improve the detection performance of gas sensors is the irradiation of gas sensors with high-energy beams, such as gamma rays and e-beams. However, it is important to optimize the radiation dose to achieve the best detection properties. Moreover, glass-based, Si-based, and MOF-based gas sensors have their own advantages such as good selectivity. Based on the results of the different strategies discussed in this review, it is speculated that the gas sensors with low power consumption, high response, and high selectivity can be achieved by combining different strategies and approaches with a reasonable selection of the sensing materials.

Although many approaches have been proposed, the response of chemiresistive sensors to very low gas concentrations are not sufficiently high because factors such as temperature and humidity can affect the sensing response. Accordingly, increased research efforts have been directed toward the development of more advanced sensing materials to improve the chemiresistive performance. In particular, the directional control of material morphology and selective gas detection, with long-term stability, will continue to be a key aspect of future research.

Author Contributions: Conceptualization: A.M., H.W.K. and S.S.K.; resources: A.M., S.N. and S.M.M.; writing and original draft preparation: S.N., S.M.M. and A.M.; review and editing: S.N., S.M.M., A.M., H.W.K. and S.S.K.; supervision: H.W.K. and S.S.K. All authors have read and approved the published version of this manuscript.

Funding: This research received no external funding.

Institutional Review Board Statement: Not applicable.

Informed Consent Statement: Not applicable.

Data Availability Statement: Not applicable.

Acknowledgments: This work was supported by an INHA UNIVERSITY Research Grant.

Conflicts of Interest: The authors declare no conflict of interest.

\section{References}

1. Jung, S.J.; Mehta, J.S.; Tong, L. Effects of environment pollution on the ocular surface. Ocul. Surf. 2018, 16, 198-205. [CrossRef] [PubMed]

2. Brugha, R.; Edmondson, C.; Davies, J.C. Outdoor air pollution and cystic fibrosis. Paed. Resp. Rev. 2018, 28, 80-86. [CrossRef] [PubMed]

3. Landrigan, P.J.; Fuller, R.; Fisher, S.; Suk, W.A.; Sly, P.; Chiles, T.C.; O'Reilly, S. Pollution and children's health. Sci. Total Environ. 2019, 650, 2389-2394. [CrossRef]

4. Pifferi, S.; Menini, A. Odorant detection and discrimination in the olfactory system. Sens. Microsyst. 2011, 91, 3-18.

5. Chiu, S.-W.; Tang, K.-T. Towards a chemiresistive sensor-integrated electronic nose: A review. Sensors 2013, $13,14214-14247$. [CrossRef]

6. Gruber, B.; David, F.; Sandra, P. Capillary gas chromatography-mass spectrometry: Current trends and perspectives. Trends Ana. Chem. 2020, 124, 115475. [CrossRef]

7. Anyakudo, F.; Adams, E.; Schepdael, A. Thin-layer chromatography-flame ionization detection. Chromatographia 2020, 83, 149-157. [CrossRef]

8. You, Y.; Moussa, S.G.; Zhang, L.; Fu, L.; Beck, J.; Staebler, R. Quantifying fugitive gas emissions from an oil sands tailings pond with open-path Fourier transform infrared measurements. Atmos. Meas. Tech. 2021, 14, 945-959. [CrossRef]

9. Mirzaei, A.; Lee, J.-H.; Majhi, S.M.; Weber, M.; Bechelany, M.; Kim, H.W.; Kim, S.S. Resistive gas sensors based on metal-oxide nanowires. J. Appl. Phys. 2019, 126, 241102. [CrossRef]

10. Brattain, W.H.; Bardeen, J. Surface properties of germanium. Bell Syst. Tech. J. 1953, 32, 1-41. [CrossRef]

11. Heiland, G. Zum Einfluß von Wasserstoff auf die elektrische Leitfähigkeit an der Oberfläche von Zinkoxydkristallen. Z. Für Phys. 1957, 148, 15-27. [CrossRef]

12. Seiyama, T.; Kato, A.; Fujiishi, K.; Nagatani, M. A new detector for gaseous components using semiconductive thin films. Anal. Chem. 1962, 34, 1502-1503. [CrossRef] 
13. Taguchi, N. A Metal Oxide Gas Sensor. Japanese Patent Application No. 45-38200. 1962. Available online: https://hal.archivesouvertes.fr/tel-00509149v1/html_references (accessed on 2 November 2021).

14. Shaver, P.J. Activated tungsten oxide gas detectors. Appl. Phys. Lett. 1967, 11, 255-257. [CrossRef]

15. Ihokura, K.; Watson, J. The Stannic Oxide Gas Sensor: Principles and Applications; CRC Press: Roca Barton, FL, USA, 1994.

16. Salehi, A. A highly sensitive self-heated $\mathrm{SnO}_{2}$ carbon monoxide sensor. Sens. Actuators B Chem. 2003, 96, 88-93. [CrossRef]

17. Schedin, F.; Geim, A.K.; Morozov, S.V.; Hill, E.W.; Blake, P.; Katsnelson, M.I.; Novoselov, K.S. Detection of individual gas molecules adsorbed on graphene. Nat. Mater. 2007, 6, 652-655. [CrossRef] [PubMed]

18. Majhi, S.M.; Mirzaei, A.; Kim, H.W.; Kim, S.S. Reduced graphene oxide (rGO)-loaded metal-oxide nanofiber gas sensors: An overview. Sensors 2021, 21, 1352. [CrossRef]

19. Han, D.; Zhao, M. Facile and simple synthesis of novel iron oxide foam and used as acetone gas sensor with sub-ppm level. J. Alloys Compd. 2020, 815, 152406. [CrossRef]

20. Zhang, S.; Song, P.; Yang, Z.; Wang, Q. Facile hydrothermal synthesis of mesoporous $\operatorname{In}_{2} \mathrm{O}_{3}$ nanoparticles with superior formaldehyde-sensing properties. Physica E 2018, 97, 38-44. [CrossRef]

21. Navale, S.T.; Jadhav, V.V.; Tehare, K.K.; Sagar, R.U.R.; Biswas, C.S.; Galluzzi, M.; Liang, W.; Patil, V.B.; Mane, R.S.; Stadler, F.J. Solid-state synthesis strategy of $\mathrm{ZnO}$ nanoparticles for the rapid detection of hazardous $\mathrm{Cl}_{2}$. Sens. Actuators B Chem. 2017, 238, 1102-1110. [CrossRef]

22. Rajesh, N.; Kannan, J.C.; Krishnakumar, T.; Leonardi, S.G.; Neri, G. Sensing behavior to ethanol of tin oxide nanoparticles prepared by microwave synthesis with different irradiation time. Sens. Actuators B Chem. 2014, 194, 96-104. [CrossRef]

23. Zhang, Y.; Xie, L.Z.; Yuan, C.X.; Zhang, C.L.; Liu, S.; Peng, Y.Q.; Li, H.R.; Zhang, M. A ppb-level formaldehyde gas sensor based on rose-like nickel oxide nanoparticles prepared using electrodeposition process. Nano 2016, 11, 1650009. [CrossRef]

24. Mane, A.T.; Kulkarni, S.B.; Navale, S.T.; Ghanwat, A.A.; Shinde, N.M.; Kim, J.; Patil, V.B. NO 2 sensing properties of nanostructured tungsten oxide thin films. Ceram. Interfaces 2014, 40, 16495-16502. [CrossRef]

25. Fan, X.; Xu, Y.; Ma, C.; He, W. In-situ growth of $\mathrm{Co}_{3} \mathrm{O}_{4}$ nanoparticles based on electrospray for an acetone gas sensor. J. Alloys Compd. 2021, 854, 157234. [CrossRef]

26. Oosthuizen, D.N.; Motaung, D.E.; Swart, H.C. Gas sensors based on $\mathrm{CeO}_{2}$ nanoparticles prepared by chemical precipitation method and their temperature-dependent selectivity towards $\mathrm{H}_{2} \mathrm{~S}$ and $\mathrm{NO}_{2}$ gases. Appl. Surf. Sci. 2020, 505, 144356. [CrossRef]

27. Navale, S.T.; Yang, Z.B.; Liu, C.; Cao, P.J.; Patil, V.B.; Ramgir, N.S.; Mane, R.S.; Stadler, F.J. Enhanced acetone sensing properties of titanium dioxide nanoparticles with a sub-ppm detection limit. Sens. Actuators B Chem. 2018, 255, 1701-1710. [CrossRef]

28. Peng, F.; Sun, Y.; Yu, W.; Lu, Y.; Hao, J.; Cong, R.; Ge, M.; Shi, J.; Dai, N. Studies on sensing properties and mechanism of CuO nanoparticles to $\mathrm{H}_{2} \mathrm{~S}$ gas. Nanomaterials 2020, 10, 774. [CrossRef] [PubMed]

29. Wang, Y.; Jiang, X.; Xia, Y. A Solution-phase, precursor route to polycrystalline $\mathrm{SnO}_{2}$ nanowires that can be used for gas sensing under ambient conditions. J Am. Chem. Soc. 2003, 125, 16176-16177. [CrossRef] [PubMed]

30. Zeng, Y.; Zhang, T.; Yuan, M.; Kang, M.; Lu, G.; Wang, R.; Fan, H.; He, Y.; Yang, H. Growth and selective acetone detection based on ZnO nanorod arrays. Sens. Actuators B Chem. 2009, 143, 93-98. [CrossRef]

31. Huang, F.; Yang, W.; He, F.; Liu, S. Controlled synthesis of flower-like $\operatorname{In}_{2} \mathrm{O}_{3}$ microrods and their highly improved selectivity toward ethanol. Sens. Actuators B Chem. 2016, 235, 86-93. [CrossRef]

32. Tan, W.; Tan, J.; Li, L.; Dun, M.; Huang, X. Nanosheets-assembled hollowed-out hierarchical $\mathrm{Co}_{3} \mathrm{O}_{4}$ microrods for fast response/recovery gas sensor. Sens. Actuators B Chem. 2017, 249, 66-75. [CrossRef]

33. Wei, S.; Zhao, G.; Du, W.; Tian, Q. Synthesis and excellent acetone sensing properties of porous $\mathrm{WO}_{3}$ nanofibers. Vacuum 2016, 124, 32-39. [CrossRef]

34. Yuan, Z.; Yin, L.; Ding, H.; Huang, W.; Shuai, C.; Deng, J. One-step synthesis of single-crystalline ZnO nanowires for the application of gas sensor. J. Mater. Sci. Mater. Electron. 2018, 29, 11559-11565. [CrossRef]

35. Tan, J.; Huang, X. Ultra-thin nanosheets-assembled hollowed-out hierarchical $\alpha-\mathrm{Fe}_{2} \mathrm{O}_{3}$ nanorods: Synthesis via an interface reaction route and its superior gas sensing properties. Sens. Actuators B Chem. 2016, 237, 159-166. [CrossRef]

36. Wang, J.; Wei, L.; Zhang, L.; Jiang, C.; Siu-Wai Kong, E.; Zhang, Y. Preparation of high aspect ratio nickel oxide nanowires and their gas sensing devices with fast response and high sensitivity. J. Mater. Chem. 2012, 22, 8327-8335. [CrossRef]

37. Cai, Z.-X.; Li, H.-Y.; Yang, X.-N.; Guo, X. NO sensing by single crystalline $\mathrm{WO}_{3}$ nanowires. Sens. Actuators B 2015, $219,346$. [CrossRef]

38. Seo, M.H.; Yuasa, M.; Kida, T.; Huh, J.S.; Yamazoe, N.; Shimanoe, K. Microstructure control of $\mathrm{TiO}_{2}$ nanotubular films for improved VOC sensing. Sens. Actuators B Chem. 2011, 154, 251-256. [CrossRef]

39. Zhang, H.; Chen, W.; Jin, L.; Cui, F. Hierarchically porous $\mathrm{WO}_{3}$ microstructures with networks for acetylene sensing application. Mater. Lett. 2018, 214, 198-201. [CrossRef]

40. Cao, J.; Zhang, H.; Yan, X. Facile fabrication and enhanced formaldehyde gas sensing properties of nanoparticles-assembled chain-like NiO architectures. Mater. Lett. 2016, 185, 40-42. [CrossRef]

41. Tan, J.; Dun, M.; Li, L.; Zhao, J.; Li, X.; Hu, Y.; Huang, G.; Tan, W.; Huang, X. Self-template derived CuO nanowires assembled microspheres and its gas sensing properties. Sens. Actuators B Chem. 2017, 252, 1-8. [CrossRef]

42. Hou, L.; Zhang, C.; Li, L.; Du, C.; Li, X.; Kang, X.F.; Chen, W. CO gas sensors based on p-type CuO nanotubes and CuO nanocubes: Morphology and surface structure effects on the sensing performance. Talanta 2018, 188, 41-49. [CrossRef] 
43. Jin, W.; Yan, S.; An, L.; Chen, W.; Yang, S.; Zhao, C.; Dai, Y. Enhancement of ethanol gas sensing response based on ordered $\mathrm{V}_{2} \mathrm{O}_{5}$ nanowire microyarns. Sens. Actuators B Chem. 2015, 206, 284. [CrossRef]

44. Qiao, P.Y.; Zhang, L.X.; Zhu, M.Y.; Yin, Y.Y.; Zhao, Z.W.; Sun, H.N.; Dong, J.Y.; Bie, L.J. Acetylene sensing enhancement of mesoporous $\mathrm{ZnO}$ nanosheets with morphology and defect induced structural sensitization. Sens. Actuators B Chem. 2017, 250, 189-197. [CrossRef]

45. Li, Z.; Wang, N.; Lin, Z.; Wang, J.; Liu, W.; Sun, K.; Fu, Y.Q.; Wang, Z. Room-temperature high-performance $\mathrm{H}_{2} \mathrm{~S}$ sensor based on porous $\mathrm{CuO}$ nanosheets prepared by hydrothermal method. ACS Appl. Mater. Interfaces 2016, 8, 20962-20968. [CrossRef]

46. Zhang, Z.; Zhu, L.; Wen, Z.; Ye, Z. Controllable synthesis of $\mathrm{Co}_{3} \mathrm{O}_{4}$ crossed nanosheet arrays toward an acetone gas sensor. Sens. Actuators B Chem. 2017, 238, 1052-1059. [CrossRef]

47. Lu, Y.; Ma, Y.H.; Ma, S.Y.; Jin, W.X.; Yan, S.H.; Xu, X.L.; Chen, Q. Curly porous NiO nanosheets with enhanced gas-sensing properties. Mater. Lett. 2017, 190, 252-255. [CrossRef]

48. Ma, Y.; Yang, J.; Yuan, Y.; Zhao, H.; Shi, Q.; Zhang, F.; Pei, C.; Liu, B.; Yang, H. Enhanced gas sensitivity and sensing mechanism of network structures assembled from $\alpha-\mathrm{Fe}_{2} \mathrm{O}_{3}$ nanosheets with exposed \{104\} facets. Langmuir 2017, 33, 8671-8678. [CrossRef]

49. Fu, H.T.; Zhang, Z.K.; Yang, X.H.; An, X.Z. Two-step synthesis of $\mathrm{V}_{2} \mathrm{O}_{5}$ nanosheets with high sensing properties toward acetone. Adv. Eng. Res. 2017, 110, 372-379.

50. Bhowmik, B.; Bhattacharyya, P. Efficient gas sensor devices based on surface engineered oxygen vacancy controlled $\mathrm{TiO}_{2}$ nanosheets. IEEE Trans. Electron Dev. 2017, 64, 2357-2363. [CrossRef]

51. Wang, M.; Wang, Y.; Li, X.; Ge, C.; Hussain, S.; Liu, G.; Qiao, G. WO 3 porous nanosheet arrays with enhanced low temperature $\mathrm{NO}_{2}$ gas sensing performance. Sens. Actuators B Chem. 2020, 316, 128050. [CrossRef]

52. Kim, K.; Choi, P.; Itoh, T.; Masuda, Y. Catalyst-free highly sensitive $\mathrm{SnO}_{2}$ nanosheet gas sensors for parts per billion-level detection of acetone. ACS Appl. Mater. Interfaces 2020, 12, 51637-51644. [CrossRef]

53. Li, S.; Fang, W.; Yang, Y.; Yu, H.; Wang, T.; Dong, X.; Liu, G.; Wang, J.; Yu, W.; Sh, K. Highly active and porous single-crystal In ${ }_{2} \mathrm{O}_{3}$ nanosheet for NOx gas sensor with excellent response at room temperature. RSC Adv. 2017, 7, 33419-33425.

54. Zhou, T.; Zhang, T.; Deng, J.; Zhang, R.; Lou, Z.; Wang, L. P-type $\mathrm{Co}_{3} \mathrm{O}_{4}$ nanomaterials-based gas sensor: Preparation and acetone sensing performance. Sens. Actuators B Chem. 2017, 242, 369-377. [CrossRef]

55. Wang, H.; Yan, L.; Li, S.; Li, Y.; Liu, L.; Du, L.; Duan, H.; Cheng, Y. Acetone sensors based on microsheet assembled hierarchical $\mathrm{Fe}_{2} \mathrm{O}_{3}$ with different $\mathrm{Fe}^{3+}$ concentrations. Appl. Phys. A 2018, 124, 1-9. [CrossRef]

56. Chen, W.G.; Gao, T.Y.; Li, Q.Z.; Gan, H.I. Enhanced gas sensing properties of flower-like ZnO nanostructure to acetylene. Mater. Technol. 2014, 30, 96-100. [CrossRef]

57. Bing, Y.; Zeng, Y.; Liu, C.; Qiao, L.; Zheng, W. Synthesis of double-shelled $\mathrm{SnO}_{2}$ nano-polyhedra and their improved gas sensing properties. Nanoscale 2015, 7, 3276-3284. [CrossRef] [PubMed]

58. Dong, H.; Liu, Y.; Li, G.; Wang, X.; Xu, D.; Chen, Z.; Zhang, T.; Wang, J.; Zhang, L. Hierarchically rosette-like $\mathrm{In}_{2} \mathrm{O}_{3}$ microspheres for volatile organic compounds gas sensors. Sens. Actuators B Chem. 2013, 178, 302-309. [CrossRef]

59. Fu, Q.; Ai, M.; Duan, Y.; Lu, L.; Tian, X.; Sun, D.; Xu, Y.; Sun, Y. Synthesis of uniform porous NiO nanotetrahedra and their excellent gas-sensing performance toward formaldehyde. RSC Adv. 2017, 7, 52312-52320. [CrossRef]

60. Meng, D.; Liu, D.; Wang, G.; San, X.; Shen, Y.; Jin, Q.; Meng, F. CuO hollow microspheres self-assembled with nanobars: Synthesis and their sensing properties to formaldehyde. Vacuum 2017, 144, 272-280. [CrossRef]

61. Cao, S.; Chen, H. Nanorods assembled hierarchical urchin-like WO3 nanostructures: Hydrothermal synthesis, characterization, and their gas sensing properties. J. Alloys Compd. 2017, 702, 644-648. [CrossRef]

62. Wang, Y.-T.; Whang, W.-T.; Chen, C.-H. Hollow $\mathrm{V}_{2} \mathrm{O}_{5}$ nanoassemblies for high-performance room-temperature hydrogen sensors. ACS Appl. Mater. Interfaces 2015, 7, 8480-8487. [CrossRef]

63. Zhu, L.; Zhang, D.; Wang, Y.; Feng, C.; Zhou, J.; Liu, C.; Ruan, S. Xylene gas sensor based on Ni doped TiO 2 bowl-like submicron particles with enhanced sensing performance. RSC Adv. 2015, 5, 28105-28110. [CrossRef]

64. Mirzaei, A.; Janghorban, K.; Hashemi, B.; Neri, G. Metal-core@ metal oxide-shell nanomaterials for gas-sensing applications: A review. J. Nanopart. Res. 2015, 17, 371. [CrossRef]

65. Mirzaei, A.; Kim, J.-H.; Kim, H.W.; Kim, S.S. How shell thickness can affect the gas sensing properties of nanostructured materials: Survey of literature. Sens. Actuators B Chem. 2018, 258, 270-294. [CrossRef]

66. Johnson, R.W.; Hultqvist, A.; Bent, S. A brief review of atomic layer deposition: From fundamentals to applications. Mater. Today 2014, 17, 236-246. [CrossRef]

67. Weber, M.; Julbe, A.; Kim, S.S.; Bechelany, M. Atomic layer deposition (ALD) on inorganic or polymeric membranes. J. Appl. Phys. 2019, 126, 041101. [CrossRef]

68. Abideen, Z.U.; Kim, J.-H.; Lee, J.-H.; Kim, J.-Y.; Mirzaei, A.; Kim, H.W.; Kim, S.S. Electrospun metal oxide composite nanofibers gas sensors: A review. J. Korean Ceram. Soc. 2017, 54, 366-379. [CrossRef]

69. Park, J.Y.; Choi, S.W.; Lee, J.W.; Lee, C.; Kim, S.S. Synthesis and gas sensing properties of $\mathrm{TiO}_{2}-\mathrm{ZnO}$ core-shell nanofibers. J. Am. Ceram. Soc. 2009, 92, 2551-2554. [CrossRef]

70. Choi, S.-W.; Park, J.Y.; Kim, S.S. Synthesis of $\mathrm{SnO}_{2}-\mathrm{ZnO}$ core-shell nanofibers via a novel two-step process and their gas sensing properties. Nanotechnology 2009, 20, 465603. [CrossRef] [PubMed]

71. Kim, J.-H.; Mirzaei, A.; Kim, H.W.; Kim, S.S. Variation of shell thickness in $\mathrm{ZnO}-\mathrm{SnO}_{2}$ core-shell nanowires for optimizing sensing behaviors to $\mathrm{CO}, \mathrm{C}_{6} \mathrm{H}_{6}$, and $\mathrm{C}_{7} \mathrm{H}_{8}$ gases. Sens. Actuators $B$ Chem. 2020, 302, 127150. [CrossRef] 
72. Choi, S.-W.; Katoch, A.; Sun, G.-J.; Kim, J.-H.; Kim, S.-H.; Kim, S.S. Dual functional sensing mechanism in $\mathrm{SnO}_{2}-\mathrm{ZnO}$ core-shell nanowires. ACS Appl. Mater. Interfaces 2014, 6, 8281-8287. [CrossRef]

73. Katoch, A.; Choi, S.-W.; Sun, G.-J.; Kim, S.S. An approach to detecting a reducing gas by radial modulation of electron-depleted shells in core-shell nanofibers. J. Mater. Chem. A 2013, 1, 13588-13596. [CrossRef]

74. Kim, J.-H.; Katoch, A.; Kim, S.S. Optimum shell thickness and underlying sensing mechanism in p-n CuO-ZnO core-shell nanowires. Sens. Actuators B Chem. 2016, 222, 249-256. [CrossRef]

75. Kim, J.-H.; Lee, J.-H.; Kim, J.-Y.; Mirzaei, A.; Kim, H.W.; Kim, S.S. Enhancement of $\mathrm{CO}$ and $\mathrm{NO}_{2}$ sensing in n-SnO ${ }_{2}-\mathrm{p}-\mathrm{Cu}_{2} \mathrm{O}$ core-shell nanofibers by shell optimization. J. Hazard. Mater. 2019, 376, 68-82. [CrossRef] [PubMed]

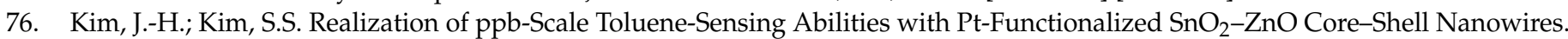
ACS Appl. Mater. Interfaces 2015, 7, 17199-17208. [CrossRef] [PubMed]

77. Spirig, J.V.; Ramamoorthy, R.; Akbar, S.A.; Routbort, J.L.; Singh, D.; Dutta, P. High temperature zirconia oxygen sensor with sealed metal/metal oxide internal reference. Sens. Actuators B Chem. 2007, 124, 192-201. [CrossRef]

78. Bang, J.H.; Lee, N.; Mirzaei, A.; Choi, M.S.; Choi, H.; Jeon, H.; Kim, S.S.; Kim, H.W. Exploration of ZrO $\mathrm{Z}_{2}$-shelled nanowires for chemiresistive detection of $\mathrm{NO}_{2}$ gas. Sens. Actuators B Chem. 2020, 319, 128309. [CrossRef]

79. Kim, J.-H.; Katoch, A.; Kim, S.-H.; Kim, S.S. Chemiresistive sensing behavior of $\mathrm{SnO}_{2}(\mathrm{n})-\mathrm{Cu}_{2} \mathrm{O}$ (p) core-shell nanowires. ACS Appl. Mater. Interfaces 2015, 7, 15351-15358. [CrossRef]

80. Lee, J.-H.; Kim, J.-H.; Kim, S.S. CuO-TiO 2 p-n core-shell nanowires: Sensing mechanism and p/n sensing-type transition. Appl. Surf. Sci. 2018, 448, 489-497. [CrossRef]

81. Katoch, A.; Choi, S.-W.; Sun, G.-J.; Kim, H.W.; Kim, S.S. Mechanism and prominent enhancement of sensing ability to reducing gases in $\mathrm{p} / \mathrm{n}$ core-shell nanofiber. Nanotechnology 2014, 25, 175501. [CrossRef]

82. Park, J.Y.; Choi, S.-W.; Kim, S.S. A model for the enhancement of gas sensing properties in $\mathrm{SnO}_{2}-\mathrm{ZnO}$ core-shell nanofibres. J. Phys. D Appl. Phys. 2011, 44, 205403. [CrossRef]

83. Kim, J.-H.; Kim, H.W.; Kim, S.S. Ultra-sensitive benzene detection by a novel approach: Core-shell nanowires combined with the Pd-functionalization. Sens. Actuators B Chem. 2017, 239, 578-585. [CrossRef]

84. Choi, M.S.; Mirzaei, A.; Bang, J.H.; Oum, W.; Jung Kwon, Y.; Kim, J.-H.; Choi, S.-W.; Kim, S.S.; Kim, H.W. Selective H2 S-sensing performance of Si nanowires through the formation of $\mathrm{ZnO}$ shells with Au functionalization. Sens. Actuators B Chem. 2019, 289, 1-14. [CrossRef]

85. Yu, Y.-T.; Dutta, P. Examination of $\mathrm{Au} / \mathrm{SnO}_{2}$ core-shell architecture nanoparticle for low temperature gas sensing applications. Sens. Actuators B Chem. 2011, 157, 444-449. [CrossRef]

86. Yanagimoto, T.; Yu, Y.-T.; Kaneko, K. Microstructure and $\mathrm{CO}$ gas sensing property of $\mathrm{Au} / \mathrm{SnO}_{2}$ core-shell structure nanoparticles synthesized by precipitation method and microwave-assisted hydrothermal synthesis method. Sens. Actuators B Chem. 2012, 166, 31-35. [CrossRef]

87. Song, H.-M.; Chon, B.-S.; Jeon, S.-H.; Rai, P.; Yu, Y.-T.; Dutta, P.K. Synthesis of Au@SnO 2 core-shell nanoparticles with controllable shell thickness and their CO sensing properties. Mater. Chem. 2015, 166, 87-94. [CrossRef]

88. Rai, P.; Khan, R.; Raj, S.; Majhi, S.M.; Park, K.-K.; Yu, Y.-T.; Lee, I.-H.; Sekhar, P.K. Au@Cu $2 \mathrm{O}$ core-shell nanoparticles as chemiresistors for gas sensor applications: Effect of potential barrier modulation on the sensing performance. Nanoscale 2014, 6, 581-588. [CrossRef] [PubMed]

89. Majhi, S.M.; Rai, P.; Raj, S.; Chon, B.-S.; Park, K.-K.; Yu, Y.-T. Effect of Au nanorods on potential barrier modulation in morphologically controlled $\mathrm{Au} @ \mathrm{Cu}_{2} \mathrm{O}$ core-shell nanoreactors for gas sensor applications. ACS Appl. Mater. Interfaces 2014, 6, 7491-7497. [CrossRef] [PubMed]

90. Majhi, S.M.; Rai, P.; Yu, Y.-T. Facile approach to synthesize Au@ ZnO core-shell nanoparticles and their application for highly sensitive and selective gas sensors. ACS Appl. Mater. Intefaces 2015, 7, 9462-9468. [CrossRef] [PubMed]

91. Majhi, S.M.; Naik, G.K.; Lee, H.-J.; Song, H.-G.; Lee, C.-R.; Lee, I.-H.; Yu, Y. Au@NiO core-shell nanoparticles as a p-type gas sensor: Novel synthesis, characterization, and their gas sensing properties with sensing mechanism. Sens. Actuators B Chem. 2018, 268, 223-231. [CrossRef]

92. Majhi, S.M.; Lee, H.-J.; Choi, H.-N.; Cho, H.-Y.; Kim, J.-S.; Lee, C.-R.; Yu, Y.-T. Construction of novel hybrid PdO-ZnO p-n heterojunction nanostructures as a high-response sensor for acetaldehyde gas. CrystEngComm 2019, 21, 5084-5094. [CrossRef]

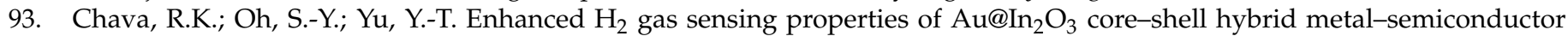
heteronanostructures. CrystEngComm 2016, 18, 3655-3666. [CrossRef]

94. Le, H.-J.; Van Dao, D.; Yu, Y.-T. Superfast and efficient hydrogen gas sensor using PdAu alloy@ ZnO core-shell nanoparticles. J. Mater. Chem. A 2020, 8, 12968-12974. [CrossRef]

95. Haruta, M.; Tsubota, S.; Kobayashi, T.; Kageyama, H.; Genet, M.J.; Delmon, B. Low-temperature oxidation of CO over gold supported on $\mathrm{TiO}_{2}, \alpha-\mathrm{Fe}_{2} \mathrm{O}_{3}$, and $\mathrm{Co}_{3} \mathrm{O}_{4}$. J. Catal. 1993, 144, 175-192. [CrossRef]

96. Matsushima, S.; Teraoka, Y.; Miura, N.; Yamazoe, N. Electronic interaction between metal additives and tin dioxide in tin dioxide-based gas sensors. Jpn. J. Appl. Phys. 1988, 27, 1798. [CrossRef]

97. Rai, P.; Majhi, S.M.; Yu, Y.-T.; Lee, J.-H. Synthesis of plasmonic Ag@SnO 2 core-shell nanoreactors for xylene detection. RSC Adv. 2015, 5, 17653-17659. [CrossRef]

98. Rai, P.; Yoon, J.-W.; Kwak, C.-H.; Lee, J.-H. Role of Pd nanoparticles in gas sensing behaviour of Pd@ $\operatorname{In}_{2} \mathrm{O}_{3}$ yolk-shell nanoreactors. J. Mater. Chem. A 2016, 4, 264-269. [CrossRef] 
99. Rai, P.; Yoon, J.-W.; Jeong, H.-M.; Hwang, S.-J.; Kwak, C.-H.; Lee, J.-H. Design of highly sensitive and selective Au@NiO yolk-shell nanoreactors for gas sensor applications. Nanoscale 2014, 6, 8292-8299. [CrossRef]

100. Majhi, S.M.; Mirzaei, A.; Kim, H.W.; Kim, S.S.; Kim, T.W. Recent advances in energy-saving chemiresistive gas sensors: A review. Nano Energy 2021, 79, 105369. [CrossRef] [PubMed]

101. Gómez-Barreiro, S.; Gracia-Fernández, C.; López-Beceiro, J.; Artiaga, R. Rheological testing of a curing process controlled by Joule heating. Polym. Test. 2016, 55, 97-100. [CrossRef]

102. Kim, J.-H.; $\mathrm{Wu}$, P.; Kim, H.W.; Kim, S.S. Highly selective sensing of $\mathrm{CO}, \mathrm{C}_{6} \mathrm{H}_{6}$, and $\mathrm{C}_{7} \mathrm{H}_{8}$ gases by catalytic functionalization with metal nanoparticles. ACS Appl. Mater. Interfaces 2016, 8, 7173-7183. [CrossRef] [PubMed]

103. Tan, H.M.; Manh Hung, C.; Ngoc, T.M.; Nguyen, H.; Duc Hoa, N.; Van Duy, N.; Hieu, N. Novel self-heated gas sensors using on-chip networked nanowires with ultralow power consumption. ACS Appl. Mater. Interface 2017, 9, 6153-6162. [CrossRef] [PubMed]

104. Kim, J.-H.; Mirzaei, A.; Kim, H.W.; Kim, S.S. Pd-functionalized core-shell composite nanowires for self-heating, sensitive, and benzene-selective gas sensors. Sens. Actuators A Phys. 2020, 308, 112011. [CrossRef]

105. Donarelli, M.; Ottaviano, L. 2D materials for gas sensing applications: A review on graphene oxide, $\mathrm{MoS}_{2}, \mathrm{WS}_{2}$ and phosphorene. Sensors 2018, 18, 3638. [CrossRef]

106. Late, D.J.; Kanawade, R.V.; Kannan, P.K.; Rout, C. Atomically thin $\mathrm{WS}_{2}$ nanosheets based gas sensor. Sens. Lett. 2016, 14, 1249-1254. [CrossRef]

107. Kim, J.-H.; Mirzaei, A.; Kim, H.W.; Kim, S.S. Flexible and low power CO gas sensor with Au-functionalized $2 \mathrm{D}$ WS 2 nanoflakes. Sens. Actuators B Chem. 2020, 313, 128040. [CrossRef]

108. Lee, J.-H.; Mirzaei, A.; Kim, J.-H.; Kim, J.-Y.; Nasriddinov, A.F.; Rumyantseva, M.N.; Kim, H.W.; Kim, S.S. Gas-sensing behaviors of $\mathrm{TiO}_{2}$-layer-modified $\mathrm{SnO}_{2}$ quantum dots in self-heating mode and effects of the $\mathrm{TiO}_{2}$ layer. Sens. Actuators B Chem. 2020, 310, 127870. [CrossRef]

109. Kim, J.-H.; Kim, J.-Y.; Mirzaei, A.; Kim, H.W.; Kim, S.S. Synergistic effects of $\mathrm{SnO}_{2}$ and Au nanoparticles decorated on WS 2 nanosheets for flexible, room-temperature CO gas sensing. Sens. Actuators B Chem. 2021, 332, 129493. [CrossRef]

110. Kim, J.-Y.; Lee, J.-H.; Kim, J.-H.; Mirzaei, A.; Kim, H.W.; Kim, S.S. Realization of $\mathrm{H}_{2} \mathrm{~S}$ sensing by Pd-functionalized networked $\mathrm{CuO}$ nanowires in self-heating mode. Sens. Actuators B Chem. 2019, 299, 126965. [CrossRef]

111. Kim, J.-H.; Mirzaei, A.; Kim, H.W.; Kim, S.S. Low-voltage-driven sensors based on ZnO nanowires for room-temperature detection of $\mathrm{NO}_{2}$ and CO gases. ACS Appl. Mater. Interfaces 2019, 11, 24172-24183. [CrossRef]

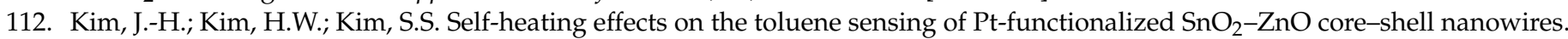
Sens. Actuators B Chem. 2017, 251, 781-794. [CrossRef]

113. Mirzaei, A.; Park, S.; Sun, G.-J.; Kheel, H.; Lee, C. CO gas sensing properties of $\mathrm{In}_{4} \mathrm{Sn}_{3} \mathrm{O}_{12}$ and TeO composite nanoparticle sensors. J. Hazard. Mater. 2016, 305, 130-138. [CrossRef]

114. Kim, J.-H.; Mirzaei, A.; Bang, J.H.; Kim, H.W.; Kim, S.S. Achievement of self-heated sensing of hazardous gases by WS 2 (core) $-\mathrm{SnO}_{2}$ (shell) nanosheets. J. Hazard. Mater. 2021, 412, 125196. [CrossRef]

115. Kim, J.-H.; Mirzaei, A.; Kim, H.W.; Kim, S.S. Low power-consumption CO gas sensors based on Au-functionalized SnO $2-\mathrm{ZnO}$ core-shell nanowires. Sens. Actuators B Chem. 2018, 267, 597-607. [CrossRef]

116. Mirzaei, A.; Kim, J.-H.; Kim, H.W.; Kim, S.S. Resistive-based gas sensors for detection of benzene, toluene and xylene (BTX) gases: A review. J. Mater. Chem. C 2018, 6, 4342-4370. [CrossRef]

117. Kim, J.-H.; Lee, J.-H.; Park, Y.; Kim, J.-Y.; Mirzaei, A.; Kim, H.W.; Kim, S.S. Toluene-and benzene-selective gas sensors based on Pt-and Pd-functionalized ZnO nanowires in self-heating mode. Sens. Actuators B Chem. 2019, 294, 78-88. [CrossRef]

118. Bang, J.H.; Choi, M.S.; Mirzaei, A.; Han, S.; Lee, H.Y.; Choi, S.W.; Kim, S.S.; Kim, H.W. Hybridization of silicon nanowires with $\mathrm{TeO}_{2}$ branch structures and Pt nanoparticles for highly sensitive and selective toluene sensing. Appl. Surf. Sci. 2020, 525, 146620. [CrossRef]

119. Kim, J.-H.; Mirzaei, A.; Bang, J.H.; Kim, H.W.; Kim, S.S. Selective $\mathrm{H}_{2} \mathrm{~S}$ sensing without external heat by a synergy effect in self-heated $\mathrm{CuO}$-functionalized $\mathrm{SnO}_{2}-\mathrm{ZnO}$ core-shell nanowires. Sens. Actuators B Chem. 2019, 300, 126981. [CrossRef]

120. Yeo, S.; Lee, C.Y.; Kim, D.-S.; Hwang, Y.S.; Park, J.K.; Jung, M.-H.; Cho, W.-J.; Lee, J.S.; Kim, C. Sensing response enhancement of graphene gas sensors by ion beam bombardment. Thin Solid Films 2019, 677, 73-76. [CrossRef]

121. Mintcheva, N.; Srinivasan, P.; Rayappan, J.B.B.; Kuchmizhak, A.A.; Gurbatov, S.; Kulinich, S. Room-temperature gas sensing of laser-modified anatase $\mathrm{TiO}_{2}$ decorated with Au nanoparticles. Appl. Surf. Sci. 2020, 507, 145169. [CrossRef]

122. Lavanya, N.; Anithaa, A.; Sekar, C.; Asokan, K.; Bonavita, A.; Donato, N.; Leonardi, S.; Neri, G. Effect of gamma irradiation on structural, electrical and gas sensing properties of tungsten oxide nanoparticles. J. Alloys Compd. 2017, 693, 366-372. [CrossRef]

123. Alali, K.T.; Liu, J.; Yu, J.; Moharram, D.; Chen, R.; Zhang, H.; Liu, Q.; Zhang, M.; Wang, J. HFIP-functionalized electrospun $\mathrm{WO}_{3}$ hollow nanofibers/rGO as an efficient double layer sensing material for dimethyl methylphosphonate gas under UV-Light irradiation. J. Alloys Compd. 2020, 832, 154999. [CrossRef]

124. Rasmidi, R.; Duinong, M.; Chee, F.P. Radiation damage effects on zinc oxide $(\mathrm{ZnO})$ based semiconductor devices-A review. Radiat. Phys. Chem. 2021, 184, 109455. [CrossRef]

125. Kang, M.; Lee, D.H.; Kang, Y.-M.; Jung, H. Electron beam irradiation dose dependent physico-chemical and electrochemical properties of reduced graphene oxide for supercapacitor. Electrochim. Acta 2015, 184, 427-435. [CrossRef] 
126. Mirzaei, A.; Kwon, Y.J.; Wu, P.; Kim, S.S.; Kim, H.W. Converting the conducting behavior of graphene oxides from n-type to p-type via electron-beam irradiation. ACS Appl. Mater. Interfaces 2018, 10, 7324-7333. [CrossRef]

127. Kim, J.-H.; Mirzaei, A.; Kim, H.W.; Wu, P.; Kim, S.S. Design of supersensitive and selective ZnO-nanofiber-based sensors for $\mathrm{H}_{2}$ gas sensing by electron-beam irradiation. Sens. Actuators B Chem. 2019, 293, 210-223. [CrossRef]

128. Kim, J.-H.; Mirzaei, A.; Kim, H.W.; Kim, S.S. Combination of Pd loading and electron beam irradiation for superior hydrogen sensing of electrospun $\mathrm{ZnO}$ nanofibers. Sens. Actuators B Chem. 2019, 284, 628-637. [CrossRef]

129. Kwon, Y.J.; Cho, H.Y.; Na, H.G.; Lee, B.C.; Kim, S.S.; Kim, H.W. Improvement of gas sensing behavior in reduced graphene oxides by electron-beam irradiation. Sens. Actuators B Chem. 2014, 203, 143-149. [CrossRef]

130. Choi, M.S.; Mirzaei, A.; Bang, J.H.; Oum, W.; Kim, S.S.; Kim, H.W. Improvement of $\mathrm{NO}_{2}$ sensing properties in Pd functionalized reduced graphene oxides by electron-beam irradiation. Front. Mater. 2019, 6, 197. [CrossRef]

131. Avasthi, D.K.; Mehta, G.K. Swift Heavy Ions for Materials Engineering and Nanostructuring; Springer Science \& Business Media: Berlin/Heidelberg, Germany, 2011; Volume 145.

132. Markwitz, A.; Leveneur, J.; Gupta, P.; Suschke, K.; Futter, J.; Rondeau, M. Transition metal ion implantation into diamond-like carbon coatings: Development of a base material for gas sensing applications. J. Nanomater. 2015, 16, 706417. [CrossRef]

133. Xiang, X.; He, Z.; Rao, J.; Fan, Z.; Wang, X.; Chen, Y. Applications of Ion Beam Irradiation in multifunctional oxide thin films: A Review. ACS Appl. Electron. Mater. 2021, 3, 1031-1042. [CrossRef]

134. Kwon, Y.J.; Kang, S.Y.; Wu, P.; Peng, Y.; Kim, S.S.; Kim, H.W. Selective improvement of $\mathrm{NO}_{2}$ gas sensing behavior in $\mathrm{SnO}_{2}$ nanowires by Ion-Beam Irradiation. ACS Appl. Mater. Interfaces 2016, 8, 13646-13658. [CrossRef]

135. Kim, J.-H.; Mirzaei, A.; Kim, J.-Y.; Lee, J.-H.; Kim, H.W.; Hishita, S.; Kim, S.S. Enhancement of gas sensing by implantation of Sb-ions in $\mathrm{SnO}_{2}$ nanowires. Sens. Actuators B Chem. 2020, 304, 127307. [CrossRef]

136. Kim, J.-H.; Kim, J.-Y.; Lee, J.-H.; Mirzaei, A.; Kim, H.W.; Hishita, S.; Kim, S.S. Indium-implantation-induced enhancement of gas sensing behaviors of $\mathrm{SnO}_{2}$ nanowires by the formation of homo-core-shell structure. Sens. Actuators B Chem. 2020, $321,128475$. [CrossRef]

137. Nag, A.; Mukhopadhyay, S.C.; Kosel, J. Wearable flexible sensors: A review. IEEE Sens. J. 2017, 17, 3949-3960. [CrossRef]

138. Molina, A.; Escobar-Barrios, V.; Oliva, J. A review on hybrid and flexible $\mathrm{CO}_{2}$ gas sensors. Synth. Met. 2020, $270,116602$. [CrossRef]

139. Mardonova, M.; Choi, Y. Review of wearable device technology and its applications to the mining industry. Energies $2018,11,547$. [CrossRef]

140. Park, J.; Kim, J.; Kim, K.; Cheong, W.; Park, K.; Song, J.; Namgoong, G.; Kim, J.; Heo, J.; Bien, F.; et al. Wearable, wireless gas sensors using highly stretchable and transparent structures of nanowires and graphene. Nanoscale 2016, 8, 10591-10597. [CrossRef]

141. Li, S.; Lin, P.; Zhao, L.; Wang, C.; Liu, D.; Liu, F.; Sun, P.; Liang, X.; Liu, F.; Yan, X. The room temperature gas sensor based on Polyaniline@flower-like $\mathrm{WO}_{3}$ nanocomposites and flexible PET substrate for $\mathrm{NH}_{3}$ detection. Sens. Actuators B Chem. 2018, 259, 505-513. [CrossRef]

142. Young, S.-J.; Lin, Z.; Hsiao, C.; Huang, C. Ethanol gas sensors composed of carbon nanotubes with Au nanoparticles adsorbed onto a flexible PI substrate. ECS J. Electron. Sci. 2017, 6, M130. [CrossRef]

143. Perillo, P.; Rodríguez, D. Low temperature trimethylamine flexible gas sensor based on $\mathrm{TiO}_{2}$ membrane nanotubes. J. Alloys Compd. 2016, 657, 765-769. [CrossRef]

144. Wang, T.; Guo, Y.; Wan, P.; Zhang, H.; Chen, X.; Sun, X. Flexible transparent electronic gas sensors. Nano-Micro Small 2016, 12, 3748-3756. [CrossRef] [PubMed]

145. Alrammouz, R.; Podlecki, J.; Abboud, P.; Sorli, B.; Habchi, R. A review on flexible gas sensors: From materials to devices. Sens. Actuators A Phys. 2018, 284, 209-231. [CrossRef]

146. Kumar, R.; Goel, N.; Hojamberdiev, M.; Kumar, M. Transition metal dichalcogenides-based flexible gas sensors. Sens. Actuators A Phys. 2020, 303, 111875. [CrossRef]

147. Park, H.J.; Kim, W.-J.; Lee, H.-K.; Lee, D.-S.; Shin, J.-H.; Jun, Y.; Yun, Y. Highly flexible, mechanically stable, and sensitive $\mathrm{NO}_{2}$ gas sensors based on reduced graphene oxide nanofibrous mesh fabric for flexible electronics. Sens. Actuators B Chem. 2018, 257, 846-852. [CrossRef]

148. Jang, N.-S.; Kim, M.S.; Kim, S.-H.; Lee, S.-K.; Kim, J.-M. Direct growth of titania nanotubes on plastic substrates and their application to flexible gas sensors. Sens. Actuators B Chem. 2014, 199, 361-368. [CrossRef]

149. Yi, J.; Lee, J.M.; Park, W.I. Vertically aligned ZnO nanorods and graphene hybrid architectures for high-sensitive flexible gas sensors. Sens. Actuators B Chem. 2011, 155, 264-269. [CrossRef]

150. Uddin, A.S.M.I.; Yaqoob, U.; Phan, D.-T.; Chung, G.-S. A novel flexible acetylene gas sensor based on PI/PTFE-supported Ag-loaded vertical ZnO nanorods array. Sens. Actuators B Chem. 2016, 222, 536-543. [CrossRef]

151. Kang, J.-Y.; Koo, W.-T.; Jang, J.-S.; Kim, D.-H.; Jeong, Y.J.; Kim, R.; Ahn, J.; Choi, S.-J.; Kim, I.-D. 2D layer assembly of Pt-ZnO nanoparticles on reduced graphene oxide for flexible $\mathrm{NO}_{2}$ sensors. Sens. Actuators B Chem. 2021, 331, 129371. [CrossRef]

152. Duy, L.T.; Baek, J.-Y.; Mun, Y.-J.; Seo, H. Patternable production of $\mathrm{SrTiO}_{3}$ nanoparticles using 1-W laser directly on flexible humidity sensor platform based on ITO/SrTiO $3 /$ CNT. J. Mater. Sci. Tech. 2021, 71, 186-194. [CrossRef]

153. Kim, J.-W.; Porte, Y.; Ko, K.Y.; Kim, H.; Myoung, J. Micropatternable double-faced ZnO nanoflowers for flexible gas sensor. ACS Appl. Mater. Interfaces 2017, 9, 32876-32886. [CrossRef] [PubMed] 
154. Zhao, Y.; Song, J.-G.; Ryu, G.H.; Ko, K.Y.; Woo, W.J.; Kim, Y.; Kim, D.; Lim, J.H.; Lee, S.; Lee, Z.; et al. Low-temperature synthesis of $2 \mathrm{D} \mathrm{MoS}_{2}$ on a plastic substrate for a flexible gas sensor. Nanoscale 2018, 10, 9338-9345. [CrossRef] [PubMed]

155. Nogami, M.; Matsumura, M.; Daiko, Y. Hydrogen sensor prepared using fast proton-conducting glass films. Sens. Actuators $B$ Chem. 2006, 120, 266-269. [CrossRef]

156. Sopiha, K.V.; Kim, J.-H.; Kim, S.S.; Wu, P. Gas sensing properties of standard soda-lime glass. Sens. Actuators B Chem. 2018, 266, 344-353. [CrossRef]

157. Kim, J.-Y.; Mirzaei, A.; Kim, J.-H.; Lee, J.-H.; Kim, H.W.; Kim, S.S. Incorporation of metal nanoparticles in soda-lime glass sensors for enhancing selective sensing. Sens. Actuators B Chem. 2019, 296, 126673. [CrossRef]

158. Kim, J.-Y.; Kim, S.S.; Tonezzer, M. Selective gas detection and quantification using a resistive sensor based on Pd-decorated soda-lime glass. Sens. Actuators B Chem. 2021, 335, 129714. [CrossRef]

159. Amato, M.; Rurali, R. Surface physics of semiconducting nanowires. Prog. Surf. Sci. 2016, 91, 1-28. [CrossRef]

160. Demami, F.; Ni, L.; Rogel, R.; Salaun, A.-C.; Pichon, L. Silicon nanowires-based resistors as gas sensors. Sens. Actuators B Chem. 2012, 170, 158-162. [CrossRef]

161. Miranda, A.; De Santiago, F.; Pérez, L.; Cruz-Irisson, M. Silicon nanowires as potential gas sensors: A density functional study. Sens. Actuators B Chem. 2017, 242, 1246-1250. [CrossRef]

162. Qin, Y.; Zang, J. Stable clusters array of silicon nanowires developed by top-plating technique as a high-performance gas sensor. Phys. E Low-Dimens. Syst. Nanostruct. 2021, 127, 114508. [CrossRef]

163. Mirzaei, A.; Kang, S.Y.; Choi, S.-W.; Kwon, Y.J.; Choi, M.S.; Bang, J.H.; Kim, S.S.; Kim, H.W. Fabrication and gas sensing properties of vertically aligned Si nanowires. Appl. Surf. Sci. 2018, 427, 215-226. [CrossRef]

164. Chen, C.Y.; Wu, C.S.; Chou, C.J.; Yen, T. Morphological control of single-crystalline silicon nanowire arrays near room temperature. Adv. Mater. 2008, 20, 3811-3815. [CrossRef]

165. Li, M.; Li, Y.; Liu, W.; Yue, L.; Li, R.; Luo, Y.; Trevor, M.; Jiang, B.; Bai, F.; Fu, P. Metal-assisted chemical etching for designable monocrystalline silicon nanostructure. Mater. Res. Bull. 2016, 76, 436-449. [CrossRef]

166. Ramírez-González, F.; García-Salgado, G.; Rosendo, E.; Díaz, T.; Nieto-Caballero, F.; Coyopol, A.; Romano, R.; Luna, A.; Monfil, K.; Gastellou, E. Porous silicon gas sensors: The role of the layer thickness and the silicon conductivity. Sensors 2020, $20,4942$. [CrossRef] [PubMed]

167. Bang, J.H.; Choi, M.S.; Mirzaei, A.; Oum, W.; Han, S.; Kim, S.S.; Kim, H.W. Porous $\mathrm{Si} / \mathrm{SnO}_{2}$ nanowires heterostructures for $\mathrm{H}_{2} \mathrm{~S}$ gas sensing. Ceram. Int. 2020, 46, 604-611. [CrossRef]

168. Lee, J.-H.; Kim, J.-Y.; Kim, J.-H.; Mirzaei, A.; Kim, H.W.; Kim, S.S. Pd-decorated Si nano-horns as sensitive and selective hydrogen gas sensors. Mater. Res. Bull. 2020, 132, 110985. [CrossRef]

169. Yao, M.S.; Tang, W.X.; Wang, G.E.; Nath, B.; Xu, G. MOF thin film-coated metal oxide nanowire array: Significantly improved chemiresistor sensor performance. Adv. Mater. 2016, 28, 5229-5234. [CrossRef]

170. Khan, N.A.; Jhung, S. Synthesis of metal-organic frameworks (MOFs) with microwave or ultrasound: Rapid reaction, phaseselectivity, and size reduction. Coord. Chem. Rev. 2015, 285, 11-23. [CrossRef]

171. Ren, J.; Langmi, H.W.; North, B.C.; Mathe, M. Review on processing of metal-organic framework (MOF) materials towards system integration for hydrogen storage. Int. J. Energy Res. 2015, 39, 607-620. [CrossRef]

172. Ghanbari, T.; Abnisa, F.; Daud, W. A review on production of metal organic frameworks (MOF) for $\mathrm{CO}_{2}$ adsorption. Sci. Total Enviro. 2020, 707, 135090. [CrossRef] [PubMed]

173. Arul, C.; Moulaee, K.; Donato, N.; Iannazzo, D.; Lavanya, N.; Neri, G.; Sekar, C. Temperature modulated Cu-MOF based gas sensor with dual selectivity to acetone and $\mathrm{NO}_{2}$ at low operating temperatures. Sens. Actuators B Chem. 2021, 329,129053 [CrossRef]

174. Drobek, M.; Kim, J.-H.; Bechelany, M.; Vallicari, C.; Julbe, A.; Kim, S.S. MOF-Based Membrane Encapsulated ZnO Nanowires for Enhanced Gas Sensor Selectivity. ACS Appl. Mater. Interfaces 2016, 8, 8323-8328. [CrossRef] [PubMed]

175. Drobek, M.; Kim, J.-H.; Bechelany, M.; Vallicari, C.; Leroy, E.; Julbe, A.; Kim, S.S. Design and fabrication of highly selective $\mathrm{H}_{2}$ sensors based on SIM-1 nanomembrane-coated ZnO nanowires. Sens. Actuators B Chem. 2018, 264, 410-418. [CrossRef]

176. Aguado, S.; Canivet, J.; Farrusseng, D. Facile shaping of an imidazolate-based MOF on ceramic beads for adsorption and catalytic applications. Chem. Comm. 2010, 46, 7999-8001. [CrossRef] [PubMed]

177. Marti, A.M.; Van, M.; Balkus, K. Tuning the crystal size and morphology of the substituted imidazole material, SIM-1. J. Porous Mater. 2014, 21, 889-902. [CrossRef]

178. Weber, M.; Kim, J.-H.; Lee, J.-H.; Kim, J.-Y.; Iatsunskyi, I.; Coy, E.; Drobek, M.; Julbe, A.; Bechelany, M.; Kim, S.S. High-performance nanowire hydrogen sensors by exploiting the synergistic effect of Pd nanoparticles and metal-organic framework membranes. ACS Appl. Mater. Interfaces 2018, 10, 34765-34773. [CrossRef]

179. Pan, Y.; Wang, B.; Lai, Z. Synthesis of ceramic hollow fiber supported zeolitic imidazolate framework-8 (ZIF-8) membranes with high hydrogen permeability. J. Memb. Sci. 2012, 421, 292-298. [CrossRef]

180. Nguyen, D.-K.; Lee, J.-H.; Nguyen, T.-B.; Doan, T.L.H.; Phan, B.T.; Mirzaei, A.; Kim, H.W.; Kim, S.S. Realization of selective CO detection by Ni-incorporated metal-organic frameworks. Sens. Actuators B Chem. 2020, 315, 128110. [CrossRef]

181. Lee, J.-H.; Nguyen, T.-B.; Nguyen, D.-K.; Kim, J.-H.; Kim, J.-Y.; Phan, B.T.; Kim, S.S. Gas Sensing Properties of Mg-Incorporated Metal-Organic Frameworks. Sensors 2019, 19, 3323. [CrossRef] [PubMed] 
182. Doan, T.L.H.; Kim, J.Y.; Lee, J.H.; Nguyen, L.H.T.; Nguyen, H.T.T.; Pham, A.T.T.; Le, T.B.N.; Mirzaei, A.; Phan, T.B.; Kim, S.S. Facile synthesis of metal-organic framework-derived $\mathrm{ZnO} / \mathrm{CuO}$ nanocomposites for highly sensitive and selective $\mathrm{H}_{2} \mathrm{~S}$ gas sensing. Sens. Actuators B Chem. 2021, 349, 130741. [CrossRef]

183. Doan, T.L.H.; Kim, J.Y.; Lee, J.H.; Nguyen, L.H.T.; Dang, Y.T.; Bui, K.B.T.; Pham, A.T.T.; Mirzaei, A.; Phan, T.B.; Kim, S.S. Preparation of $\mathrm{n}-\mathrm{ZnO} / \mathrm{p}-\mathrm{Co}_{3} \mathrm{O}_{4}$ heterojunctions from zeolitic imidazolate frameworks (ZIF-8/ZIF-67) for sensing low ethanol concentrations. Sens. Actuators B Chem. 2021, 348, 130684. [CrossRef]

184. Hwang, I.; Kim, S.; Choi, J.; Choi, J.; Ji, H.; Kim, G.; Cao, G.; Lee, J. Synthesis and gas sensing characteristics of highly crystalline $\mathrm{ZnO}-\mathrm{SnO}_{2}$ core-shell nanowires. Sens. Actuators B Chem. 2010, 148, 595-600. [CrossRef]

185. Park, S.; An, S.; Mun, Y.; Lee, C. UV-enhanced $\mathrm{NO}_{2}$ gas sensing properties of $\mathrm{SnO}_{2}$-core/ZnO-shell nanowires at room temperature. ACS Appl. Mater. Interfaces 2013, 5, 4285-4292. [CrossRef]

186. Mirzaei, A.; Janghorban, K.; Hashemi, B.; Bonyani, M.; Leonardi, S.G.; Neri, G. A novel gas sensor based on $\mathrm{Ag} / \mathrm{Fe}_{2} \mathrm{O}_{3}$ core-shell nanocomposites. Ceram. Int. 2016, 42, 18974-18982. [CrossRef]

187. Woo, H.; Na, C.W.; Kim, I.D.; Lee, J.H. Highly sensitive and selective trimethylamine sensor using one-dimensional $\mathrm{ZnO}^{-\mathrm{Cr}_{2} \mathrm{O}_{3}}$ hetero-nanostructures. Nanotechnology 2012, 23, 245501. [CrossRef]

188. Jang, Y.G.; Kim, W.S.; Kim, D.H.; Hong, S.H. Fabrication of $\mathrm{Ga}_{2} \mathrm{O}_{3} / \mathrm{SnO} 2$ core-shell nanowires and their ethanol gas sensing properties. J. Mater. Res. 2011, 26, 2322-2327. [CrossRef]

189. Nguyen, T.T.D.; Dao, D.V.; Kim, D.S.; Lee, H.J.; Oh, S.Y.; Lee, I.H.; Yu, Y.T. Effect of core and surface area toward hydrogen gas sensing performance using Pd@ZnO core-shell nanoparticles. J. Collide Interfaces Sci. 2021, 587, 252-259. [CrossRef] [PubMed]

190. Kwon, S.H.; Kim, T.H.; Kim, S.M.; Oh, S.; Kim, K.K. Ultraviolet light-emitting diode-assisted highly sensitive room temperature $\mathrm{NO}_{2}$ gas sensors based on low-temperature solution-processed $\mathrm{ZnO} / \mathrm{TiO}_{2}$ nanorods decorated with plasmonic Au nanoparticles. Nanoscale 2021, 13, 12177-12184. [CrossRef] [PubMed]

191. Park, S.; Kim, S.; Sun, G.J.; Lee, W.I.; Kim, K.K.; Lee, C. Fabrication and $\mathrm{NO}_{2}$ gas sensing performance of $\mathrm{TeO}_{2}$-core $/ \mathrm{CuO}$-shell heterostructure nanorod sensors. Nanoscale Res. Lett. 2014, 9, 638. [CrossRef]

192. Nguyen, T.T.D.; Dao, D.V.; Lee, I.H.; Yu, Y.T.; Oh, S.Y. High response and selectivity toward hydrogen gas detection by $\mathrm{In}_{2} \mathrm{O}_{3}$ doped Pd@ZnO core-shell nanoparticles. J. Alloys Compd. 2021, 854, 157280. [CrossRef]

193. Dao, D.V.; Nguyen, T.T.D.; Kim, D.S.; Yoon, J.W.; Yu, Y.T.; Lee, I.H. Core and dopant effects toward hydrogen gas sensing activity using Pd@N-CeO 2 core-shell nanoflatforms. J. Ind. Eng. Chem. 2021, 95, 325-332. [CrossRef]

194. Yun, J.; Jin, C.Y.; Ahn, J.H.; Jeon, S.; Park, I. A self-heated silicon nanowire array: Selective surface modification with catalytic nanoparticles by nanoscale Joule heating and its gas sensing applications. Nanoscale 2013, 5, 6851-6856. [CrossRef]

195. Ahn, J.H.; Yun, J.; Moon, D.I.; Choi, Y.K.; Park, I. Self-heated silicon nanowires for high performance hydrogen gas detection. Nanotechnology 2015, 26, 095501-095511. [CrossRef]

196. Seo, J.Y.; Shin, H.J. Self-heating hydrogen gas sensor based on an array of single suspended carbon nanowires functionalized with palladium nanoparticles. Sens. Actuators B Chem. 2017, 247, 564-572. [CrossRef]

197. Moon, H.G.; Shim, Y.S.; Kim, D.H.; Jeong, H.Y.; Jeong, M.; Jung, J.Y.; Han, S.M.; Kim, J.K.; Kim, J.S.; Park, H.H.; et al. Self-activated ultrahigh chemosensitivity of oxide thin film nanostructures for transparent sensors. Sci. Rep. 2012, 2, 588. [CrossRef] [PubMed]

198. Kim, S.S.; Na, H.G.; Kim, H.W.; Kulish, V.; Wu, P. Promotion of acceptor formation in $\mathrm{SnO}_{2}$ nanowires by e-beam bombardment and impacts to sensor application. Sci. Rep. 2015, 5, 10723.

199. Byoun, Y.; Park, S.; Jin, C.; Song, Y.J.; Choi, S.W. Highly sensitive and selective ethanol detection at room temperature utilizing holey SWCNT-Sn/SnO 2 nanocomposites synthesized by microwave irradiation. Sens. Actuators B Chem. 2019, 290, 467-476. [CrossRef]

200. Bae, G.; Song, D.S.; Lim, Y.R.; Jeon, I.S.; Jang, M.; Yoon, Y.; Jeon, C.; Song, W.; Myung, S.; Lee, S.S.; et al. Chemical patterning of graphene via metal-assisted highly energetic electron irradiation for graphene homojunction-based gas sensors. ACS Appl. Mater. Interfaces 2020, 12, 47802-47810. [CrossRef]

201. Jeong, H.Y.; Lee, D.S.; Choi, H.K.; Lee, D.H.; Kim, J.-E.; Lee, J.Y.; Lee, W.J.; Kim, S.O.; Choi, S.-Y. Flexible room-temperature NO 2 gas sensors based on carbon nanotube/reduced graphene oxide hybrid films. Appl. Phys. Lett. 2010, 96, 213105. [CrossRef]

202. Lee, C.; Ahn, J.; Lee, K.B.; Kim, D.; Kim, J. Graphene-based flexible $\mathrm{NO}_{2}$ chemical sensors. Thin Solid Films 2012, 520 , 5459-5462. [CrossRef]

203. Kim, Y.H.; Kim, S.J.; Kim, Y.-J.; Shim, Y.-S.; Kim, S.Y.; Hong, B.H.; Jang, H.W. Self-activated transparent all-graphene gas sensor with endurance to humidity and mechanical bending. ACS Nano 2015, 9, 10453-10460. [CrossRef] [PubMed]

204. Yun, Y.J.; Hong, W.G.; Choi, N.J.; Kim, B.H.; Jun, Y.; Lee, H.K. Ultrasensitive and highly selective graphene-based single yarn for use in wearable gas sensor. Sci. Rep. 2015, 5, 10904. [CrossRef] [PubMed]

205. Kang, M.A.; Ji, S.; Kim, S.; Park, C.Y.; Myung, S.; Song, W.; Lee, S.S.; Lim, J.; An, K.-S. Highly sensitive and wearable gas sensors consisting of chemically functionalized graphene oxide assembled on cotton yarn. RSC Adv. 2018, 8, 11991-11996. [CrossRef]

206. Lee, S.W.; Jung, H.G.; Jang, J.W.; Park, D.; Lee, D.; Kim, I.; Kim, Y.; Cheong, D.Y.; Hwang, K.S.; Lee, G.; et al. Graphene-based electronic textile sheet for highly sensitive detection of $\mathrm{NO}_{2}$ and $\mathrm{NH}_{3}$. Sens. Actuators $B$ Chem. 2021, 345, 130361. [CrossRef]

207. Ugale, A.D.; Umarji, G.G.; Jung, S.H.; Deshpande, N.G.; Lee, W.; Cho, H.K.; Yoo, J.B. ZnO decorated flexible and strong graphene fibers for sensing $\mathrm{NO}_{2}$ and $\mathrm{H}_{2} \mathrm{~S}$ at room temperature. Sens. Actuators B Chem. 2020, 308, 127-690. [CrossRef]

208. Lee, S.H.; Eom, W.; Shin, H.; Ambade, R.B.; Bang, J.H.; Kim, H.W.; Han, T.H. Room-temperature, highly durable Ti ${ }_{3} \mathrm{C}_{2} \mathrm{Tx}_{\mathrm{x}}$ MXene/Graphene hybrid fibers for $\mathrm{NH}_{3}$ gas sensing. ACS Appl. Mater. Interfaces 2020, 12, 10434-10442. [CrossRef] 
209. Li, H.Y.; Lee, C.S.; Kim, D.H.; Lee, J.H. Flexible room-temperature $\mathrm{NH}_{3}$ sensor for ultrasensitive, selective, and humidityindependent gas detection. ACS Appl. Mater. Interfaces 2018, 10, 27858-27867. [CrossRef]

210. Na, C.W.; Kim, J.H.; Kim, H.J.; Woo, H.S.; Gupta, A.; Kim, H.K.; Lee, J.H. Highly selective and sensitive detection of $\mathrm{NO}_{2}$ using rGO- $\operatorname{In}_{2} \mathrm{O}_{3}$ structure on flexible substrate at low temperature. Sens. Actuators B Chem. 2018, 255, 1671-1679. [CrossRef]

211. Yaqoob, U.; Phan, D.T.; Iftekhar Uddin, A.S.M.; Chung, G.S. Highly flexible room temperature $\mathrm{NO}_{2}$ sensor based on MWCNTs$\mathrm{WO}_{3}$ nanoparticles hybrid on a PET substrate. Sens. Actuators B Chem. 2015, 221, 760-768. [CrossRef]

212. Kim, J.; Oh, S.D.; Kim, J.H.; Shin, D.H.; Kim, S.; Choi, S.-H. Graphene/Si-nanowire heterostructure molecular sensors. Sci. Rep. 2014, 4, 5384. [CrossRef]

213. Eom, N.; Cho, H.B.; Lim, H.R.; Hwan, T.Y.; Song, Y.; Choa, Y.H. Ultrasensitive detection of low-ppm $\mathrm{H}_{2} \mathrm{~S}$ gases based on palladium-doped porous silicon sensors. RSC Adv. 2018, 8, 29995. [CrossRef]

214. Noh, J.S.; Kim, H.; Kim, B.S.; Lee, E.; Cho, H.H.; Lee, W. High-performance vertical hydrogen sensors using Pd-coated rough Si nanowires. J. Mater. Chem. 2011, 21, 15935-15939. [CrossRef]

215. Lee, J.H.; Nguyen, T.T.T.; Nguyen, L.; Phan, T.B.; Kim, S.S.; Doan, T.L.H. Functionalization of zirconium-based metal-organic frameworks for gas sensing applications. J. Hazard. Mater. 2021, 403, 124104. [CrossRef] [PubMed]

216. Koo, W.T.; Qiao, S.; Ogata, A.F.; Jha, G.; Jang, J.S.; Chen, V.T.; Kim, I.D.; Penner, R.M. Accelerating palladium nanowire $\mathrm{H}_{2}$ sensors using engineered nanofiltration. ACS Nano 2017, 11, 9276-9285. [CrossRef]

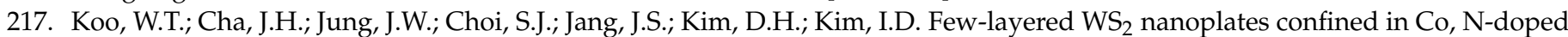
hollow carbon nanocages: Abundant $\mathrm{WS}_{2}$ edges for highly sensitive gas sensors. Adv. Funct. Mater. 2018, 28, 1802575. [CrossRef]

218. Jo, Y.M.; Kim, T.H.; Lee, C.S.; Lim, K.; Na, C.W.; Abdel-Hady, F.; Wazzan, A.A.; Lee, J.H. Metal-organic framework-derived hollow hierarchical $\mathrm{Co}_{3} \mathrm{O}_{4}$ nanocages with tunable size and morphology: Ultrasensitive and highly selective detection of methylbenzenes. ACS Appl. Mater. Interfaces 2018, 10, 8860-8868. [CrossRef] [PubMed]

219. Koo, W.T.; Yu, S.; Choi, S.J.; Jang, J.S.; Cheong, J.Y.; Kim, I.D. Nanoscale PdO catalyst functionalized $\mathrm{Co}_{3} \mathrm{O}_{4}$ hollow nanocages using MOF templates for selective detection of acetone molecules in exhaled breath. ACS Appl. Mater. Interfaces 2017, 9, 8201-8210. [CrossRef]

220. Jang, J.S.; Koo, W.T.; Kim, D.H.; Kim, I.D. In situ coupling of multidimensional MOFs for heterogeneous metal-oxide architectures: Toward sensitive chemiresistors. ACS Cent. Sci. 2018, 4, 929-937. [CrossRef] [PubMed]

221. Wong, D.; Abuzalat, O.; Mostafa, S.; Park, S.S.; Kim, S. Intense pulsed light-based synthesis of hybrid $\mathrm{TiO}_{2}-\mathrm{SnO}_{2} / \mathrm{MWCNT}$ doped Cu-BTC for room temperature ammonia sensing. J. Mater. Chem. C 2020, 8, 7567-7574. [CrossRef]

222. Jo, Y.M.; Lim, K.; Yoon, J.W.; Jo, Y.K.; Moon, Y.K.; Jang, H.W.; Lee, J.H. Visible-light-activated Type II heterojunction in $\mathrm{Cu}_{3}$ (hexahydroxytriphenylene) $)_{2} / \mathrm{Fe}_{2} \mathrm{O}_{3}$ hybrids for reversible $\mathrm{NO}_{2}$ sensing: Critical role of $\pi-\pi^{*}$ transition. ACS Cent. Sci. 2021, 7, 1176-1182. [CrossRef] 